PNL-3470

UC-94e

\title{
Water Coning in Porous \\ Media Reservoirs for \\ Compressed Air Energy \\ Storage
}

L. E. Wiles

R. A. McCann

June 1981

Prepared for the U.S. Department of Energy

under Contract DE-AC06-76RLO 1830

Pacific Northwest Laboratory

Operated for the U.S. Department of Energy

by Battelle Memorial Institute 
NOTICE

This report was prepared as an account of work sponsored by the United States Government. Neither the United States nor the Department of Energy, nor any of their employees, nor any of their contractors, subcontractors, or their employees, makes any warranty, express or implied, or assumes any legal liability or responsibility for the accuracy, completeness or usefulness of any information, apparatus, product or process disclosed, or represents that its use would not infringe privately owned rights.

The views, opinions and conclusions contained in this report are those of the contractor and do not necessarily represent those of the United States Government or the United States Department of Energy.

\author{
PACIFIC NORTHWEST LABORATORY \\ operated by \\ BATTELLE \\ for the \\ UNITED STATES DEPARTMENT OF ENERGY \\ Under Contract DE-AC06-76RLO 1830
}

\author{
Printed in the United States of America \\ Available from \\ National Technical Information Service \\ United States Department of Commerce \\ 5285 Port Royal Road \\ Springfield, Virginia 22151
}

Price: Printed Copy \$

$\because$ Microfiche $\$ 3.00$

NTIS

-Pages Selling Price

\begin{tabular}{|l|l|}
\hline $001-025$ & $\$ 4.00$ \\
\hline $026-050$ & $\$ 4.50$ \\
\hline $051-075$ & $\$ 5.25$ \\
\hline $076-100$ & $\$ 6.00$ \\
\hline $101-125$ & $\$ 6.50$ \\
$126-150$ & $\$ 7.25$ \\
$151-175$ & $\$ 8.00$ \\
$176-200$ & $\$ 9.00$ \\
$201-225$ & $\$ 9.25$ \\
$226-250$ & $\$ 9.50$ \\
$251-275$ & $\$ 10.75$ \\
$276-300$ & $\$ 11.00$
\end{tabular}


WATER CONING IN POROUS

MEDIA RESERVOIRS FOR

COMPRESSED AIR ENERGY STORAGE

L. E. Wiles

R. A. McCann

June 1981

Prepared for

the U.S. Department of Energy under Contract DE-AC06-76RLO 1830

Pacific Northwest Laboratory

Richland, Washington 99352 

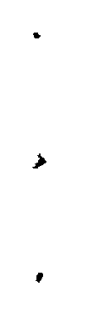


\section{FOREWORD}

The Compressed Air Energy Storage Technology Program at the Pacific Northwest Laboratory (PNL) is sponsored by the Department of Energy, Divisions of Physical and Chemical Energy Storage and Electric Energy Systems. The program scope includes a group of studies directed at developing a new energy storage technology to improve the cost and efficiency of electrical power utilization and reducing the dependence on petroleum fuels such as oil and natural gas. The program has two major thrusts --- Reservoir Stability Criteria Studies and SecondGeneration Concepts Studies. These have the following objectives:

- Reservoir Stability Criteria

Develop stability criteria for long-term operation of underground reservoirs used for compressed air energy storage (CAES) in order to accelerate the commercialization of the concept.

- Second-Generation Concepts Studies Develop and assess advanced CAES concepts that require little or no supplementary firing by petroleum fuels in order to eliminate the dependence of CAES on petroleum fuels.

The ultimate objective of this program is to reduce the consumption of natural gas and oil used for peak-power generation plants by about 100,000,000 barrels per year. This could be accomplished by replacing conventional gas turbine peaking plants currently being used by utilities with CAES plants.

The following documents have been issued or are in preparation by PNL or by subcontractors to PNL, reporting the results of the work toward these objectives.

- Technical and Economic Feasibility Analysis of the No-Fuel Compressed Air Energy Storage Concept, D.K. Kreid, BNWL-2065, May 1976. 
- FY-1977 Progress Report - Stability and Design Criteria Studies for Compressed Air Energy Storage Reservoirs, G.C. Smith, J.A. Stottlemyre, L.E. Wiles, W.V. Loscutoff and H.J. Pincus, PNL -2443 March 1978.

- FY-1977 Progress Report Compressed Air Energy Storage Advanced Systems Analysis, D.K. Kreid and M.A. McKinnon, PNL-2464, March 1978.

- Preliminary Stability Criteria for Compressed Air Energy Storage in Porous Media Reservoirs, J.A. Stottlemyre, PNL-2685, June 1978.

- Preliminary Long-Term Stability Criteria for Compressed Air Energy Storage Caverns in Salt Domes, R.L. Thoms and J.D. Martinez, PNL-2871, August 1978.

- Numerical Analysis of Temperature and Flow Effects in a Dry, OneDimensional Aquifer Used for Compressed Air Energy Storage, G. C. Smith, L.E. Wiles, and W.V. Loscutoff, PNL-2546, February 1979.

- The Effects of Water on Compressed Air Energy Storage in Porous Rock Reservoirs, L.E. Wiles, PNL-2869, March 1979.

- Pacific Northwest Laboratory Annual Report for 1978 to the DOE Division of Energy Storage Systems - Compressed Air Energy Storage Technology Program, W. V. Loscutoff, PNL-2935, June 1979.

- Incremental Cost Analysis of Advanced Concept CAES Systems, C.A. Knutsen, Knutsen Research Services, Bothe11, WA, PNL-3118, September 1979.

- Numerical Analys is of Temperature and Flow Effects in a Dry, TwoDimensional, Porous-Media Reservoir Used for Compressed Air Energy Storage, L.E. Wiles, PNL-3047, October 1979.

- Potential Petrophysical and Chemical Property Alterations in a Compressed Air Energy Storage Porous Rock Reservoir, J.A. Stottlemyre, R.L. Erikson and R.P. Smith, PNL-2974, October 1979. 
- The Economics of Compressed Air Energy Storage Employing Thermal Energy Storage, S. C. Schulte and R. W. Rei11y, PNL-3191, November 1979.

- Structural Analysis of Porous Rock Reservoirs Subjected to Conditions of Compressed Air Energy Storage, J.R. Friley, PNL-3231, January 1980.

- Compressed Air Energy Storage Technology Program Annual Report for 1979, W. V. Loscutoff, Staff Members and Subcontractors of Pacific Northwest Laboratory, PNL-3395, June 1980.

- Porous Media Experience Applicable to Field Evaluation for Compressed Air Energy Storage, R. D. Allen and P. J. Gutknecht, PNL-3294, June 1980.

- Technical and Economic Assessment of Fluidized Bed Augmented Compressed Air Energy Storage System, A. J. Giramonti, R. D. Lessard, D. Merrick and M. J. Hobson, United Technologies Research Center, East Hartford, CT, PNL-3686, UTRC R80-954490-20, Volumes 1-3, June 1980.

- An Experimental Study of the Response of the Galesville Sandstone to Simulated CAES Conditions, R. L. Erikson, J. A. Stottlemyre, and R. P. Smith, PNL-3399, JuTy 1980.

- Conceptual Design and Engineering Studies of Adiabatic CAES with Thermal Energy Storage, M. J. Hobson, Acres American, Inc., Columbia MD, March 1981.

- CAES and UPHS in Hard Rock Caverns: I. Geological and Geotechnica Aspects, D.S. Port-Keller and P.F. Gnirk, Re/Spec Inc., Rapid City, SD, PNL-2886 (RSI-0076), In process.

- CAES and UPHS in Hard Rock Caverns: III. Prel iminary Stability and Design Criteria for Compressed Air Energy Storage Caverns, P.F. Gnirk, Re/Spec Inc., Rapid City, SD, PNL-2916 (RSI-0079), In process.

- CAES and UPHS in Hard Rock Caverns: IV. Prel iminary Stability and Design Criteria for Underground Pumped Hydro Storage Caverns, P.F. Gnirk, Re/Spec Inc., Rapid City, SD, PNL-3262 (RSI-0110), In process. 
- Numerical Modeling of Behavior of Caverns in Salt for Compressed Air Energy Storage (CAES), S. Serata and T. E. Cundey, Serata Geomechanics Inc., Berkeley, CA, Volumes 1 and 2, May 1979.

- Numerical Modeling of Behavior of Caverns in Salt for Compressed Air Energy Storage (CAES), S. Serata, Serata Geomechanics, Inc., Berkeley, $\mathrm{CA}$, (condensed version), in process. 
The analysis described in this report is a continuation of work initiated at Pacific Northwest Laboratory (PNL) in FY-1977. The general purpose of the work is to define the hydrodynamic and thermodynamic response of a CAES porous media reservoir subjected to simulated air mass cycling. The knowledge gained by this research will provide or assist in providing design guidelines for the efficient and stable operation of the air storage reservoir.

Previous investigations have dealt with one- and two-dimensional modeling of dry reservoirs (Smith, Wiles, Loscutoff 1979, Wiles October 1979). A ore-dimensional modeling of water wet reservoirs has also been performed (Wiles March 1979). This report presents the analysis and results for the two-phase (air-water), two-dimensional, numerical modeling of CAES porous media reservoirs. The effects of capillary pressure and relative permeability were included. The fluids were considered to be immiscible; there was no phase change; and the system was isothermal.

The specific purpose of this analysis was to evaluate the reservoir parameters that were believed to be important to water coning. This phenomenon may occur in reservoirs in which water underlies the air storage zone. It involves the possible intrusion of water into the wellbore or near-wellbore region. The water movement is in response to pressure gradients created during a reservoir discharge cycle. Potential adverse effects due to this water movement are associated with the pressure response of the reservoir and the geochemical stability of the near-wellbore region.

The results obtained for the simulated operation of a CAES reservoir suggest that water coning should not be a severe problem. This is primarily due to the slow response of the water to the pressure gradients and the relatively short duration in which those gradients exist. However, water coning will depend on site-specific conditions, particularly the fluid distributions following bubble development, and, therefore, a water coning analysis should be included as part of site evaluation. 
The parameters that were known to have an effect on the reservoir pressure response, and, therefore on water coning, were evaluated with the following results:

- The wellbore producing length may extend to within a few meters of the air-water interface before significant intrusion of water into the wellbore will occur by the conclusion of one air extraction cycle.

- The avoidance of water coning by reduction of the producing length will have a greater impact on the pressure response of thin reservoirs.

- The pressure drop across the reservoir is proportional to the air mass flow rate so that more severe water coning will be associated with higher flow rates.

- In reservoirs having homogeneous permeability, water coning is more severe for large values of permeability, given a constant pressure drop across the reservoir as a basis for comparison.

- Even a slight reduction in vertical permeability can significantly reduce the severity of water coning.

- A layer of low permeability will inhibit water coning only if the bottom of the wellbore does not extend through the layer.

- The severity of water coning was not particularly sensitive to the capillary pressure and relative permeability functions evaluated by this analysis.

Certain characteristics of water coning that were observed include:

- If water enters the bottom of the wellbore, the low flow resistance allows the water level in the wellbore to rise significantly faster than the air-water interface in the surrounding region. Then capillary forces can pull this water into the sand adjacent to the wellbore and ahead of the frontal advance of the air-water interface. 
- The reservoir pressure response is affected most by the accumulation of water in the sand immediately adjacent to the wellbore and to a lesser extent by the water content in the wellbore.

- Water coning may be described as having two modes. In one, water movement is a response to the sharp pressure gradients near the wellbore. In the second, the water movement is a response to the pressure differential across the entire reservoir. In this second mode the air-water interface apparently moves much more slowly. 


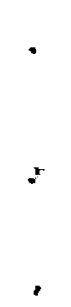




\section{CONTENTS}

FOREWORD........................... $i$ $i$.

SUMMARY ................................ vii

NOMENCLATURE. .................................

FIGURES ..................................

TABLES. .......................... xix

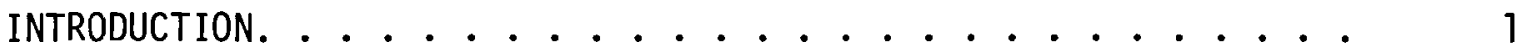

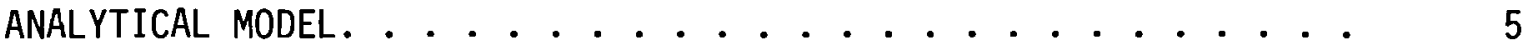

GOVERNING EQUATIONS. . . . . . . . . . . . 5

INITIAL CONDITIONS .................. 8

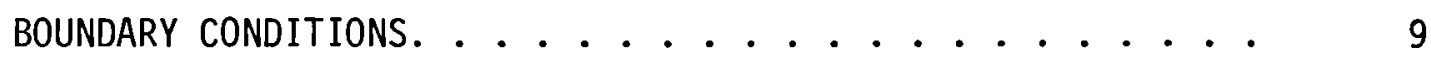

NUMERICAL MODEL . . . . . . . . . . . . . . . . 13

LITERATURE REVIEW. . . . . . . . . . . . 13

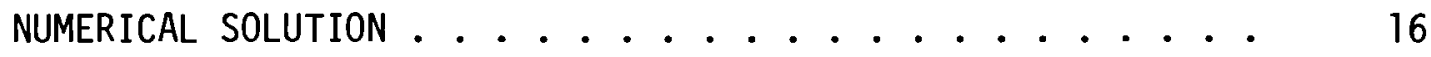

CONDITIONS OF THE ANALYSIS. ........................ 21

REFERENCE CONDITIONS ................... 21

WEEKLY CAES CYCLE. ................ 23

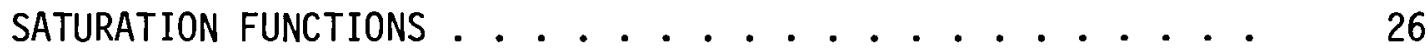

RESULTS OF THE WATER CONING ANALYSIS. . . . . . . . . 29

REFERENCE RESERVOIR ANALYSIS ............. 29

PRODUCING LENGTH . . . . . . . . . . . . . . 35

AIR STORAGE ZONE THICKNESS .............. 42

AIR MASS FLOW RATE ..................... 45

PERMEABILITY ........................... 47

Absolute Permeability. . . . . . . . . 48

Permeability Ratio. . . . . . . . . . 50

Permeability Stratification .......... 52

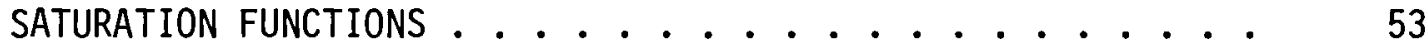

CONCLUSIONS AND RECOMMENDATIONS FOR FURTHER STUDY . . . . . . 61

REFERENCES. .......................... 65 
APPENDIX A - FINITE DIFFERENCE EQUATIONS. ......... A- .

APPENDIX B - FLOW CONNECTORS. . . . . . . . ..... B-

APPENDIX C - SIMULTANEOUS SOLUTION ALGORITHM. . . . . . . . C C

APPENDIX D - ADDITIVE CORRECTIONS ............ D D-

APPENDIX E - EQUIVALENT WELLBORE PERMEABILITY . . . . . . . E E-1

APPENDIX F - TRANSITION ZONE FLUID DISTRIBUTION . . . . . . F F-1

DISTRIBUTION. . . . . . . . . . . . . . Distr-1 


\section{NOMENCLATURE}

\section{Analytic Terms}

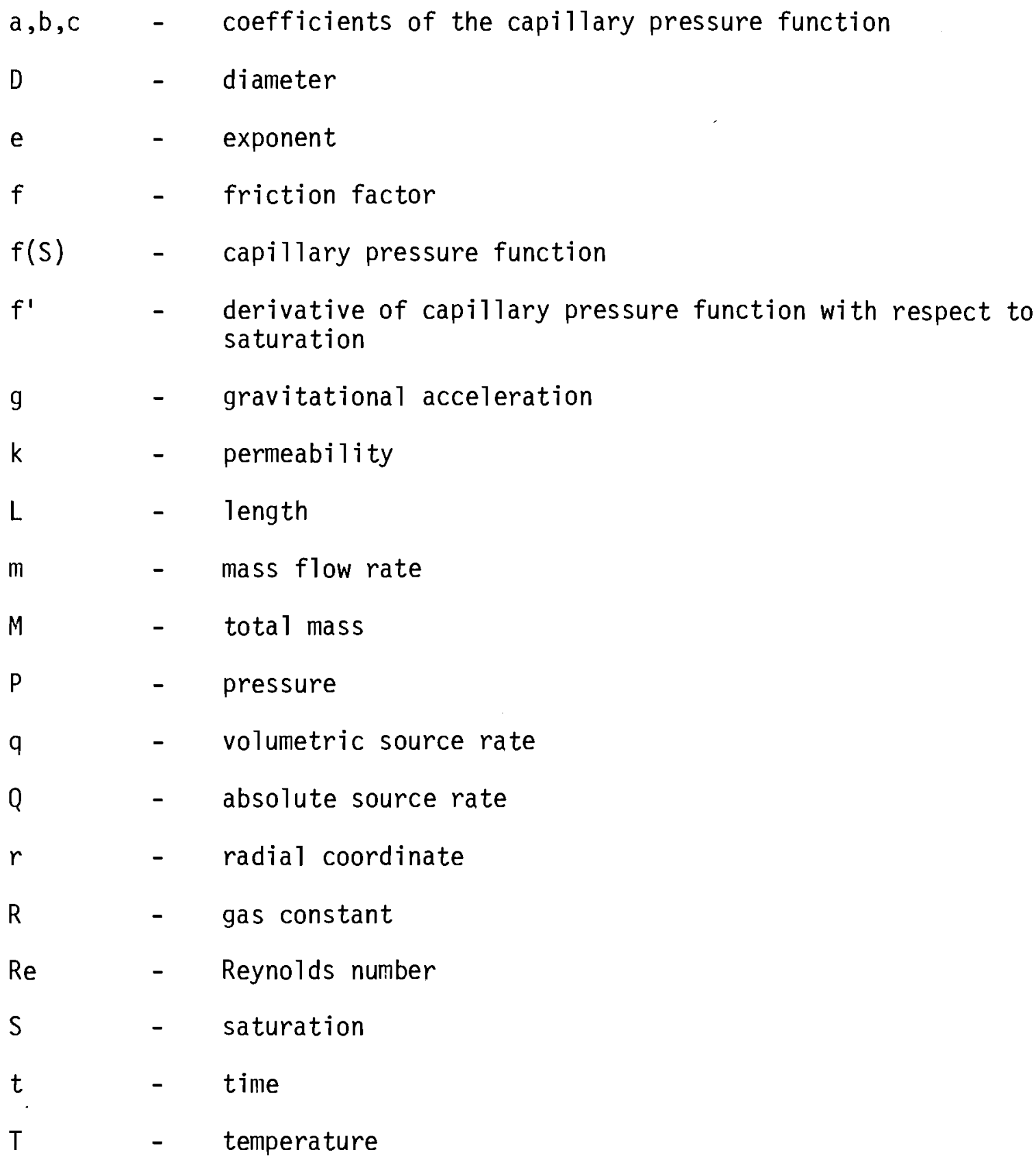




$\begin{array}{lll}\vec{v} & - & \text { velocity vector } \\ v & - & \text { velocity } \\ v_{p} & - & \text { pore volume } \\ x & - & \text { measure of length } \\ z & - & \text { vertical coordinate }\end{array}$

Numerical Terms

$A J(A K) \quad$ - flow connector in the j-direction (k-direction)

AJP(AKP) - flow connector in the j-direction (k-direction) multiplying the gas pressure

AJS(AKS) - flow connector in the j-direction (k-direction) multiplying the saturation; includes effect of upstream permeability for negative flow

$\mathrm{BP}(\mathrm{BS}) \quad-\quad$ sum of flow connectors and storage term multiplying the gas pressure (saturation)

$\overrightarrow{\mathrm{BP}}(\overrightarrow{\mathrm{BS}}) \quad$ - sum of flow connectors, storage term, and forward solution terms multiplying the gas pressure (saturation) in the simultaneous solution algorithm

CJS(CKS) - flow connector in the j-direction (k-direction) multiplying the saturation; includes effect of upstream permeability for positive flow

$\mathrm{CP}(\mathrm{CS}) \quad$ - $\quad$ storage term multiplying the gas pressure (saturation)

D - mass balance error

$D^{C} \quad$ - corrected mass balance error

$\tilde{D} \quad$ - sum of mass balance error and forward solution terms in simultaneous solution algorithm

$E P, E S, F \quad-\quad$ coefficients of back solution for gas pressure and saturation

$\Phi J(\Phi K) \quad$ - flow potential in j-direction (k-direction) 
Greek

$\begin{array}{lll}\alpha(\beta) & - & \text { one-dimensional correction in the } j \text {-direction (k-direction) } \\ \lambda & - & \text { percent of mass cycled } \\ \phi & - & \text { porosity } \\ \rho & - & \text { density } \\ \mu & - & \text { viscosity } \\ \omega & - & \text { over-relaxation factor } \\ \Omega & - & \text { relaxation parameter }\end{array}$

Subscripts

b $\quad$ - refers to boundary separating two numerical cells

d - refers to flow loss computed by Darcy flow equation

f - refers to flow loss computed for viscous flow in a pipe

$k(j) \quad-\quad$ node index in vertical (horizontal) direction

$r \quad$ - radial coordinate or relative permeability

w - wellbore

z $\quad$ - vertical coordinate

0 - refers to top of air storage zone

1,2 - refers to limits of integration

Superscripts

c - refers to capillary pressure

g - gas phase

i - arbitrary phase

1 - liquid phase 


\section{Operators}

$\nabla$

$\triangle$

$\delta$

a

$\Sigma$
- del operator

- difference

- smal1 variation

- partial derivative

- summation 
FIGURES

1 Water Coning During Reservoir Extraction Cycle. . . . . . . 3

2 Relative Permeability to a Gas and a Liquid in Consolidated and Unconsolidated Sands. . . . . . . . . . . . . 7

3 Communication Between Computational Zone and Aquifer, A) Strong, B) Weak. . . . . . . . . . . . . . 10

4 Numerical Grid Definition (m) and Initial Vertical Saturation Distribution for Reference Reservoir . . . . . . 24

5 Reference Weekly Cycle for Reservoir Average Pressure . . . . 25

6 Reference Relative Permeability Functions . . . . . . . . . 26

7 Reference Relative Permeability Functions for the Open Wellbore. . . . . . . . . . . . . . . . 27

8 Reference Capillary Pressure Function . . . . . . . . . . 27

9 Radial Saturation Distributions for Three Elevations (m) Showing Change with Time. . . . . . . . . . . . . .

10 Radial Saturation Distributions at Elevation $21.5 \mathrm{~m}$ for:

1) Initial, 2) After First Weekend Charge, 3) After Final Extraction of First Week, 4) After Third Weekend Charge,

5) After Final Extraction of Third Week . . . . . . . . .

11 Reservoir Pressure Loss as a Function of Producing Length Following 1.5 and 10.0 Hours of Air Extraction in a 30-mThick Reservoir....................

12 Radial Saturation Profiles for Various Producing Lengths (m) After 10 Hours of Air Extraction for Elevation $21.5 \mathrm{~m}$ Defined by Figure 4 . . . . . . . . . . . . . . .

13 Radial Pressure Profiles After 10 Hours of Air Extraction for Elevations (m) Defined by Figure 4. Bottom of Wellbore is at Elevation $26 \mathrm{~m}$.

14 Reservoir Pressure Loss Versus Reservoir Thickness for the Bottom of the Wellbore $3 \mathrm{~m}$ from the Air-Water Interface.

15 Reservoir Pressure Loss Versus Reservoir Thickness for the Bottom of the Wellbore $6 \mathrm{~m}$ from the Air-Water Interface.... 
16 Radial Saturation Profiles After 10 Hours of Air Extraction for Various Mass Flow Rates as Multiples of the Reference Flow Rate. . . . . . . . . . .

17 Radial Saturation Profiles After 10 Hours of Air Extraction for Various Mass Flow Rates as Multiples of the Reference Flow Rate: Producing Length $=27 \mathrm{~m} . .$. .

18 Reservoir Pressure Loss as a Function of Absolute Permeabilities for Homogeneous Reservoirs ........

19 Radial Saturation Profiles After 10 Hours of Air Extraction for Reservoirs of Various Permeabilities (md) but Operating with Similar Pressure Losses....... 50

20 Radial Saturation Profiles After 10 Hours of Air Extraction for Various Ratios of Vertical to Horizontal Permeability. The Horizontal Permeability

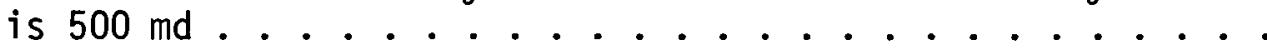

21 Radial Saturation Profiles After 10 Hours of Air Extraction for Three Cases of Permeability Stratification. The Elevations, as Defined by Figure 4, are the Vertical Centers of 3 -m-Thick Zones of $50 \mathrm{md}$.........

22 Capillary Pressure and Relative Permeability as Functions of Saturation .................. 56

A.1 Finite Difference Grid System . . . . . . . . . . A-2

B. 1 Geometry for Radial Flow Connector, $A_{j, k} \ldots \ldots$ B-3

B.2 Geometry for Vertical Flow Connector, $\mathrm{AK}_{j, k} \ldots \ldots$ B-5

D.1 Two-Dimensional Grid System ............ D-2

D.2 Effective Grid System for One-Dimensional Correction in

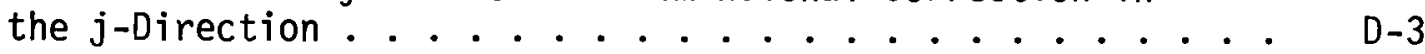




\section{TABLES}

1 Reference Conditions. ............... 22

2 Radial Saturation Distributions at the Beginning

of Each Week at Elevation $21.5 \mathrm{~m}$ as Defined by

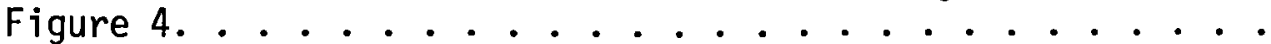

3 Vertical Saturation Distributions for Comparison of Reference and Smeared Profile Solutions......... 34

4 Air Mass Production Rates for Study of Reservoir Thickness. . 43

5 Radial Saturation Distributions After 10 Hours of Air Extraction for Various Homogeneous Absolute Permeabilities. . 48

6 Saturation Functions. . . . . . . . . . . 55

7 Transition Zone Saturation Distributions for the Capillary Pressure Functions. 


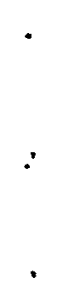




\section{INTRODUCTION}

The numerical analysis of the hydrodynamic and thermodynamic behavior of a compressed air energy storage (CAES) porous media reservoir was initiated in FY-1977. The fundamental objectives of this analysis are:

- characterize the fundamental response of the reservoir to CAES loading conditions

- define the sensitivity of reservoir performance to variations in reservoir parameters

- provide performance predictions to the parallel efforts of structural analysis, geochemical evaluations and field studies

- develop tools for site evaluations for field studies and commercial CAES facilities.

Meeting these objectives allows for the establishment of design guidelines that will enhance the efficiency and stability of reservoir operation.

The numerical analysis involves the development of computer codes that solve the transport equations for the reservoir using finite difference methods. The initial code was based upon a one-dimensional (radial), single-phase (air) approximation of the reservoir. It was used to evaluate the sensitivity of reservoir performance to fundamental reservoir properties, geometry, and operating conditions (Smith, Wiles, Loscutoff 1979). The second code was one-dimensional (radial) and twophase (air-water) although liquid mobility was not included. This model was used to evaluate the conditions affecting dehydration of the nearwellbore region (Wiles March 1979). A third model was developed for a two-dimensional cylindrical reservoir and a single fluid phase (air). The third model was used to investigate the sensitivity of reservoir performance to parameters that could be evaluated as a result of inclusion of the vertical dimension. These parameters included the wellbore producing length, permeability stratification and parameters involving wellbore heat transfer between the earth surface and the reservoir (Wiles oct. 1979). 
A significant result of the two-dimensional (cylindrical), single phase (air) reservoir analysis was that the pressure loss between the bulk of the reservoir and the wellbore was very sensitive to the producing length of the wellbore. To minimize this pressure loss the producing length must be as long as possible. However, in some reservoirs the air storage zone may be bounded from below by a water bearing region. In this situation the producing length will have to be established in consideration of the potential for water coning. Since water coning is a response to the pressure gradients in the reservoir, other parameters that significantly influence the pressure gradients will also have to be fully evaluated. These include the air mass flow rate and the permeability.

Water coning, which is described by several authors (Muskat, Wyckoff 1935; Muskat 1949; Meyer, Searcy 1956; Arthur 1944; Katz et al 1979), is illustrated in Figure 1. During a discharge cycle the depressurization around the wellbore causes a cone of water to rise towards the wellbore. The intrusion of water into the near-wellbore region could have two primary adverse effects on reservoir operation. First, the water would reduce the relative permeability to the flow of air, thereby increasing the pressure drop in the reservoir if the air mass flow rate is held constant. This effect could occur whether or not the reservoir is being used for thermal energy storage. Second, in reservoirs that are being operated above about $75^{\circ} \mathrm{C}$, geochemical reactions may occur due to the interaction of air and water (Stottlemyre, Erikson 1980). The potential problems increase with temperature. Such reactions could increase the resistance to the flow of air because the reactions can reduce the absolute permeability. (Geochemical effects have not been coupled into the water coning model used in this analysis.) Since most of the reservoir pressure loss occurs in the convergent region near the wellbore, increasing the flow resistance in that area will result in a greater pressure loss if the air mass flow rate is held constant. Thus, the ability to predict the conditions for which water coning may occur is crucial to the development of appropriate design guidelines for a porous media CAES facility. In this light, the development of a two-phase, two-dimensional numerical computer code was initiated. 


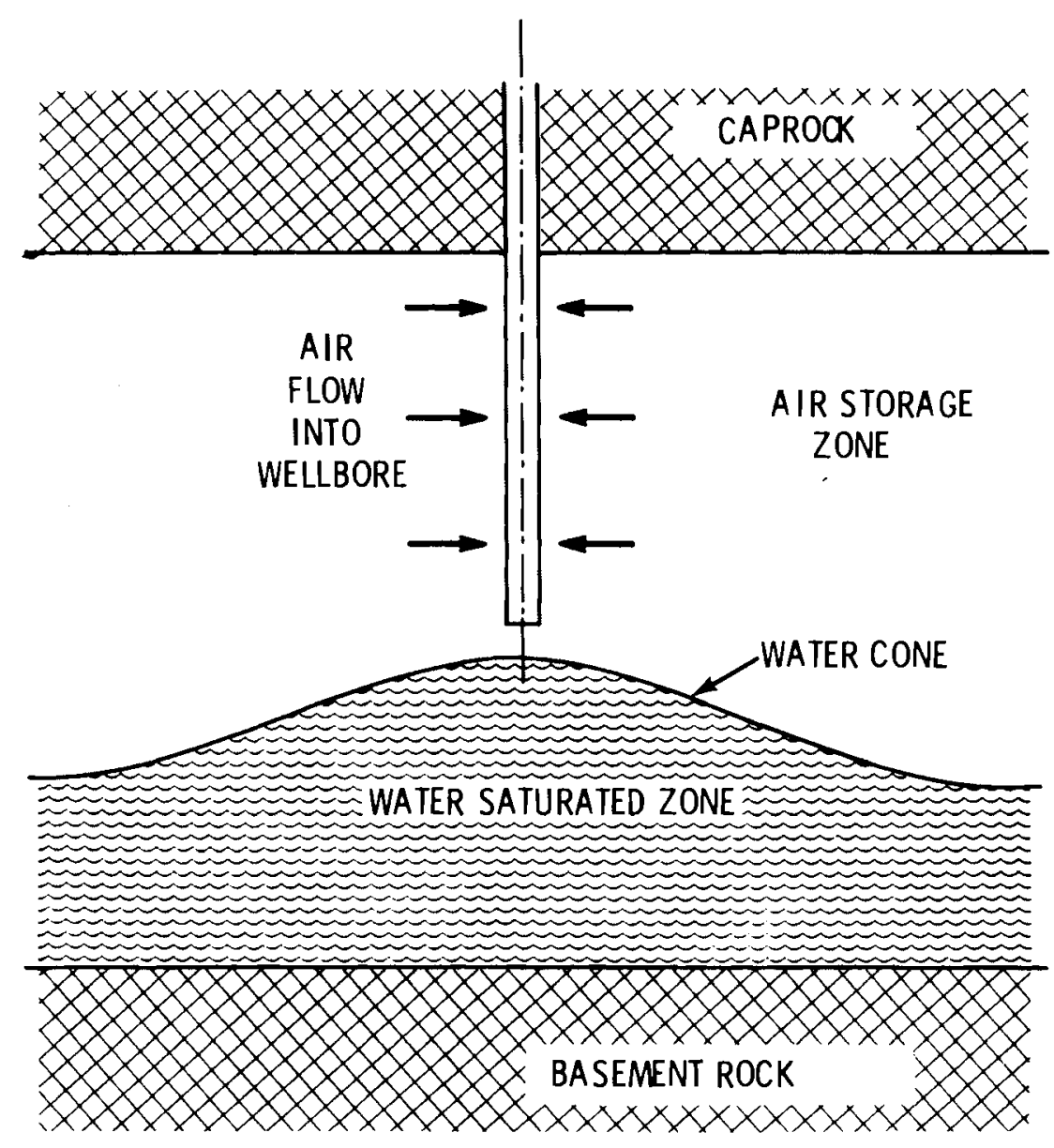

FIGURE 1. Water Coning During Reservoir Extraction Cycle

As the basis for previous analyses, both two-phase, one-dimensional (Wiles March 1979), and single-phase, two-dimensional (Wiles Oct. 1979) models had been developed. In the two-phase model the liquid water was immobile, a reasonable condition provided that the local pore water content never greatly exceeded the residual value. Both of those models coupled the fluid and thermal behavior in the reservoir. The code used in the water coning analysis models two-phase, two-dimensional flow in the reservoir, thus extending our modeling capability. Furthermore, two important physical phenomena were coupled to the flow equations. These are the relative permeability and the capillary pressure. Both of these quantities are functions of the saturation. The highly nonlinear effects introduced by the inclusion of these phenomena requires that the flow 
equations be solved using some relatively sophisticated techniques. The inherent difficulty of achieving such solutions is supported in an extensive amount of literature that is primarily due to the petroleum industry. Additional nonlinearities associated with temperature change were avoided because it was concluded that water coning could be evaluated adequately with an isothermal model.

Another factor that results in further complexity of the numerical model is the inclusion of an open wellbore in the computational grid. Discontinuities in the relative permeability and capillary pressure functions at the wellbore-sand interface can be efficiently modeled only by using special techniques. To our knowledge, no similar analysis has been reported for these conditions, i.e., an open, multi-cell wellbore coupled to the porous zone. On a global scale the effects of the open wellbore have less importance and those effects can be included using simpler models. For CAES, however, modeling the open wellbore allows for a more accurate determination of reservoir pressure 1oss, a term that is extremely important to the operational efficiency of the reservoir.

The development of the two-phase, two-dimensional reservoir model follows the obvious need generated from the results of previous work regarding the producing length. In addition to water coning, another important matter is the development of the air storage bubble. This involves the injection of air into a fully saturated porous zone, thereby displacing the aquifer water. Experience in natural gas storage (Katz et a1. 1979) and estimates for CAES (Katz, Lady 1976) indicate that the time required for bubble development for a large commercial site is on the order of years. The two-dimensional, two-phase model will provide a tool for the evaluation of various bubble development strategies, thus minimizing the time required for bubble development. The analysis of bubble development will be the subject of a future report. 
ANALYTICAL MODEL

Two-phase, isothermal flow in a porous media is described by an appropriate set of conservation equations, constitutive relations, initial conditions, and boundary conditions. Together these form the analytical model that is presented in this section.

\section{GOVERNING EQUATIONS}

The fundamental description of two-phase, isothermal flow in porous media is based on the individual-phase equations for conservation of mass and momentum. The constitutive relations that are combined with the conservation equations to form the governing equations are those between relative permeability and saturation (percent of pore volume containing liquid) and capillary pressure and saturation. The resulting governing equations describe the fluid motion in consideration of four forces acting on the system:

- gravitation

- viscosity

- capillary pressure, and

- imposed pressure.

The relationships of relative permeability and capillary pressure as functions of saturation, as well as other characteristics of two-phase flow in porous media, are described by several authors (Muskat 1949; Amyx, Bass, Whiting 1960; Buckley, Leverett 1942; Leverett 1941).

An important initial assumption in the development of the governing equations is that the air and water are completely immiscible so that neither phase is carried by the other phase. With this assumption the conservation of mass equations are:

Gas Phase

$$
\frac{\partial}{\partial t}\left\{\phi(1-S) \rho^{g}\right\}+\nabla \cdot\left(\rho^{g} \vec{v}^{g}\right)=q^{g}
$$


Liquid Phase

$$
\frac{\partial}{\partial t}\left(\phi S \rho^{l}\right)+\nabla \cdot\left(\rho^{l} \vec{v}^{l}\right)=q^{l}
$$

It is implied in the equations that the gas and liquid occupy all the available pore volume. One would often see in the literature that gas and liquid saturations are defined such that

$$
s^{g}+s^{l}=1
$$

In this work the saturation, $S$, represents only the liquid saturation and $1-S$ is used in place of the gas saturation.

A second assumption is that the bulk fluid velocity and the pressure gradient in that fluid are related by the Darcy flow equation, giving

$$
\vec{v}^{i}=-\frac{k k_{r}^{i}}{\mu^{i}}\left(\nabla P^{i}-\rho \stackrel{i}{g}\right)
$$

Equation 4 represents conservation of momentum in a porous media.

The relative permeability, $k_{r}^{i}$, is introduced in Equation 4 . If a pressure gradient is imposed on a porous material in which a liquid and gas coexist, the total flow of both fluids will be less than what would be predicted by using the permeability of the material as measured in the presence of a single component. The permeability to a single component is termed the absolute permeability while the apparent reduced permeability in the presence of more than one component is termed the relative permeability. The relative permeability for a given material is measured as a function of the saturation. Typical curves are shown in Figure 2 for consolidated and unconsolidated sands (Katz et a1. 1979; Amyx, Bass, Whiting 1960). The sum of the relative permeabilities of each phase at a given saturation is generally less than unity, particularly through the middle of the curve where viscous interaction of the two components is most pronounced. 


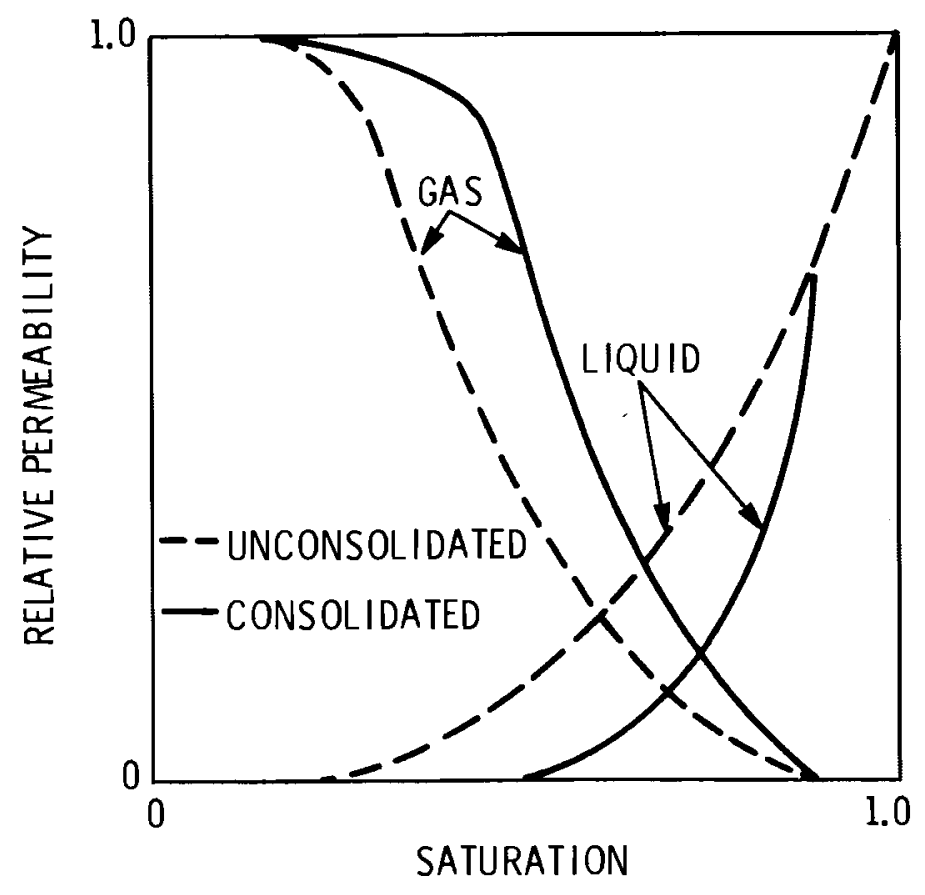

FIGURE 2. Relative Permeability to a Gas and a Liquid in Consolidated and Unconsolidated Sands

When the saturation approaches unity, the liquid displaces the gas from the flow paths, which reduces the permeability to the flow of gas. For low values of saturation the permeability to the flow of liquid is reduced because liquid is held in dead-end pores and by capillary forces.

The substitution of Equation 4 into 1 and 2 yields

Gas Phase

$$
\frac{\partial}{\partial t}\left\{\phi(1-S) \rho^{g}\right\}-\nabla \cdot\left\{\frac{k k_{r}^{g} \rho^{g}}{\mu^{g}}\left(\nabla p^{g}-\rho^{g} g\right)\right\}=q^{g}
$$

\section{Liquid Phase}

$$
\frac{\partial}{\partial t}\left(\phi S^{l}\right)-\nabla \cdot\left\{\frac{k k_{r}^{l} \rho^{l}}{\mu^{l}}\left(\nabla P^{l}-\rho^{l} \underline{g}\right)\right\}=q^{\ell}
$$


Given that the densities are determined from the state equations, there are three unknowns in these two equations. The unknowns are the phase pressures, $\mathrm{p}^{g}$ and $\mathrm{P}^{l}$, and the saturation. These three unknowns are related by the functional relationship between the capillary pressure and the saturation,

$$
p^{C}=p^{g}-p^{l}=f(S)
$$

That the phase pressures are not generally equal is due to the curvature of the pore spaces, the wettability of the surfaces, and the interfacial tension between the fluid phases.

Equations 5, 6, and 7 represent the governing equations that describe two-phase, immiscible, isothermal flow in porous media.

\section{INITIAL CONDITIONS}

The fluid distribution that would characterize the initial cyclic operation of the reservoir was established by consideration of the fact that the true fluid distribution will depend on site specific conditions. During the development of the cushion air bubble in the reservoir the injected air will displace the water. But as the saturation decreases, the displacement process becomes less efficient. As the saturation approaches the residual value, the liquid mobility approaches zero. Therefore, bubble development is characterized by a broad smearing of the saturation front. Complete gravitational-capillary equilibrium would occur only after a very long period of time. For this reason, a gravitational-capillary equilibrium distribution would not generally represent an accurate initial condition for the analysis of cyclic operation of the reservoir. On the other hand, the fluid distribution that exists immediately following the bubble development is also not likely to represent an accurate initial condition. A lengthy bubble development time will provide for some unknown extent of gravity drainage to influence the fluid distribution. 
In this analysis the gravitational-capillary equilibrium fluid distribution was used as an initial condition. The following reasoning supports this choice. The equilibrium solution can be easily computed analytically for any capillary pressure function, regardless of the other imposed conditions in the reservoir. Thus, this distribution represents a fixed reference condition. A distribution taken from a bubble development solution would be dependent on such imposed conditions as reservoir thickness, permeability, and well penetration. Thus, each parametric case would require a unique bubble development solution. This approach would not be economically practicle.

In consideration of the above discussion the initial vertical fluid saturation distribution in the reservoir is characterized by three regions. At the top of the reservoir only residual water exists. This water is immobile. At the bottom of the reservoir the porous material is essentially saturated. We selected an initial saturation of 0.9995 for the saturated region. This value allows some effective compressibility in the liquid. The region separating the saturated zone and the residual water zone is known as the transition zone. In this zone the fluid distribution is dependent on the capillary pressure function. The method for computing the distribution is given in Appendix $F$.

\section{BOUNDARY CONDITIONS}

The generally symmetric operation of adjacent wells in the reservoir leads to the assumption that the performance of the reservoir can be evaluated by considering the performance of a single well. In this model the computational region is cylindrical with the wellbore at the center, resulting in axisymmetric, two-dimensional flow.

To evaluate water coning, two outer radial boundary conditions have been identified which apply in different portions of the reservoir. At the outer regions of the reservoir the air storage zone adjacent to a given wellbore may be in strong communication with the surrounding aquifer water, as shown in Figure $3(A)$. In this case, aquifer water may contribute to the build-up of a cone. For the inner regions of the 


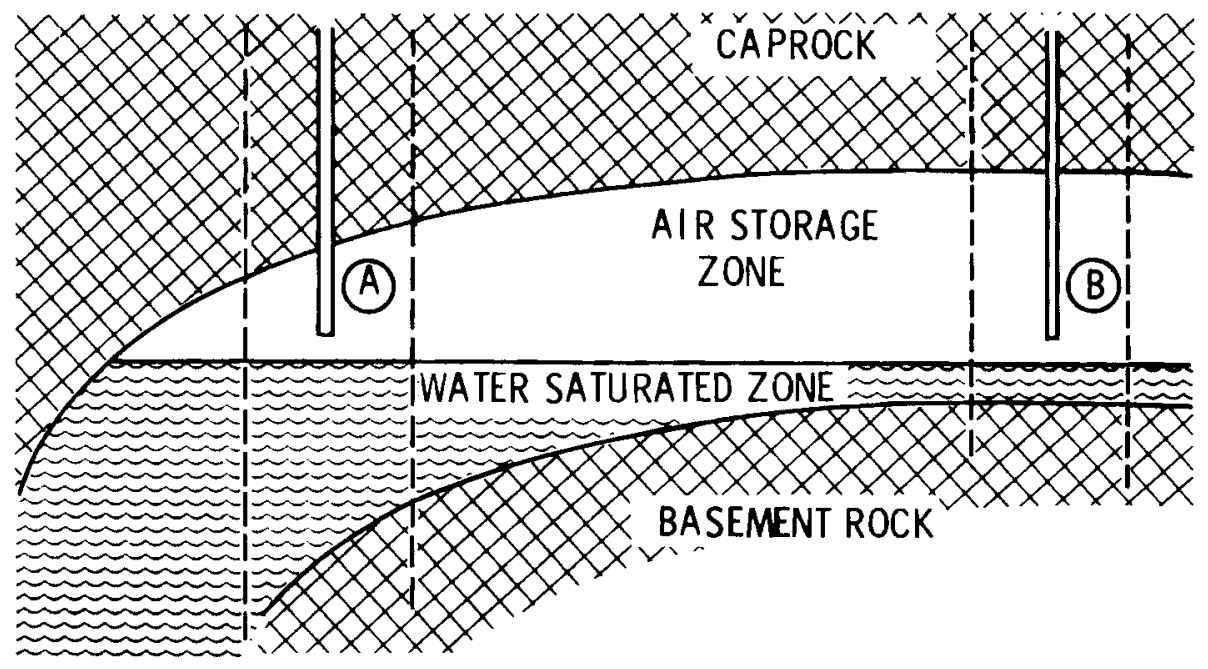

FIGURE 3. Communication Between Computational Zone and Aquifer, A) Strong, B) Weak

reservoir the water beneath a given wellbore may have minimal communication with the aquifer water outside the air storage bubble. If these inner wells are operated symmetrically, then no fluids, either air or water, would flow across the outer boundaries of the region of influence of the individual wells. This insulated case is shown in Figure $3(B)$. In actua?ity the communication between the water beneath the air storage zone and the surrounding aquifer is neither complete nor nonexistent. However, the analysis of both cases establishes the extremes of water coning.

In this analysis the open wellbore is an integral part of the computational region, having an effective permeability on the order of $5 \cdot 10^{9} \mathrm{md}$. Studies of two-phase flow in porous media reservoirs have typically been done by treating the production at the well with source terms along the wellbore-sand interface. Such modeling ignores the phenomenon created by the unique conditions in the wellbore. Since there is no capillary pressure in an open wellbore, then a saturation and/or pressure build-up must occur adjacent to the wellbore before breakthrough of water will occur. The saturation build-up would reduce the capillary pressure gradient across the interface. The pressure build-up imposed by production from the well would overcome the capillary 
pressure difference. This phenomenon, termed the "outlet effect" in the literature regarding petroleum reservoir analysis, is attributed to the discontinuity in the capillary pressure and effective permeability functions at the wellbore-sand interface.

Sonier et a1. (1973) included the outlet effect in a coning analysis but did not allow for friction in the wellbore. The fluid pressure in the wellbore was determined hydrostatically. The modeling of implicit specified flow rate was based on a guess of wellbore fluid pressure with a subsequent iterative correction to satisfy the flow. Settari and Aziz (1974) apparently improved on the modeling of the outlet effect by using a grid system that defined node points on the wellbore boundary. This grid also permitted a simple treatment of the effects of friction in the wellbore. In both of these studies the well wall was treated as a boundary so that special handling was required to simulate the wellbore flow. Also, Settari and Aziz stated that breakthrough of the wetting phase would not occur until the capillary pressure in that phase was equal on both sides of the wellbore. This is not necessary, physically, since if the wetting phase has a finite mobility and the net pressure gradient in that phase is towards the wellbore, then breakthrough will occur.

There is some question regarding the importance of the outlet effect when considering global reservoir performance. However, it is essential that it be accounted for in laboratory determination of properties and in performance modeling of individual wells.

While the open wellbore has been included as a part of the computational grid, no detail has been included regarding the specific flow behavior in the wellbore. During single phase flow this would require the wellborefluid friction to be dependent on the flow velocity whereas in the porous media the fluid friction is determined by material properties. Thus, special logic would be required to computationally provide a unique fluid friction model in the wellbore. In fact, the governing equations in the porous media and wellbore would be different, necessitating an explicit coupling of the two regimes. More complex conditions would involve 
turbulent, two-phase, bubbly flow with droplet entrainment and solutioning of the air and water. This would represent an extremely difficult problem in itself that would not logically be completely coupled to a full scale reservoir model. It satisfies the present need to approximate wellbore friction with an equivalent permeability. Also, inclusion of the discontinuities of the saturation functions at the wellbore-sand interface adequately provides for the dominant feature of wellborereservoir fluid coupling. 


\section{NUMERICAL MODEL}

The numerical solution of the governing equations has proved to be a unique challenge for several reasons. First, the numerical model is based upon Equations 5, 6, and 7. With the inclusion of the functional relationships for relative permeability, capillary pressure, and the state conditions, the system of equations is highly nonlinear. Second, for convergent flow problems like water coning, rapid saturation changes can occur in the vicinity of the wellbore. Third, the inclusion of an open wellbore, which produces discontinuities in effective permeability and capillary pressure at the wellbore-sand interface creates a highly anisotropic computational regime. As a result of these characteristics it has been necessary to use numerical methods characterized by implicit determination of the nonlinear coefficients, and by implicit coupling of the flow equations to be able to perform computations with physically meaningful time steps.

\section{LITERATURE REVIEW}

To solve the flow equations applicable to this problem, considerable guidance has been taken from the open literature. Much of the literature is due to the petroleum industry.

The finite difference method has been applied to the flow equations. At least four basic techniques are available within this method, and several variations exist for each technique. The application of any method must deal with the need for sequential or simultaneous solution of the coupled equations and the degree of implicitness of the nonlinear terms. These variations are discussed by Peaceman (1977). The implicitness of the nonlinear terms in multiphase reservoir simulators has been dealt with by several other authors (MacDonald, Coats 1970; Letkeman, Ridings 1970; Coats, Terhune 1966; Blair, Weinaug 1969; Nolen, Berry 1972).

Perhaps the most straightforward method for solving the reservoir flow equations is line successive over relaxation (LSOR). Although the method avoids complexity, it is considered to be applicable to a more 
restricted class of problems than the other methods (MacDonald, Coats 1970; Letkeman, Ridings 1970). However, it has been applied to the simulation of coning in $0 i 1$ and gas reservoirs (Letkeman, Ridings 1970; Settari, Aziz 1974). The computational strength of LSOR can be enhanced by the coupled use of a technique referred to as "additive corrections", introduced by Watts (1971). This method smears locally high continuity errors. For anisotropic problems where locally high continuity errors are more likely to occur, the combination of LSOR and additive corrections is very effective.

The application of the alternating direction implicit (ADI) method was introduced in the mid-1950s by Peaceman and Rachford (1955), and Douglas (1955). These authors later applied the techniques to two-phase flow and presented an algorithm for the simultaneous solution of the dependent variables (Douglas, Peaceman, Rachford 1959). The ADI technique requires the selection of a series of iteration parameters to achieve convergence, a problem that is avoided with the LSOR technique. MacDonald and Coats (1970) indicate that they had very little difficulty in selecting effective iteration parameters in their coning analysis. Meanwhile, Letkeman and Ridings (1970) suggest that the selection of the iteration parameters was actually somewhat difficult, pointing out that an improper set may preclude convergence. Peaceman (1977) points out that for nonhomogeneous and/or anisotropic problems the ADI technique is not as successful as other methods. In spite of the potential for difficulty, the ADI technique has been applied successfully to problems similar to those encountered in the present study (MacDonald, Coats 1970; Welge, Weber 1974; Coats, Richardson 1967).

A third method of solution is the strongly implicit procedure (SIP) introduced by Stone (1968). The method is based upon an approximate factorization of the coefficient matrix. This matrix represents the coefficients of the dependent variables in the set of difference equations that are written for each grid point. The method allows the dependent variables at a grid point to be evaluated based on a more accurate description of the influence of neighboring cells. The technique was 
applied to multiphase reservoir problems, including coning, and was shown to be superior to the ADI method of Peaceman and Rachford (1955), particularly as the complexity of the problem increased (Weinstein, Stone, Kwan 1969).

A fourth method of solution is by direct solution. This method is undesirable due to the necessity of computing and storing a large coefficient matrix and the computing time required for the subsequent solution. This would be particularly true for the nonlinear reservoir equations, which would require that the coefficient matrix be routinely redefined. However, for some problems direct methods may be the most appropriate means of obtaining a solution (Peaceman 1977). Techniques that restructure the coefficient matrix can reduce the work required (Price, Coats 1974).

A technique known as vertical equilibrium is a method which could be applied within the structure of any of the four methods discussed above. The vertical equilibrium concept is described by Coats et al. (1967). They state that for a reservoir to be in vertical equilibrium the pressure in each fluid phase must vary hydrostatically in the direction normal to the confining strata, i.e., the fluids are assumed to be gravity segregated within any vertical column (a transition zone may exist). Conditions that enhance vertical equilibrium are: 1) high permeability normal to the confining strata, 2) a porous zone thin in the direction normal to the confining strata, and 3 ) low rates of flow parallel to the confining strata. The method allows the details of the vertical dimension to be avoided by integrating over the reservoir normal to the confining strata. However, the vertical integration results in a loss of the gravitationally induced pressure gradient. To provide for the flow that would occur due to this gradient, the method introduces a pseudocapillary pressure term, which is defined by the fluid saturations. The psuedo-capillary pressure accounts for the actual capillary pressure as well as the gravitational term. Also, pseudo-relative permeabilities are introduced to account for the fact that the actual mobilities of the segregated fluids are higher than the mobilities that would be predicted 
using a column averaged saturation. This method could be used to allow a two-dimensional flow to be described by a one-dimensional model or a three-dimensional flow to be described by a two-dimensional model. Either case could result in significant computational savings. Variations of the method are most accurately applied when reservoir data is available. The relative permeability and capillary pressure functions are adjusted, based on engineering judgment and experience, until a history matching of past reservoir performance has been achieved. Then, based on the adjusted saturation functions, successful forecasting of future reservoir performance is possible (but certainly not guaranteed).

\section{NUMERICAL SOLUTION}

The approach to developing a numerical model for the two-dimensional, two-phase flow was to attempt the least complex method that was thought to be applicable. In the first model the mass balance equations were solved for the phase pressures. The difference in phase pressure, which defines the capillary pressure, was used to obtain the saturation through the functional relationship. This method, termed "explicit saturations", was relatively free of complexity, particularly regarding the flow resistance terms which multiply the pressures. However, the solution for the phase pressures is obtained using explicit saturations computed from the previous iteration. Thus, the coupling of the pressures and saturations is not strong. This method proved to be unsatisfactory for the water coning problem where fluid saturations and pressures can change rapidly.

To achieve a tighter coupling of the pressures and saturations, the liquid pressure in the liquid continuity equation was replaced by $p^{l}=p^{g}-f(S)$. With this substitution for $\mathrm{P}^{\ell}$, the dependent variables in the governing equations were the gas phase pressure and the saturation. This method, termed "implicit saturation", resulted in greater complexity of the flow resistance terms. However, the implicit computation of gas pressure and saturation resulted in a computationally more efficient algorithm. 
The finite difference equations are developed in Appendix $A$. Equations A-14 and A-22 are the coupled mass balance equations implicit in gas pressure and saturation. These equations could be solved sequentially, whereby Equation A-14 is solved for gas pressure using saturations from the previous iteration. Then Equation A-22 would be solved for the saturations using the updated gas pressures. While each equation is implicit in one dependent variable, the coupling of the equations is explicit. The success of such an approach would be on the order of that for the explicit saturation method.

The simultaneous solution method described in Appendix $C$ has been used to make the computations more implicit in both dependent variables by making the flow equations implicitly coupled. (a) This method was apparently first employed in petroleum reservoir analysis by Douglas, Peaceman, and Rachford (1959). It involves reducing the mass balance equations to the following form

$$
\begin{aligned}
& \overline{\mathrm{BP}}_{j, k}^{g} \delta P_{j, k}^{g}+\overline{\mathrm{BS}}_{j, k}^{g} \delta S_{j, k}=\overline{\bar{D}}_{j, k}^{g} \\
& \overline{\mathrm{BP}}_{j, k}^{\ell} \delta P_{j, k}^{g}+\overline{\mathrm{BS}}_{j, k}^{\ell} \delta S_{j, k}=\bar{D}_{j, k}^{\ell}
\end{aligned}
$$

These equations are written for the corrections to gas pressure, $\delta \mathrm{P}_{j, k}^{\mathrm{g}}$, and saturation, $\delta S_{j, k}$, that will reduce the mass balance error in cell $(j, k)$. The coefficients and the right-hand sides are known. The equations are solved simultaneously as one would solve any linear set of two equations and two unknowns. The determinant of the coefficients is first evaluated,

$$
\operatorname{det}=\overline{\mathrm{BP}}_{j, k}^{g} \overline{\mathrm{BS}}_{j, k}^{\ell}-\overline{\mathrm{BP}}_{j, k}^{\ell} \overline{\mathrm{BS}}_{j, k}^{g}
$$

(a) For the equations to be fully implicit in all respects, the coefficients would have to be written in terms of the implicit dependent variables. The resulting set of finite difference equations would be nonlinear. The nonlinear equations can be solved by conventional algorithms only by using approximations such as described by Nolen and Berry (1972). 
Then, the pressure and saturation corrections are computed by

$$
\delta P{ }_{j, k}^{g}=\frac{1}{\operatorname{det}}\left(\overline{B S}_{j, k}^{l} \overline{\bar{D}}_{j, k}^{g}-\overline{B S}_{j, k}^{q} \overline{\bar{D}}_{j, k}^{\ell}\right)
$$

and

$$
\delta S_{j, k}=\frac{1}{\operatorname{det}}\left(\overline{\mathrm{BP}}_{j, k}^{g} \overline{\bar{D}}_{j, k}^{\ell}-\overline{\mathrm{BP}}_{j, k}^{\ell} \overline{\bar{D}}_{j, k}^{g}\right)
$$

The simultaneous solution of Equations 8 and 9, using LSOR, is not in itself an efficient tool for performing the water coning analysis described by this report. The final ingredient necessary to achieve an efficient solution is known as "additive corrections". The method is applied to accelerate the convergence of the iterative solution. This method, outlined in Appendix $D$, treats the computational region as onedimensional, either in the $j$ or $k$ directions. This is done by lumping all the cells in a j-column or k-row, into a single cell. The resultant one-dimensional problem is solved to find gas pressure and saturation corrections unique to each lumped cell. These corrections are then applied to each individual cell composing the lumped cell. The result is that locally high mass balance errors are smeared over a larger number of cells, thus reducing the maximum error.

To achieve the maximum benefit from the additive correction scheme requires that the global mass balance error be zero. This is accomplished by summing over the entire computational region to determine the total mass of gas in place and liquid in place. This computed mass in place for each phase is compared against the sum of the original mass and the net influx for each phase. A correction to the gas pressure and the saturation is then determined. These corrections adjust the error in the total mass of each phase to zero. The corrections for each phase are then applied to each cell in the computational grid. The global mass balance correction is applied previous to each application of the additive correction algorithm. 
In summary, the numerical solution consists of a simultaneous solution for gas pressure and saturation using LSOR. The convergence rate is improved considerably by judicious application of additive corrections and a qlobal mass balance. Another important issue is the degree of implicitness of the nonlinear terms. The optimum sequencing of the LSOR sweeps within the application of additive corrections and the updating of nonlinear terms is problem dependent. Experience in the art of numerical analysis is an invaluable tool in this regard. 


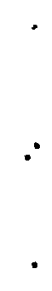


The two-phase, two-dimensional numerical model describing isothermal mass transport in a porous media reservoir has been applied in a study of the parameters believed to be important to water coning. In this section the specific physical models and other conditions applied to the analysis are outlined.

\section{REFERENCE CONDITIONS}

The water coning analysis is based upon a set of reference conditions applied to the reservoir geometry, material properties, and operating conditions. The selected reference values of these parameters are given in Table 1. These values are consistent with the values used in previous analyses of compressed air energy storage in porous media reservoirs (Smith, Wiles, Loscutoff 1979; Wiles March 1979; Wiles Oct. 1979). The reference functions relating relative permeability and capillary pressure to saturation are provided. These functions are discussed below in more detail. Also, a brief discussion is provided to define the basis for some of the other parameters.

The desired nominal reservoir pressure was $5070 \mathrm{kPa}$. The depth required to conform to the nominal pressure was approximately $520 \mathrm{~m}$.

The percent of air cycled is the variation between the weekly maximum and minimum values of the stored air mass in the reservoir. It is defined as

$$
\lambda=\left(\frac{M_{\max }-M_{\min }}{M_{\max }}\right) \times 100 \%
$$

The injection and extraction air mass flow rates are computed by the code to conform to the specified value of $\lambda$. This facilitates comparison of the results. For example, for otherwise equivalent conditions, 
TABLE 1. Reference Conditions

Geometry

Reservoir Depth

Vertical Thickness (Air Zone)

(Water Zone)

Reservoir Diameter

Wel1 Diameter

Producing Length

\author{
$520.0 \mathrm{~m}$ \\ $30.0 \mathrm{~m}$ \\ $20.0 \mathrm{~m}$ \\ $120.0 \mathrm{~m}$ \\ $0.20 \mathrm{~m}$ \\ $24.0 \mathrm{~m}$
}

Properties

Porosity

Permeability (Horizontal)

$20 \%$

Wellbore Porosity (Vertical)

$500 \mathrm{md}$

$500 \mathrm{md}$

$100 \%$

Wellbore Permeability

$5.0 \cdot 10^{9} \mathrm{md}$

Operating Conditions

Nominal Pressure

Air Flow Rate (Injection)

(Extraction)

Percent of Air Cycled

Temperature

$50 \operatorname{atm}(5070 \mathrm{kPa})$

$6.66 \mathrm{~kg} / \mathrm{s}$

$8.79 \mathrm{~kg} / \mathrm{s}$

$12 \%$

$300^{\circ} \mathrm{K}$

Saturation Functions

Relative Permeability (Porous Media)

$$
\begin{array}{ll}
\text { (air) } & k_{r}{ }^{g}=(0.90-S)^{2}\left\{2.34-1.37(0.90-S)^{2}\right\} \\
\text { (water) } & k_{r}{ }^{\ell}=(S-0.20)^{3}\{4.93-3.72(S-0.20)\}
\end{array}
$$

Relative Permeability (Wellbore)

$$
\begin{array}{ll}
\text { (air) } & k_{r, w}^{g}=\left(\frac{1.0-S}{0.9995}\right)^{2}\left\{2.0-\left(\frac{1.0-S}{0.9995}\right)^{2}\right\} \\
\text { (water) } & k_{r, w}^{\ell}=\left(\frac{S-0.0005}{0.9995}\right)^{2}\left\{2.0-\left(\frac{S-0.0005}{0.9995}\right)^{2}\right\}
\end{array}
$$

Capillary Pressure (Porous Media)

$$
P^{C}=\left(\frac{0.05525}{S-0.15}\right)-0.065 \mathrm{~atm}
$$

Capillary Pressure (We11bore)

$$
P^{C}=0.0 \mathrm{~atm}
$$


two reservoirs having different thicknesses will have about the same air flow velocity at the wellbore if both reservoirs have the same value of $\lambda$. Thus the pressure response for those two cases would be comparable.

The reservoir geometry and numerical grid are shown in Figure 4. The node points are centered between the grid boundaries. The initial values of saturation in each cell or region are given. These values are. defined for each horizontal zone; i.e., they are independent of radial position. The values are based on gravitational-capillary equilibrium. The bottom of the transition zone is at the elevation of $20 \mathrm{~m}$. The actual transition zone height for the reference capillary pressure function is $10.7 \mathrm{~m}$. This requires that the top cell in the transition zone, centered at $30.5 \mathrm{~m}$, be given an initial saturation that is an average accounting for the portion of the cell that contains top of the transition zone and the remaining portion of the cell that contains only residual saturation.

\section{WEEKLY CAES CYCLE}

Included in the reference conditions is the specification of a weekly operating cycle that defines when the reservoir is to be charged or discharged and when there is no air flow to the reservoir. The operating cycle is essentially identical to that used for the onedimensional analysis of dry reservoirs. The development of the cycle is described in the report issued on that analysis. (Smith, Wiles, Loscutoff 1979).

The weekly reservoir pressure cycle applied to the reference case of this analysis is shown in Figure 5 . The weekly cycle begins and ends on Friday at 8:00 p.m. The duration of each weekly charge or discharge cycle is 10 hours. The reservoir is closed for 2 hours between each of these daily cycles. On the weekend, a 10-hour charging cycle begins on Friday at 8:00 p.m. It is followed, in order, by 18 hours of no flow, 16 hours of charging, and 16 hours of no flow, which end on Monday morning at 8:00 a.m. Since there are 40 hours of injection during the 


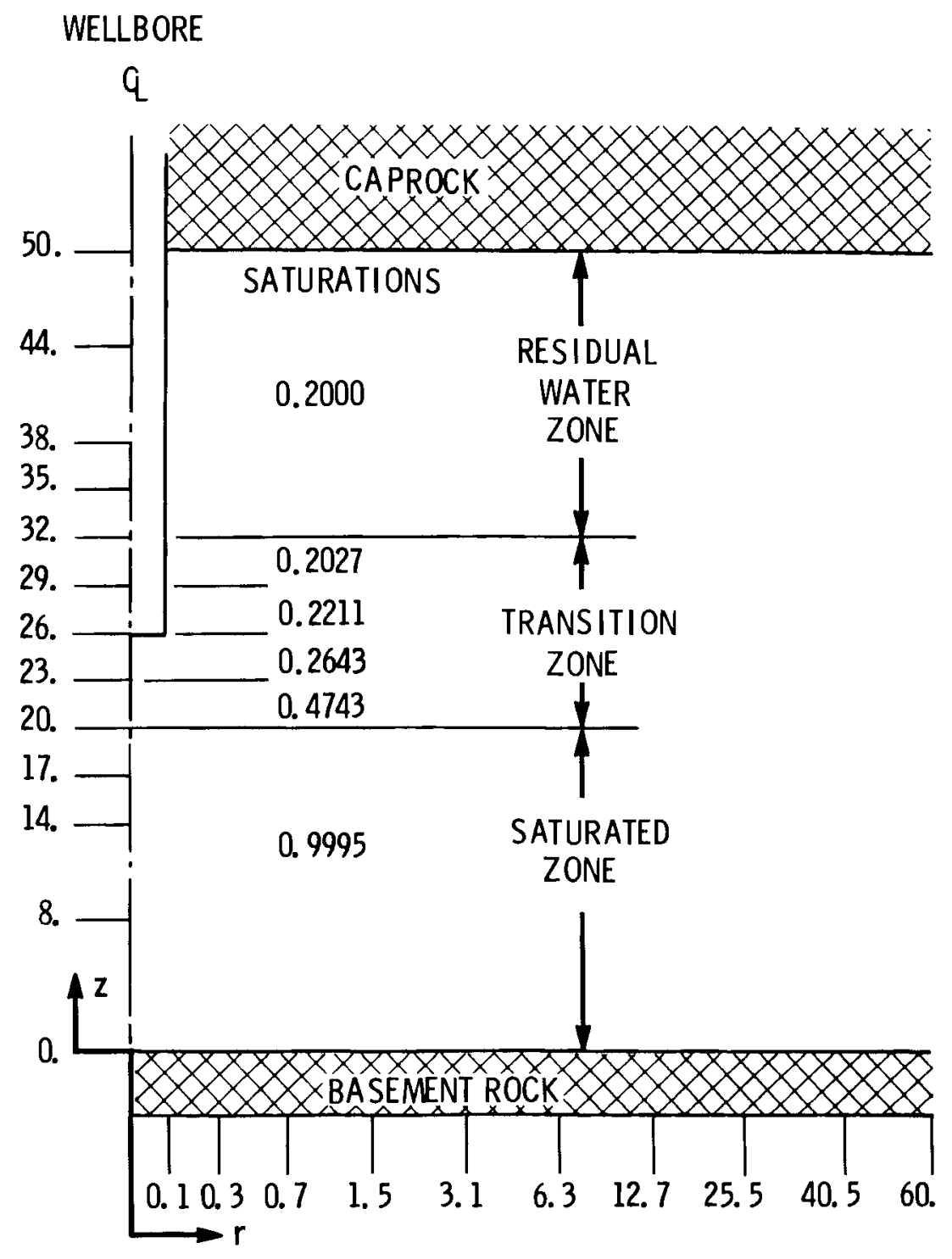

FIGURE 4. Numerical Grid (m) and Initial Vertical Saturation Distribution of Reference Reservoir 


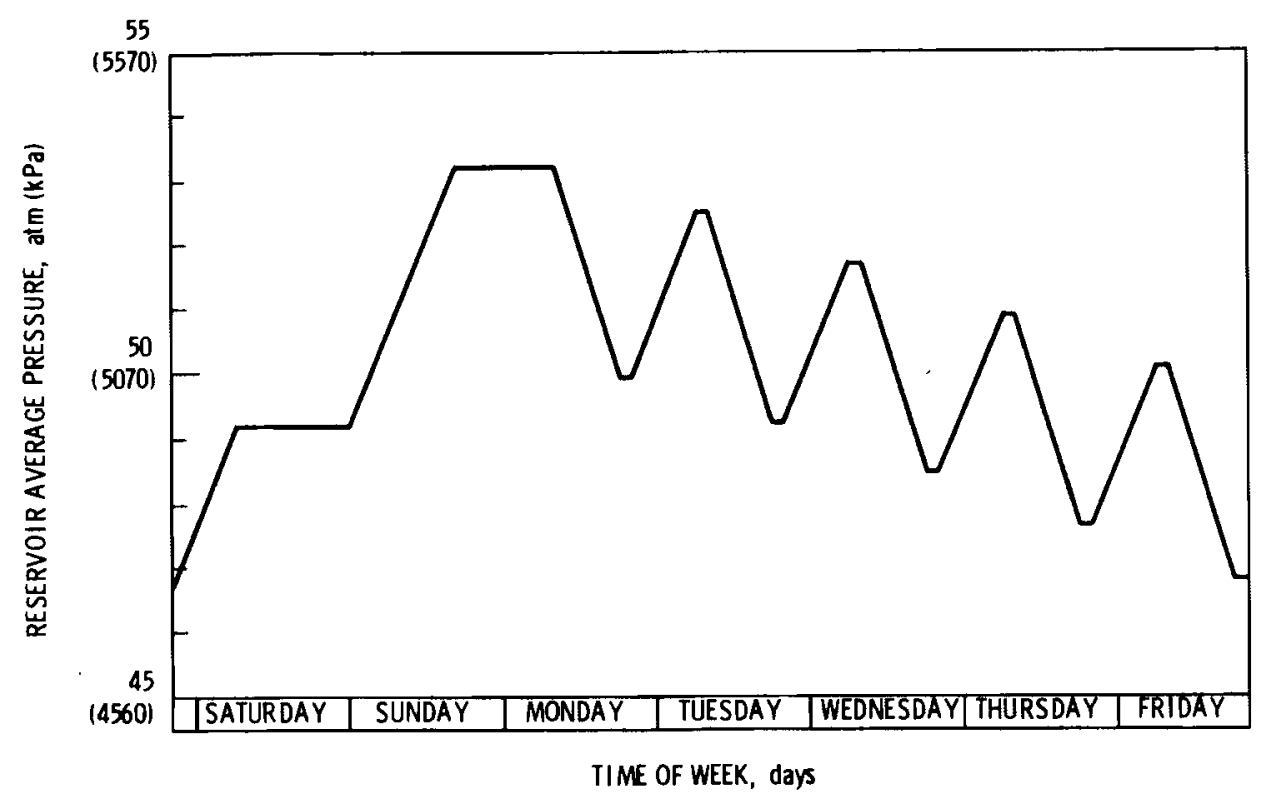

FIGURE 5. Reference Weekly Cycle for Reservoir Average Pressure

weekdays, then the total injection time is 66 hours. The fraction of the weekly stored mechanical energy that is supplied to the reservoir on the weekend is $26 / 66=0.394$. There are 50 hours of extraction each week. To balance the reservoir air mass, the extraction air mass flow rate is $66 / 50=1.320$ times the injection rate.

Although the weekly cycle was available in the code, we found that it was impractical to apply it to every case. As discussed previously with regard to the initial conditions, the initial fluid distribution in the reservoir was based on total gravitational-capillary equilibrium. When the weekly cycle was applied to the reference reservoir, the fluid distribution at the beginning of each week changed slightly. If the cycling had been continued for some indefinite time, perhaps a quasisteady-state fluid distribution would have been reached. Applying such an approach to each parametric case was impractical with respect to computing cost. Therefore, the only portion of the cycle used in the parametric study was the initial extraction cycle. This approach perhaps reduces the quantitative accuracy of the results. However, the conclusions 
regarding the sensitivity of parameters with respect to coning should still be valid based on a relative comparison of results.

\section{SATURATION FUNCTIONS}

The saturation functions used in the reference analysis are given in Table 1. These functions are plotted in Figures 6,7 , and 8 . The relative permeability curves were established to conform in general shape to data presented by Katz et a1., (1979) and by Amyx, Bass, and Whiting (1960). We found that it was advantageous numerically that the slope of the curves be zero at the points of residual saturation (zero mobility). Intuitively, such a condition seems physically accurate.

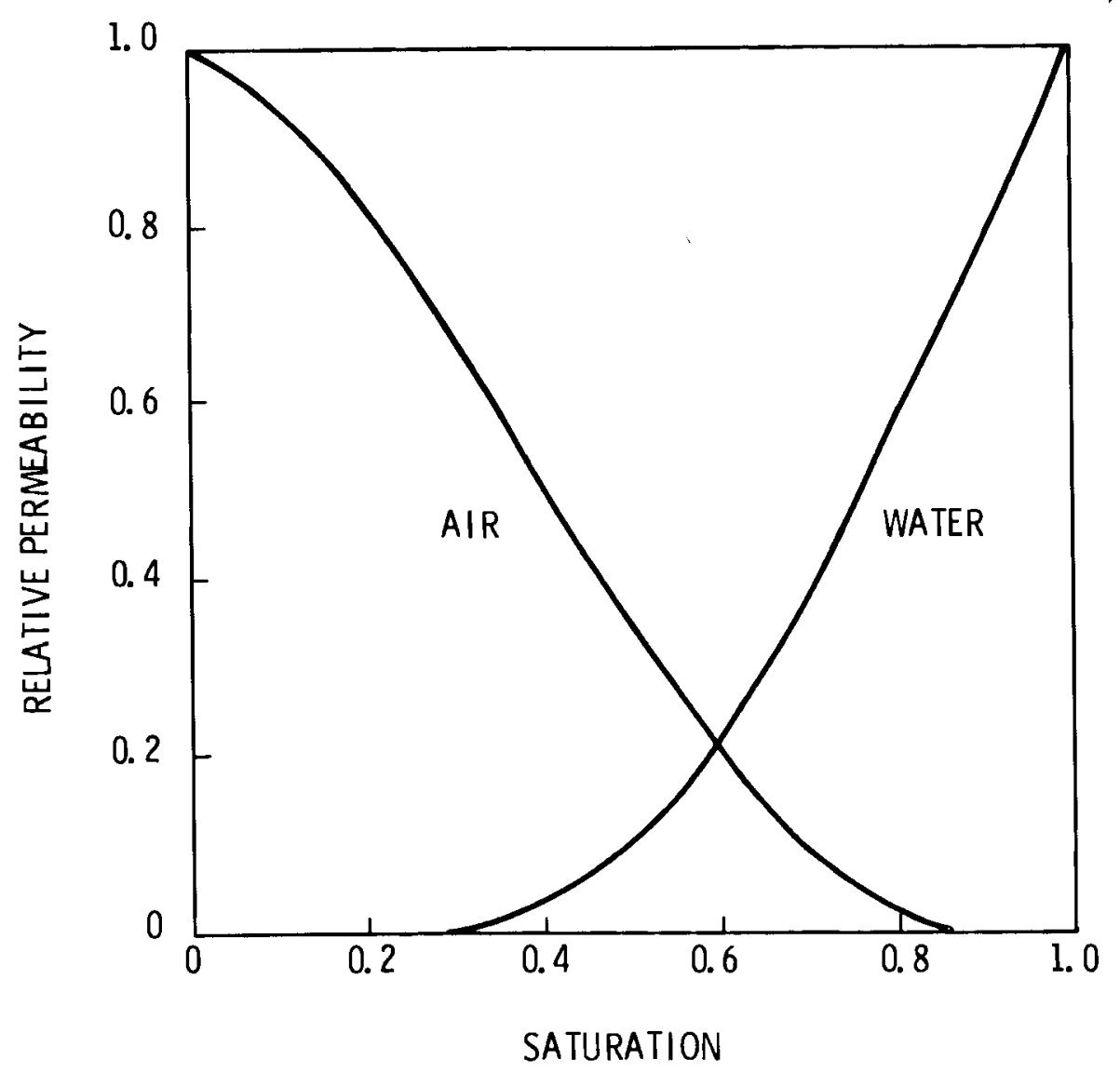

FIGURE 6. Reference Relative Permeability Functions 


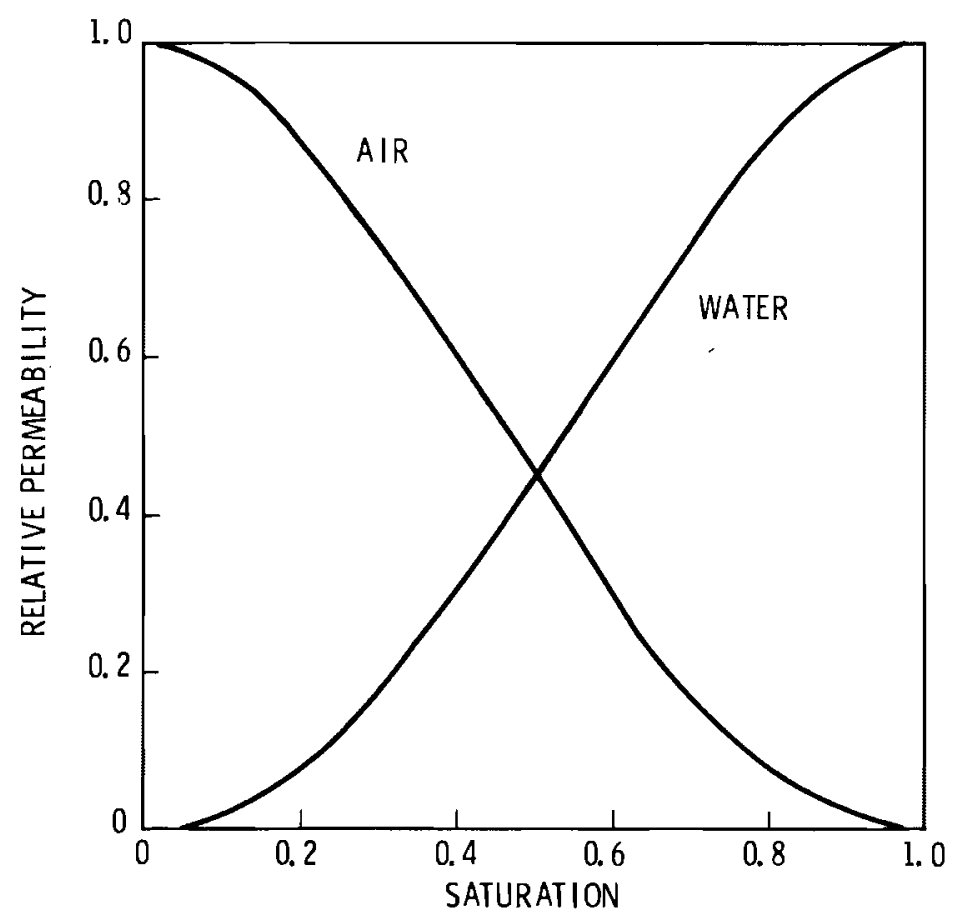

FIGURE 7. Reference Relative Permeability Functions for the Open Wellbore

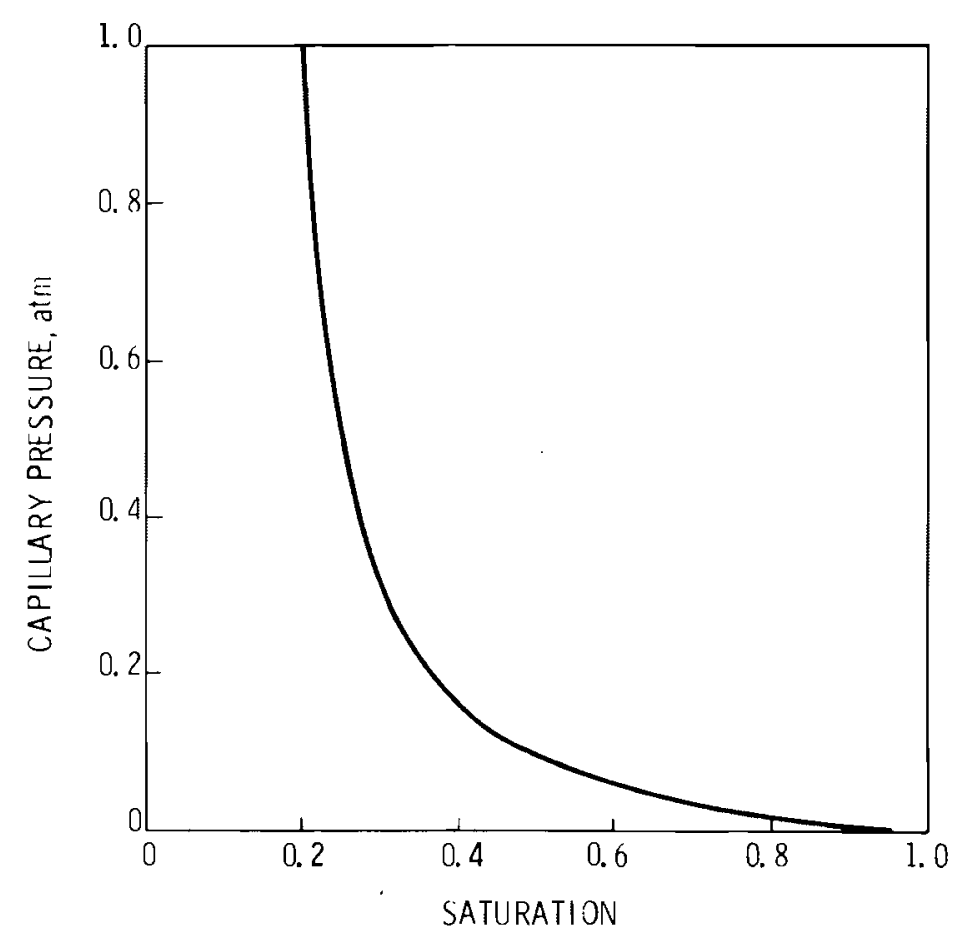

FIGURE 8. Reference Capillary Pressure Function 
Numerically as the computed saturation of either phase approaches the residual value, the computed saturation of that phase may actually oscillate above and below its residual saturation with each iteration or directional sweep within a given time step. Thus, the mobility of that phase oscillates between a finite value and zero, changing perhaps by several orders of magnitude with each iteration. Such behavior is quite adverse to rapid convergence. The zero slope at residual saturation on the relative permeability curves lessens the severity of this oscillation.

The capillary pressure function is also a generalization of data presented by Amyx, Bass, and Whiting (1960). The slope of the curves approach infinity in the neighborhood of residual saturation of the liquid. The value of this residual saturation generally increases as permeability decreases. However, there is a great deal of variation in most reported data.

The method developed in Appendix $F$ was used with the capillary pressure function to obtain the fluid distribution in the transition zone shown in Figure 4. This fluid distribution was applied as the initial condition for all the parametric cases that used the reference capillary pressure function.

The initial saturation in the wellbore was set at $1 \cdot 10^{-4}$. The relative permeability for water in the wellbore is zero for saturations below $5 \cdot 10^{-4}$.

Another approach to developing the saturation functions would have been to use generalized functions such as those presented by Corey (1954) and Brooks and Corey (1966). Graphically, our functions are not unlike theirs, but their functions did not suit our specific numerical needs. 
The parameters that were identified that were believed to have an effect on the potential for water coning are

- producing length

- air storage zone thickness

- air mass flow rate

- permeability

- absolute permeability

- permeability ratio

- permeability stratification

- saturation functions.

Each of these parameters will affect the pressure drop across the reservoir. As a result, each parameter may have an impact on water coning. A discussion of the analysis of each of these parameters is given in this section.

Before the analysis of each of these parameters is presented, the results applicable to the reference reservoir are discussed.

\section{REFERENCE RESERVOIR ANALYSIS}

The weekly cycle described previously was applied to the conditions of the reference reservoir. The intent of this analysis was to evaluate the potential for water coning to occur and to observe the behavior of the saturation distribution from one week to the next. The discussion regarding the transient saturation distribution is important with respect to the initial saturation distribution used throughout the remainder of the water coning analysis. The initial saturation distribution was based on gravitational-capillary equilibrium. Cycling the air in the reservoir was expected to adjust this equilibrium distribution until a quasi-steady state was reached. Then the saturation distribution at a given time of the week would be identical from one week to the next. From that point the quantitative analysis of water coning would be based on the most accurate conditions that could be developed without going through a bubble development analysis. But like the bubble development 
analysis, the quasi-steady-state solution for the saturation distribution would have to be computed for each parametric case. As pointed out previously, such an approach was impractical with respect to computer costs.

Before discussing the quasi-steady-state saturation solution, the results with respect to the analyses of water coning in the reference reservoir will be briefly presented. The immediate observation is that water coning should have no direct impact on the reservoir pressure response for conditions typical of the reference reservoir. Water does rise towards the wellbore, however, which could impact the geochemical stability of the porous material, thereby affecting the reservoir performance. Even for this case the effect should be small because the water intrudes only in the region near the bottom of the wellbore. Most of the producing section of the wellbore would be unaffected.

In the attempt to achieve a quasi-steady-state saturation distribution, the weekly cycle was carried out for three full weeks. Since the quasisteady state was not reached by that time, the computation was terminated. It was evident that, due to the computational expense, a similar analysis could not be performed for each parametric case. The expense is a factor because of the necessity of tracking the daily charge and discharge cycles. With each cycle the water moves in and out of the small numerical cells near the wellbore. Rapid saturation changes occur which continuously hold down the allowable time step size. Thus, a larger time step, which would be achievable for a continuous injection or extraction problem, never materializes.

Radial saturation distributions at various times in the simulation of the reference reservoir are presented in Figures 9 and 10, and Table 2 . The adjustment of the initial saturation distribution towards a quasisteady state primarily involves the region in and just below the transition zone. The distributions are shown for the elevations that incur the greatest change. These elevations correspond to the grid elevations defined in Figure 4. 


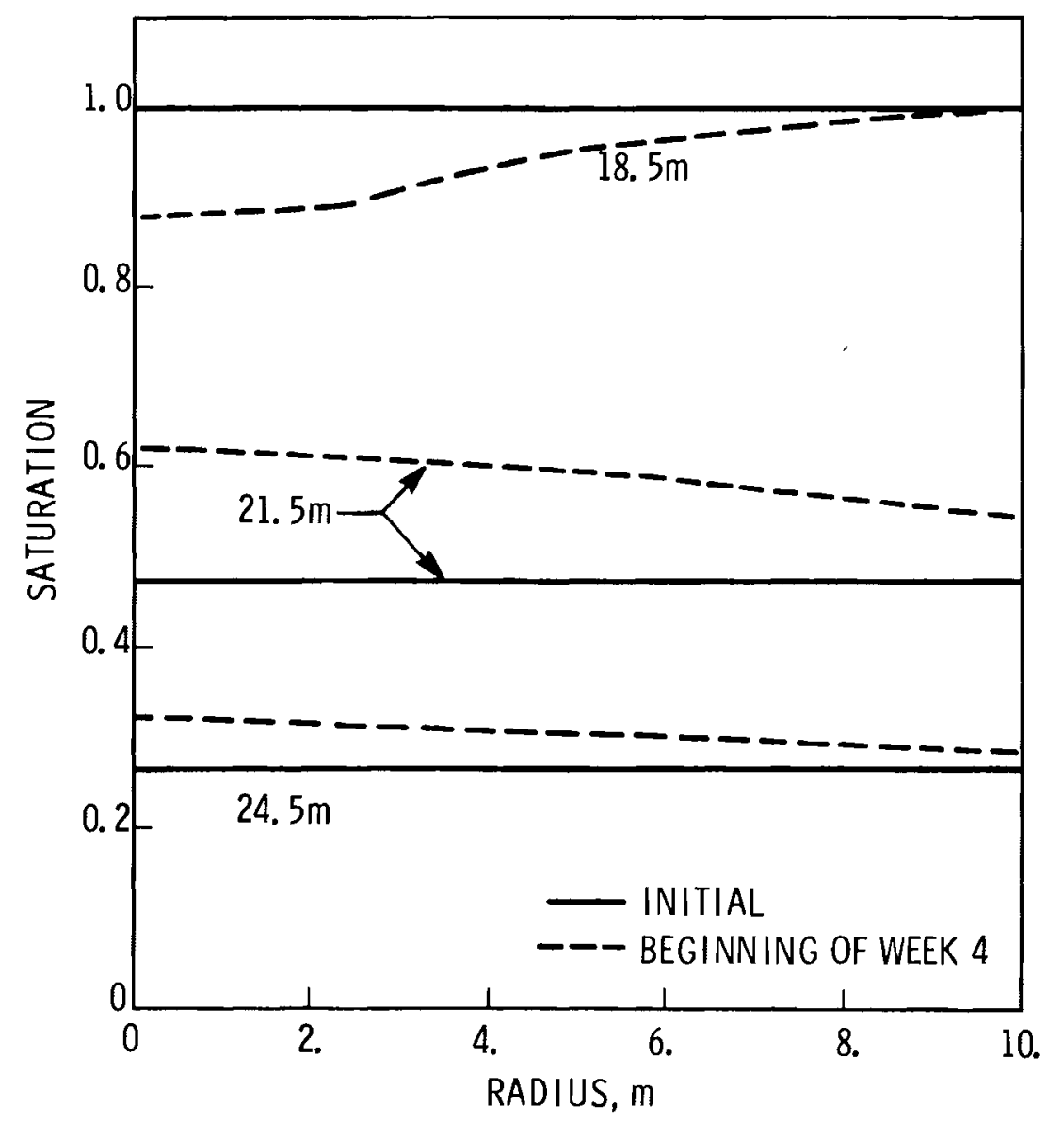

FIGURE 9. Radial Saturation Distributions for Three Elevations (m) Showing the Change with Time

In Figure 9 the initial saturation distributions are compared against the saturation distributions representing the beginning of the fourth week. This shows that a smearing of the transition zone has occurred. Charging the reservoir creates an inverted cone, or depression, at the air-water interface. The air is immobile for saturations above 0.90 as specified by the relative permeability function for air. Air can enter the fully saturated zone during a charging cycle due to its upstream mobility. During a subsequent discharge cycle the air is essentially trapped so that the fully saturated condition cannot recover. The water that is forced out of the region below the wellbore builds up 


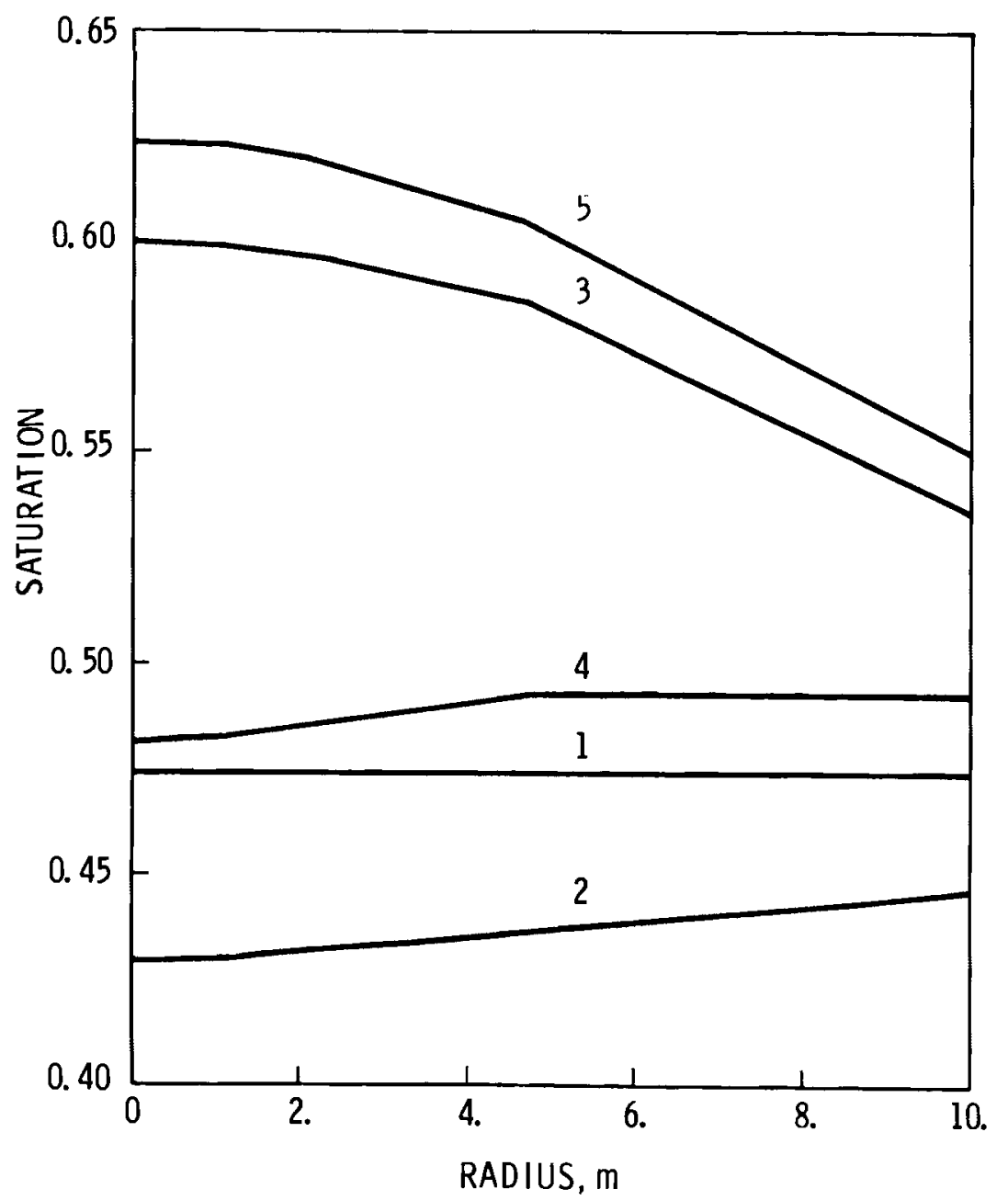

FIGURE 10. Radial Saturation Distributions at Elevation $21.5 \mathrm{~m}$ for: 1) Initial, 2) After First Weekend Charge, 3) After Final Extraction of First Week, 4) After Third Weekend Charge, and 5) After Final Extraction of Third Week

just outside the near-wellbore region. Note in Figure 9 that the depression, shown at elevation $18.5 \mathrm{~m}$, vanishes at a radius of only about $10 \mathrm{~m}$ while the outer reservoir radius is $60 \mathrm{~m}$. This indicates that the extent of the depression is relatively small.

During an extraction cycle the depressurization at the wellbore causes water to move towards the wellbore. This water moves in a direction 
TABLE 2. Radial Saturation Distributions at the Beginning of Each Week at Elevation $21.5 \mathrm{~m}$ as Defined by Figure 4

\begin{tabular}{|c|c|c|c|c|}
\hline \multirow[b]{2}{*}{ Radius (m) } & & & \\
\hline & 1 & 2 & 3 & 4 \\
\hline 0.05 & 0.4743 & 0.5975 & 0.6166 & 0.6208 \\
\hline 0.20 & 0.4743 & 0.5975 & 0.6166 & 0.6208 \\
\hline 0.50 & 0.4743 & 0.5974 & 0.6164 & 0.6206 \\
\hline 1.10 & 0.4743 & 0.5967 & 0.6155 & 0.6197 \\
\hline 2.30 & 0.4743 & 0.5940 & 0.6120 & 0.6160 \\
\hline 4.70 & 0.4743 & 0.5844 & 0.5990 & 0.6022 \\
\hline 9.50 & 0.4743 & 0.5402 & 0.5519 & 0.5548 \\
\hline
\end{tabular}

of decreasing saturation, which implies decreasing liquid mobility. In the subsequent charging cycle the liquid does not recede to its original distribution because it is held up by its lower mobility. This is similar to placing a dry sponge in a pan of water. The sponge will become saturated. But if the water is removed from the pan, most of the water in the sponge will remain there. Thus in Figure 9 the distributions for the two elevations above the air-water interface will gradually adjust to higher saturations until the quasi-steady state is reached. Table 2 shows the changes that continue to occur for the elevation $21.5 \mathrm{~m}$ as defined by Figure 4 . The fluctuation of the saturation distribution at this elevation is shown in Figure 10. Curve 1 is the initial radial saturation distribution. Curves 2 and 4 are the distributions taken after the first and third weekend charging cycles. Curves 3 and 5 are the distributions predicted after the final extractions of the first and third weeks. After the final extraction the pressure drawdown in the reservoir is at its extreme condition. At this point water coning would be most severe. The predicted saturation in the bottom wellbore cell for this condition is less than one percent. Liquid breakthrough has occurred but the amount of water is certainly small. 
It is evident from the results that a quasi-steady-state saturation distribution can not be reached immediately but requires considerable computation even before such a condition is approached. As a result, it was decided to perform the parametric study using only a single extraction cycle of 10 hours, with the gravitational-capillary equilibrium saturation distribution as a starting condition.

To test the acceptability of such an approach, a solution was developed using a smeared saturation distribution. The purpose, of course, was to evaluate the impact on the quantitative results of doing a parametric study using the equilibrium saturation distribution as a starting condition.

The initial vertical saturation distributions for the reference case and the smeared test case are compared in Table 3. To make the solution of the test case and the reference case comparable, the selected values of stored air mass and wellbore air mass flow rate were identical for both cases. This was accomplished in consideration of the saturation distributions by setting the porosity for the test case to 0.2128 .

TABLE 3. Vertical Saturation Distributions for Comparison of Reference and Smeared Profile Solutions

Node Elevation (m)

47.0

41.0

36.5

33.5

30.5

27.5

24.5

21.5

18.5

15.5

11.0

4.0

\section{Saturation}

\begin{tabular}{ccc} 
Reference & & Test Case \\
\cline { 1 - 1 } 0.20 & & 0.25 \\
0.20 & 0.25 \\
0.20 & 0.26 \\
0.20 & 0.27 \\
0.2027 & 0.28 \\
0.2211 & 0.30 \\
0.2643 & 0.45 \\
0.4743 & 0.70 \\
0.9995 & 0.85 \\
0.9995 & 0.87 \\
0.9995 & 0.92 \\
0.9995 & 0.9995
\end{tabular}


The results for the reference case and the smeared distribution test case were compared on following a simulated 10-hour extraction cycle. For the reference case there is no water breakthrough. (In fact, it required 44 hours of continuous extraction for breakthrough to occur for the reference conditions.) Also, the pressure drop across the reservoir at the conclusion of the 10-hour air extraction simulation was $1.57 \mathrm{~atm}$ $(159 \mathrm{kPa})$. For the smeared test case, breakthrough occurs after 2.3 hours of extraction. The greater initial saturations for the test case coupled with the buildup of saturation due to greater liquid mobility causes a reduction in the relative permeability of the air. As a result, the reservoir pressure loss at the conclusion of the cycle is $1.87 \mathrm{~atm}$ $(190 \mathrm{kPa})$. The difference in pressure loss for the two cases is 0.30 atm $(30 \mathrm{kPa})$. However, before breakthrough of the test case, the difference for the two cases is $0.25 \mathrm{~atm}(25 \mathrm{kPa})$. This indicates that most of the difference in pressure response for the two cases is due to the reduced relative permeability to air associated with the greater saturations for the test case. The remainder apparently is due to water coning.

The conclusion that can be made from this analysis is that the quantitative results can be somewhat affected by the choice of the initial vertical saturation distribution near the wellbore. However, as stated in previous discussion, any choice of an initial distribution other than the gravitational-capillary equilibrium saturation distribution is site dependent. Therefore, as a reference condition, the equilibrium distribution has been used in the parametric study. The quantitative results must be evaluated in this context. This analysis of the smeared test case distribution serves to show the general magnitude of the effect of greater saturations and greater liquid mobility in the vicinity of the well ibore.

\section{PRODUC ING LENGTH}

The producing length is the section of the wellbore that is open to the flow of air into or out of the reservoir. In the analysis of this 
parameter, the length is defined from the top of the air storage zone unless otherwise specified. The bottom of the wellbore is closed.

A single-phase (dry air), two-dimensional computer model was used previously to study the producing length (Wiles 0ct 1979). The pressure loss across the reservoir which is essentially equivalent to the quasisteady-state pressure difference referred to in previous reports (Smith, Loscutoff, Wiles 1979; Wiles March 1979; Wiles Oct. 1979), proved to be very sensitive to the producing length. To minimize the pressure loss the producing length should be maximized. But in the case where the region underlying the air storage zone is water saturated, the potential for water coning exists if the producing section extends near to the air-water interface. Thus, the pressure loss must be weighed against the adverse effects of water coning.

For the analysis of the producing length, all reservoir parameters were fixed at the reference values while the producing length was varied. A longer producing length would result in a smaller bulk air velocity at the wellbore. Therefore, the pressure loss across the reservoir would be smaller. For longer producing lengths water coning is expected to be more severe. But the coincident reduction in pressure loss associated with the longer producing length reduces the driving force, i.e., the pressure drop, that creates water coning.

The reservoir pressure loss, i.e., the difference between wellbore pressure and the bulk reservoir pressure, as a function of producing length is shown in Figure 11. The results are taken at the conclusion of 10 hours of air extraction, and are also shown for 1.5 hours of extraction. For the reference conditions the pressure loss is a minimum for a producing length of about $27 \mathrm{~m}$ in a reservoir having an air storage zone vertical thickness of $30 \mathrm{~m}$. In other words, for these conditions, water coning does not affect the reservoir pressure response unless the producing section extends almost to the air-water interface. 


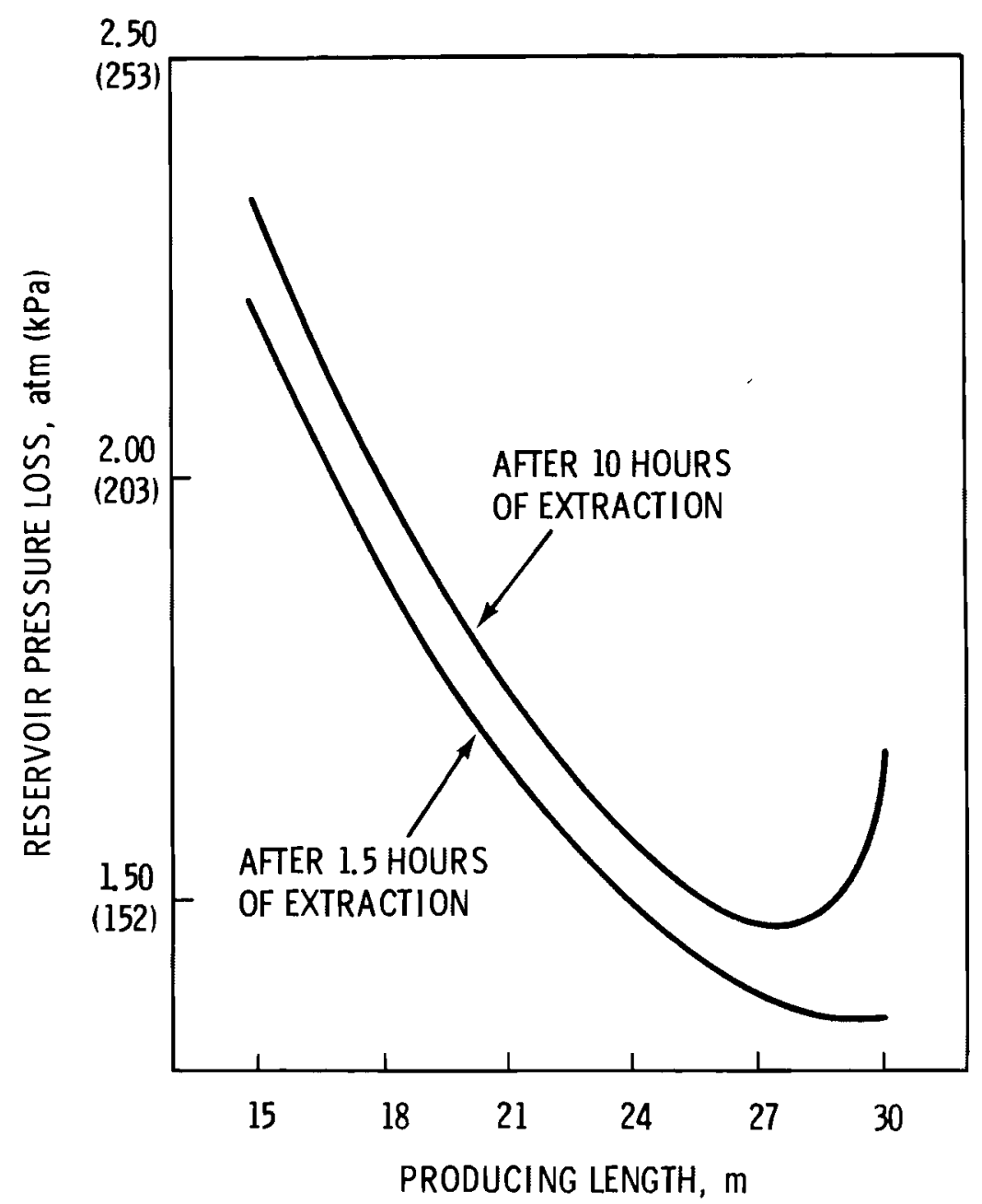

FIGURE 11. Reservoir Pressure Loss as a Function of Producing Length following 1.5 and 10.0 Hours of Air Extraction in a $30-\mathrm{m}-$ Thick Reservoir

The results indicate that the reservoir pressure loss is unaffected until liquid water enters the wellbore and near-wellbore region. Water breakthrough occurs almost immediately after the initiation of air extraction for the 30-m producing length. Breakthrough occurs for the 27-m wellbore after about 5 hours of air extraction and not at all for the other cases $(24,21,18$ and $15 \mathrm{~m})$. Overal1, the reservoir pressure loss gradually increases with time, apparently because as air is extracted the density drops, thus requiring a greater velocity to achieve a prescribed air mass flow rate. 
The saturation buildup after 10 hours of air extraction is shown in Figure 12 for wellbore producing lengths of $21,24,27$ and $30 \mathrm{~m}$. The reservoir thickness was $30 \mathrm{~m}$. The results are shown for an elevation of $21.5 \mathrm{~m}$ as defined by Figure 4 . At this elevation the initial saturation was 0.474 . At a radius of $50 \mathrm{~m}$ the saturation was about 0.467 at the end of the simulation for each case. The net effect is that water for the cone is supplied by the large volume of water beyond the near wellbore region.

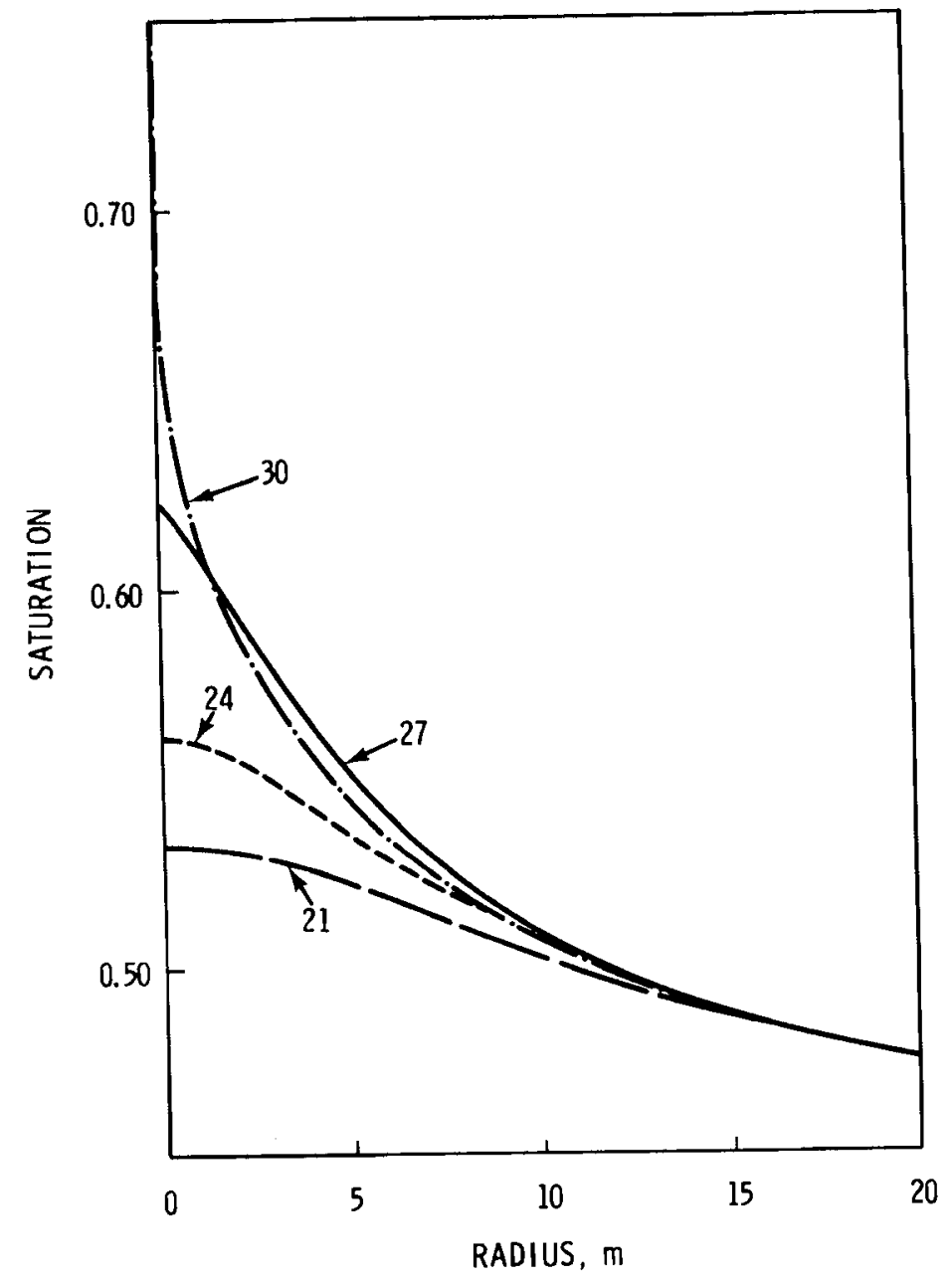

FIGURE 12. Radial Saturation Profiles for Various Producing Lengths ( $m$ ) After 10 Hours of Air Extraction for Elevation $21.5 \mathrm{~m}$ Defined by Figure 4 
For the cases where water breakthrough occurs the results have helped to characterize the behavior of the flow of water near the wellbore. At the outset of air extraction the water begins to move towards the bottom of the wellbore. As the saturation increases, the capillary pressure difference across the wellbore-sand interface decreases. The direction of the capillary pressure force at the wellbore-sand interface is radially outward, thereby resisting the influx of water at the wellbore. When the saturation buildup reaches the point where the induced pressure force, due to the production of air, exceeds the capillary pressure force, then the breakthrough of water into the wellbore occurs provided that there is mobile water adjacent to the wellbore at that location. Due to the difference in flow resistance the water level in the wellbore rises much faster than does the saturation buildup in the adjacent porous materia1. While water continues to flow into the wellbore at the bottom, water begins to flow out of the wellbore at the top of the water column. This outflow is due to the capillary pressure gradient across the wellbore-sand interface. The outflow will continue at a given elevation until a saturation buildup occurs in the surrounding material sufficient to balance the capillary pressure gradient with the induced pressure gradient. Further saturation buildup adjacent to the wellbore at that elevation will occur primarily because of the continued rise of the air-water interface, i.e., the water cone. The continued buildup of water further reduces the capillary pressure. Then the direction of water flow reverses, with water entering the wellbore. By this mechanism, there is a gradual increase in the elevation of the wellbore below which water enters.

This behavior also suggests that since water can rise rapidly in the wellbore, being supplied from mobile water at the well bottom, then the water can reach elevations that would not otherwise be affected. This could be very important to the impact of water coning, particularly with respect to the geochemical effect. This behavior could not be predicted without considering the unique effects of the open wellbore. 
After 10 hours of extraction about $40 \%$ of the $30-m-1$ ong wellbore was filled with water. This would suggest that, due to the loss of flow area, the reservoir pressure loss would increase by nearly a corresponding value. The fact that the pressure loss increases by only about $15 \%$ (over the increase that would have occurred without water influx) deserves some speculation. Even though there is a significant amount of water in the wellbore, the effective permeability to the flow of air remains high compared to that in the adjacent sand. In addition, air that enters the wellbore below the top of the water column will be driven vertically by strong buoyancy forces. Thus, the effect on the pressure loss due to water coning is not greatly dependent on the water in the wellbore. A closer look at the results showed that the vertical average of the saturations in the cells adjacent to the wellbore at the time of breakthrough was about 0.24 . After 10 hours of simulated air extraction the average had increased to about 0.32 . This change results in a reduction of relative permeability for the air from about 0.76 to 0.63. This results in an increase in flow resistance that is consistent with the impact on the pressure response. These results indicate that the effect of water coning on the reservoir pressure response is dominated by the saturation buildup in the sand immediately adjacent to the wellbore, rather than by water that enters the wellbore.

This study of the producing length has led to the observation that there may be two separate modes of water coning. Most of the pressure loss across the reservoir occurs within the near-wellbore region as shown for the reference case in Figure 13. The ordinate is the difference between the local air pressure and the reservoir average air pressure. The effect of the gravitational gradient has been deleted. In Figure 13, the radial pressure profile is seen to be nearly independent of the elevation for elevations above the bottom of the wellbore. The nature of the vertical pressure gradient below the wellbore can also be inferred from this result. The vertical gradient dissipates very rapidly and exists out to a radius on the order of only $5 \mathrm{~m}$. Thus, the vertical gradient, like the radial pressure gradient, is canfined to a relatively 


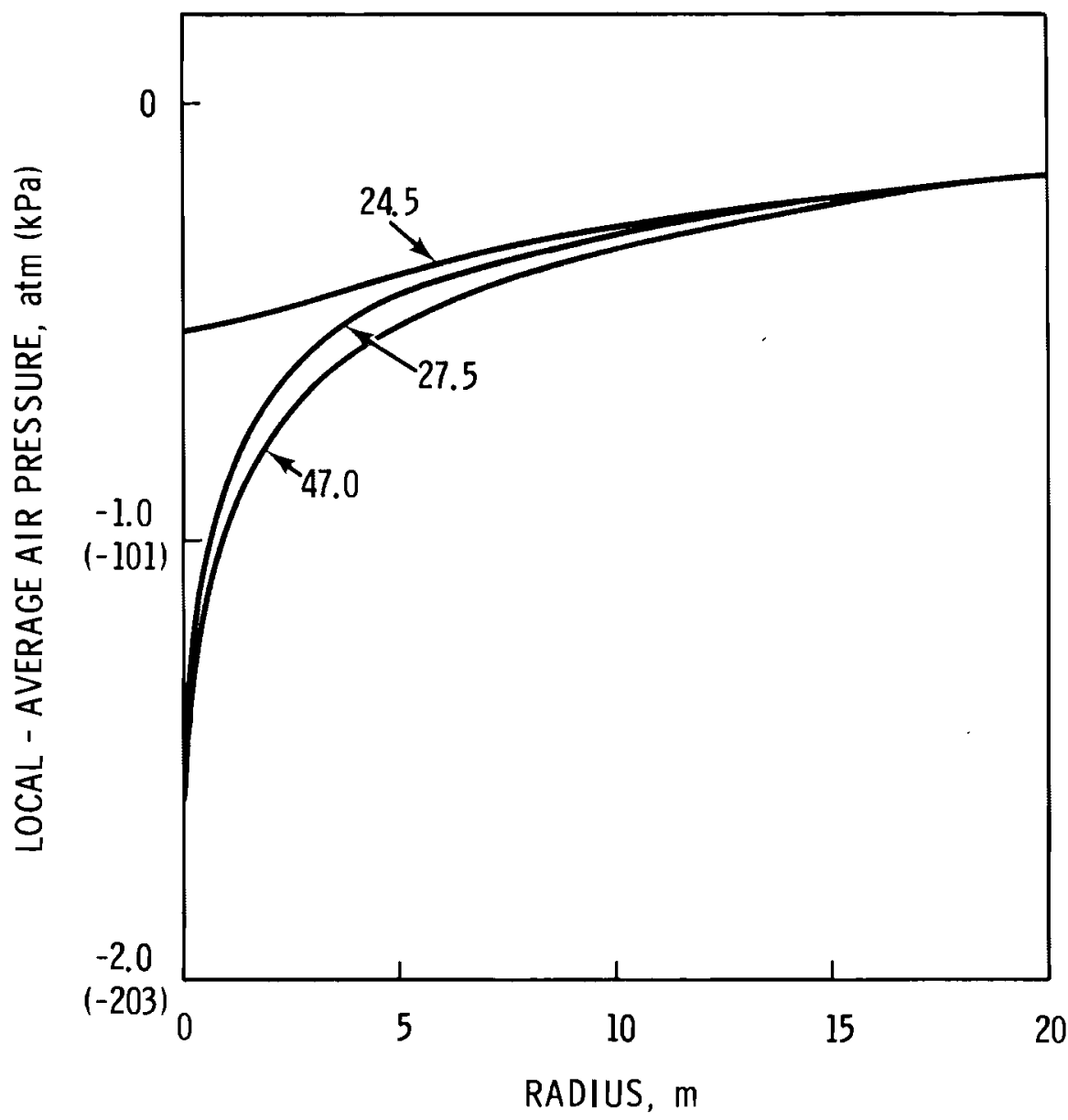

FIGURE 13. Radial Pressure Profiles After 10 Hours of Air Extraction for Elevations (m) Defined by Figure 4. Bottom of wellbore is at elevation $26 \mathrm{~m}$.

small zone near the wellbore. The results indicate that these nearwellbore pressure gradients will induce rapid water coning and breakthrough only if the air-water interface is within the zone affected by those gradients. 0therwise, a second mode of water coning prevails. For the reference conditions the pressure drop across the reservoir is on the order of $2 \mathrm{~atm}(203 \mathrm{kPa})$. This gradient could induce a cone of water of about $20 \mathrm{~m}$ in height if hydrostatic equilibrium were reached. Due to the high flow resistance in the porous material, the air-water interface responds quite slowly to this driving force. Nevertheless, by this second mode, a water cone could develop even though the air-water interface 
is far below the bottom of the wellbore and the point where the vertical pressure gradient has effectively ended.

\section{AIR STORAGE ZONE THICKNESS}

The effect of the air storage zone thickness on water coning has been studied on the basis of a simulated 10-hour extraction cycle. The air storage zone thicknesses evaluated were $12,18,24$, and the reference value of $30 \mathrm{~m}$. The various thicknesses were obtained by removing the appropriate number of cells from the top of the grid in Figure 4. The water saturated zone and transition zone defined by Figure 4 were unchanged.

The results of the analysis of producing length indicate that the effects of water coning are noticeable for the reference conditions only when the bottom of the wellbore is within $6 \mathrm{~m}$ of the air-water interface. For each reservoir thickness, two cases were studied. The bottom of the wellbore was defined to be at either 6 or $3 \mathrm{~m}$ above the air-water interface.

An important condition imposed on the analysis was that the percent of mass cycled was the same for every case. Given the percent of mass cycled, the air mass flow rates were computed based on the stored air mass. The stored air mass was not quite linearly related to the reservoir thickness because the transition zone saturation distribution is independent of thickness. In other words, the average saturation is greater for thinner reservoirs. As a result, the air mass production rates per unit reservoir thickness, compared in Table 4, are smaller for thinner reservoirs.

The intent of establishing the production rates in this manner was to make the pressure drops comparable for all cases. This was not actually achieved, however, because the producing length as a percentage of thickness was different for each case.

The pressure loss across the reservoir is shown in Figures 14 and 15 as a function of the reservoir thickness. The results presented in Figure 14 apply to the cases for which the bottom of the wellbore extended 


\section{TABLE 4. Air Mass Production Rates for Study of Reservoir Thickness}

$\begin{array}{cc}\begin{array}{c}\text { Thickness } \\ (\mathrm{m})\end{array} & \begin{array}{c}\text { Air Flow per Meter } \\ \text { of Thickness } \\ (\mathrm{kg} / \mathrm{sec})\end{array} \\ 30 & 0.291 \\ 24 & 0.287 \\ 18 & 0.282 \\ 12 & 0.270\end{array}$

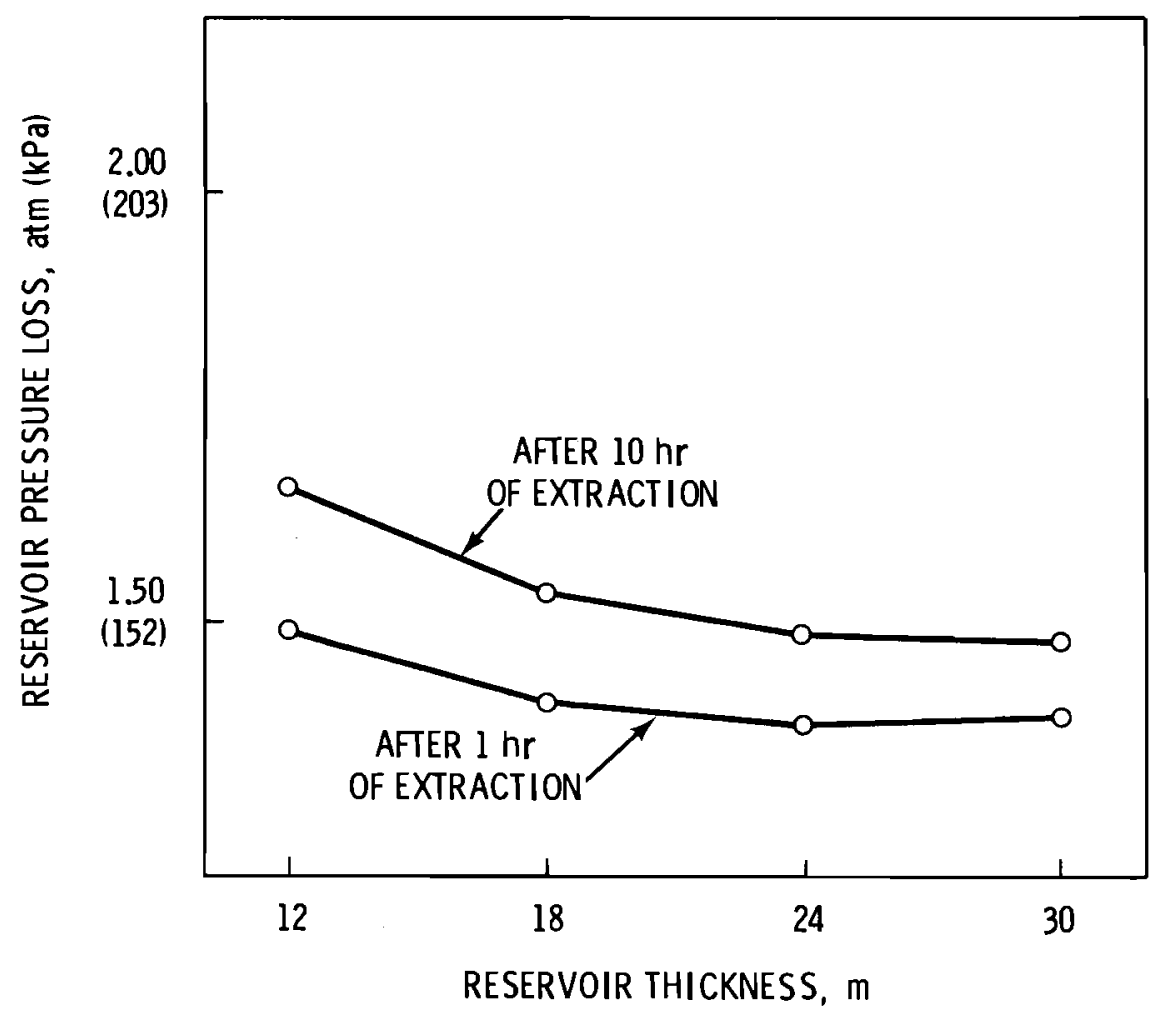

FIGURE 14. Reservoir Pressure Loss Versus Reservoir Thickness for the Bottom of the Wellbore $3 \mathrm{~m}$ from the Air-Water Interface 


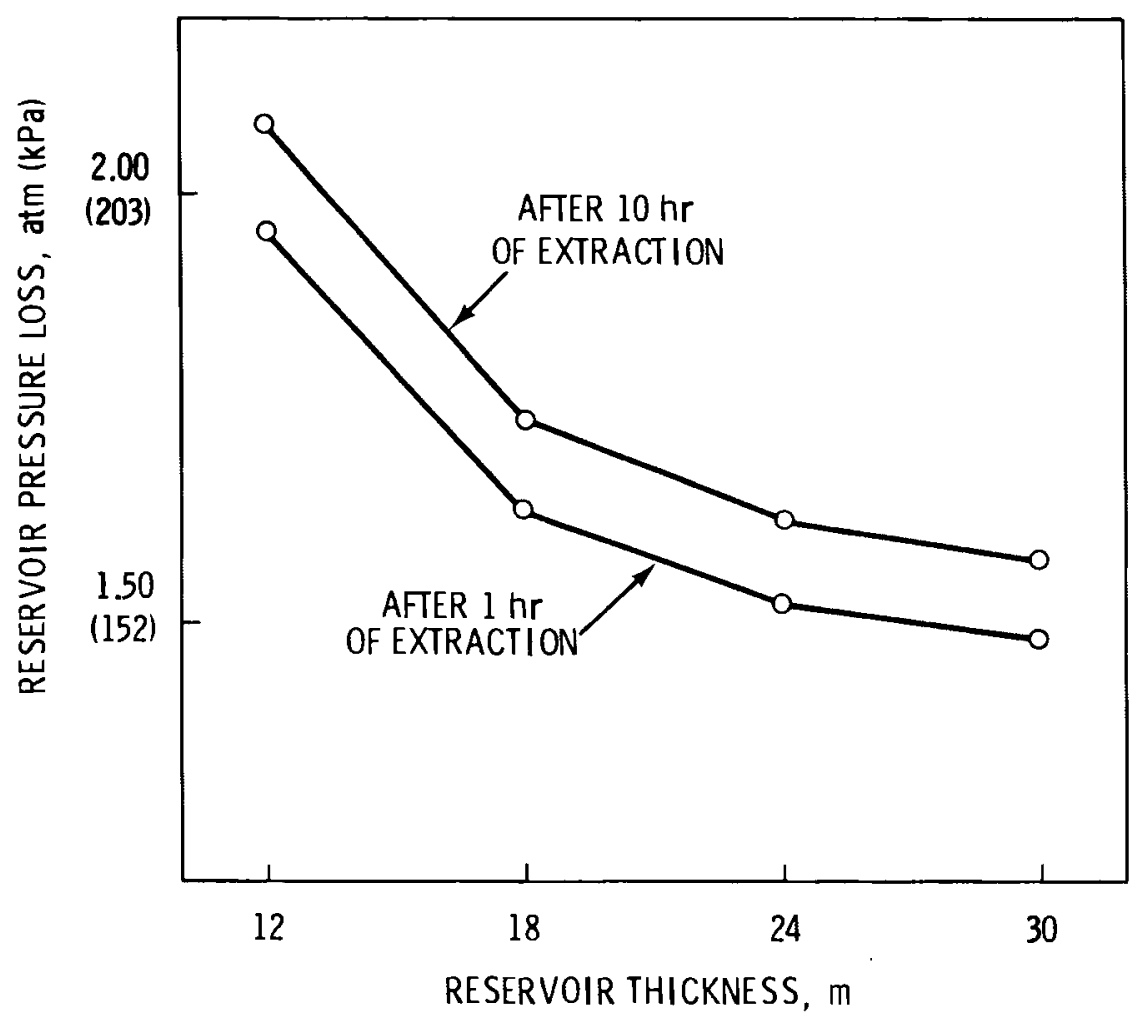

FIGURE 15. Reservoir Pressure Loss Versus Reservoir Thickness for the Bottom of the Wellbore $6 \mathrm{~m}$ from the Air-Water Interface

to $3 \mathrm{~m}$ above the air-water interface. In Figure 15, the results apply to the cases for which the bottom of the wellbore extended to $6 \mathrm{~m}$ above the air-water interface.

By comparing the pressure loss after 1 hour and at the end of the simulated 10-hour extraction cycle, the impact of water coning is inferred. For the cases defined for Figure 15, water coning had essentially no effect on the pressure response. Breakthrough did not occur for any of the cases. For the cases of Figure 14, water coning had some effect on the pressure response. The change in the pressure drop over the duration of the extraction cycle was greater for thinner reservoirs. Breakthrough occurred for each of these cases. The saturation of the bottom wellbore cell varied from 0.37 for the 30 -m-thick reservoir to 0.59 for the $12-\mathrm{m}$ thick reservoir. 
These results lead to the conclusion that the effect of water coning on pressure response is independent of reservoir thickness until breakthrough occurs. After breakthrough, a thinner reservoir will incur more rapid water coning because the saturation buildup has a greater percentage effect on reducing the relative permeability near the wellbore. This results in a relative acceleration of the water cone for thin reservoirs in comparison to thicker reservoirs. However, for the conditions imposed by this analysis the radial saturation profiles are almost independent of reservoir thickness. If the extraction were to continue, then the differentiation of the distinct cases would become more apparent.

\section{AIR MASS FLOW RATE}

The air mass flow rate was varied to determine the impact of that parameter on water coning. Two approaches were taken. Since breakthrough did not occur for the reference conditions, the flow rate was increased. For the reference conditions with a $27-m$ producing length, breakthrough did occur. This case was evaluated again with lower flow rates. This analysis determined the sensitivity of the breakthrough time to the flow rate for different producing lengths.

The air mass flow rate of the reference conditions was doubled and breakthrough did not occur within the simulated 10-hour extraction cycle. Then the reference air mass flow rate was quadrupled. For this case, breakthrough occurred almost immediately. The results indicated that the time of breakthrough is not a particularly effective measure of water coning. Breakthrough only indicates that mobile water exists adjacent to the wellbore where the flow potential is towards the wellbore. The induced pressure gradient is approximately proportional to the flow rate. For the higher flow rate the induced pressure gradient is sufficient to immediately overcome the capillary pressure gradient. Then breakthrough occurs very soon after the start of flow. 
A better indication of water coning for the reference conditions is the saturation profiles of Figure 16 . These were taken at the end of the 10-hour extraction cycle and apply to the elevation of $21.5 \mathrm{~m}$ as defined by Figure 4 . These profiles indicate the relative amount of water movement.

With a 27-m producing length in the reference reservoir, breakthrough occurred after about 5 hours of air extraction. Breakthrough could be avoided with this producing length if the flow rate were reduced. When the flow rate was cut to $75 \%$ of the reference flow rate, breakthrough was delayed until 9 hours after the initiation of air extraction. When the reference flow rate was cut in half, no breakthrough occurred within

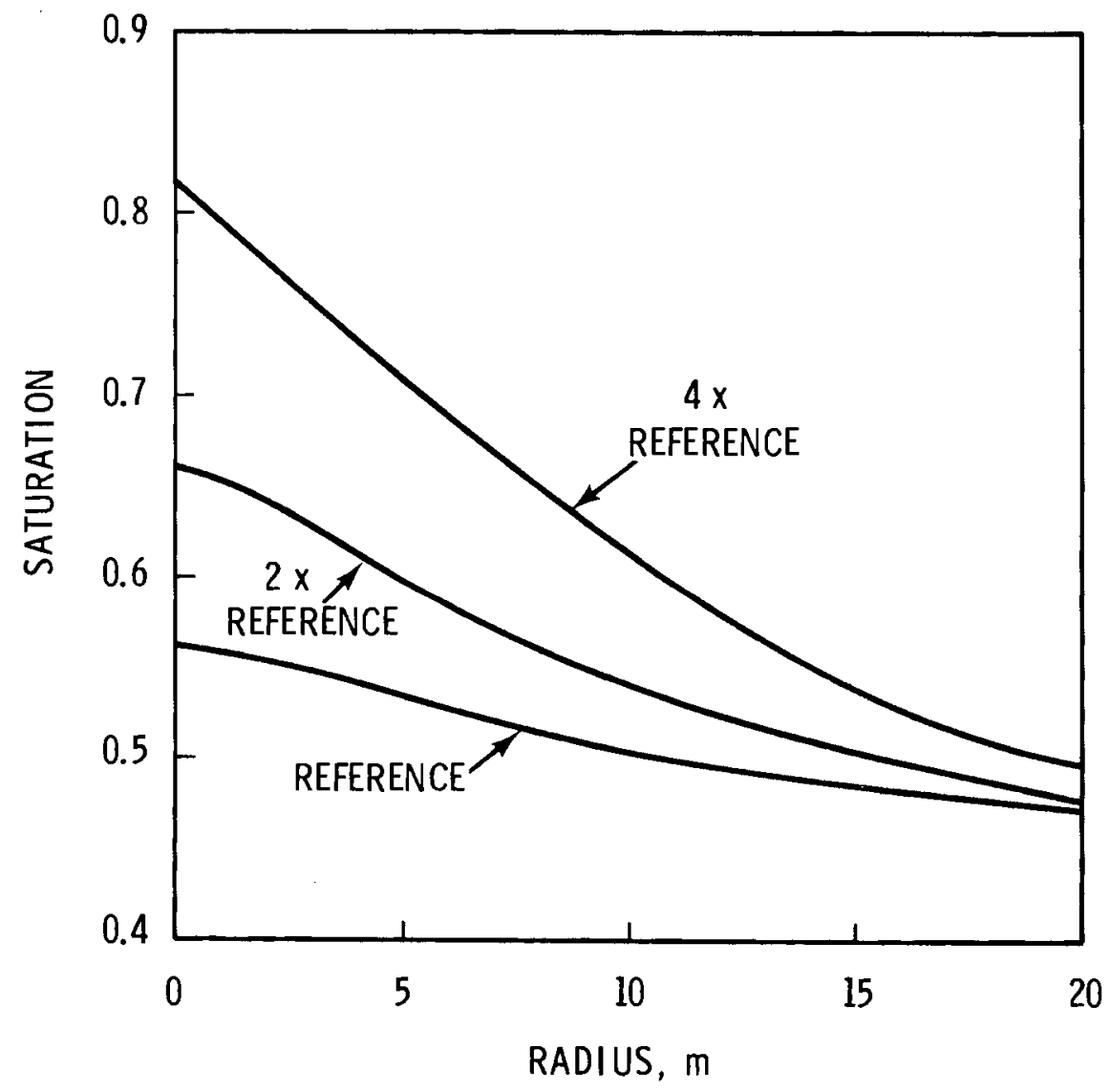

FIGURE 16. Radial Saturation Profiles After 10 Hours of Air Extraction for Various Mass Flow Rates as Multiples of the Reference Flow Rate 
the 10-hour simulation period. The radial saturation profiles for the three cases are shown in Figure 17. The results apply at the end of the 10-hour extraction cycle for an elevation of $21.5 \mathrm{~m}$ as defined by Figure 4 .

\section{PERMEABILITY}

The absolute permeability is the most important reservoir material property affecting the pressure drop. However, water coning may not be as strongly related to permeability as might be expected. For smaller values of permeability the pressure drop will be greater given that other conditions are unchanged. However, the coning response may not be proportionally greater because the lower permeability inhibits the flow of water. This analysis was performed to determine whether or not coning may be independent of absolute permeability in a homogeneous reservoir. 0ther conditions exist for which coning would not be independent of the permeable nature of the material. In general, vertical permeability is less than the horizontal permeability. Another factor is that a layer of low permeability will significantly inhibit coning. Each of

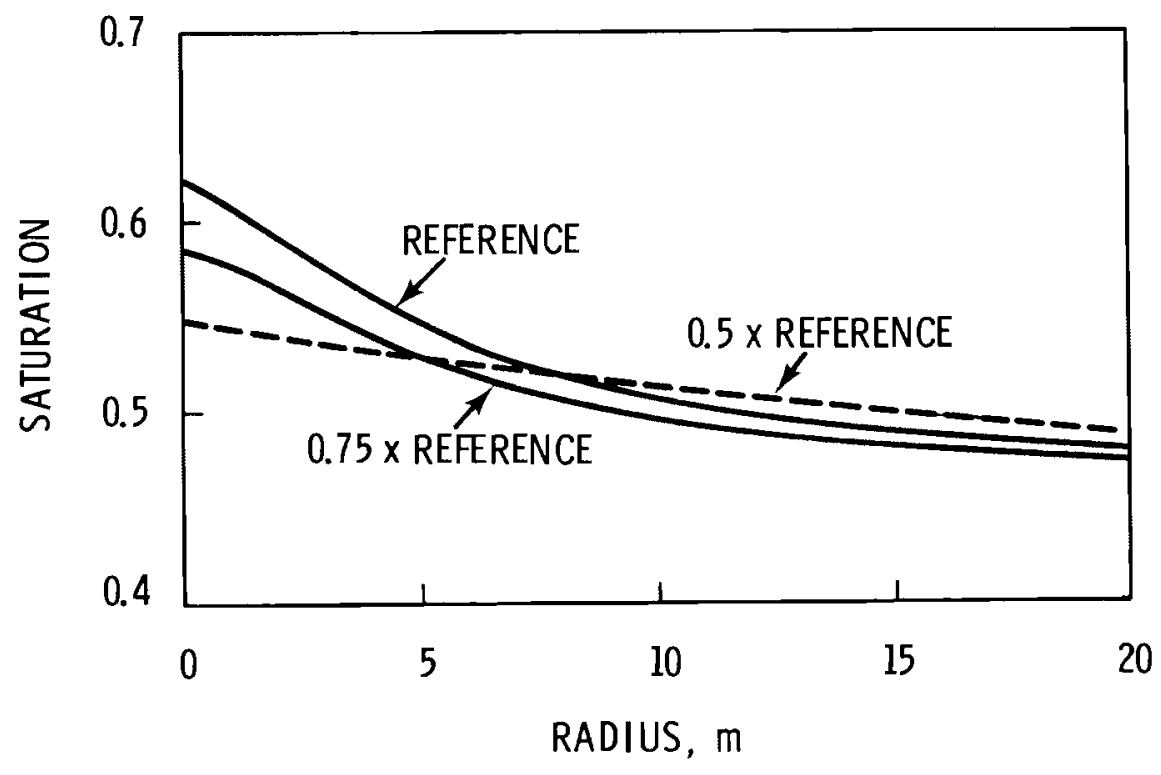

FIGURE 17. Radial Saturation Profiles After 10 Hours of Air Extraction for Various Mass Flow Rates as Multiples of the Reservoir Flow Rate. Producing Length $=27 \mathrm{~m}$. 
these conditions, absolute permeability, permeability ratio (vertical/ horizontal) and permeability stratification are examined below.

\section{Absolute Permeability}

The effect of the absolute permeability on water coning has been evaluated by considering homogeneous reservoirs having permeabilities from 50 to $2000 \mathrm{md}$. Figure 18 shows the pressure loss in the reservoir. Saturation profiles taken at the end of the 10-hour extraction cycle are presented in Table 5. For these results the absolute permeability is the only variation from the reference conditions.

The pressure loss curve of Figure 18 is similar to results presented in a previous report (Smith, Wiles, Loscutoff 1979). There is no indication that water coning has any impact on the various cases. This is further amplified by the results of Table 5 . An examination of the data shows that the saturation profiles are essentially indistinguishable. Thus provided that the reservoir operation conditions and design are constant, then absolute permeability will have essentially no effect on water coning.

TABLE 5. Radial Saturation Distributions after 10-Hours of Air Extraction for Various Homogeneous Absolute Permeabilities

\begin{tabular}{|c|c|c|c|}
\hline \multirow{2}{*}{$\begin{array}{c}\text { Radius } \\
(\mathrm{m})\end{array}$} & \multicolumn{3}{|c|}{ Permeability (md) } \\
\hline & 100 & 500 & 1000 \\
\hline .05 & 0.574 & 0.562 & 0.550 \\
\hline .20 & 0.574 & 0.562 & 0.550 \\
\hline .50 & 0.573 & 0.561 & 0.550 \\
\hline 1.10 & 0.571 & 0.560 & 0.549 \\
\hline 2.30 & 0.564 & 0.554 & 0.544 \\
\hline 4.70 & 0.546 & 0.5389 & 0.530 \\
\hline 9.50 & 0.514 & 0.509 & 0.504 \\
\hline 19.10 & 0.481 & 0.478 & 0.476 \\
\hline
\end{tabular}




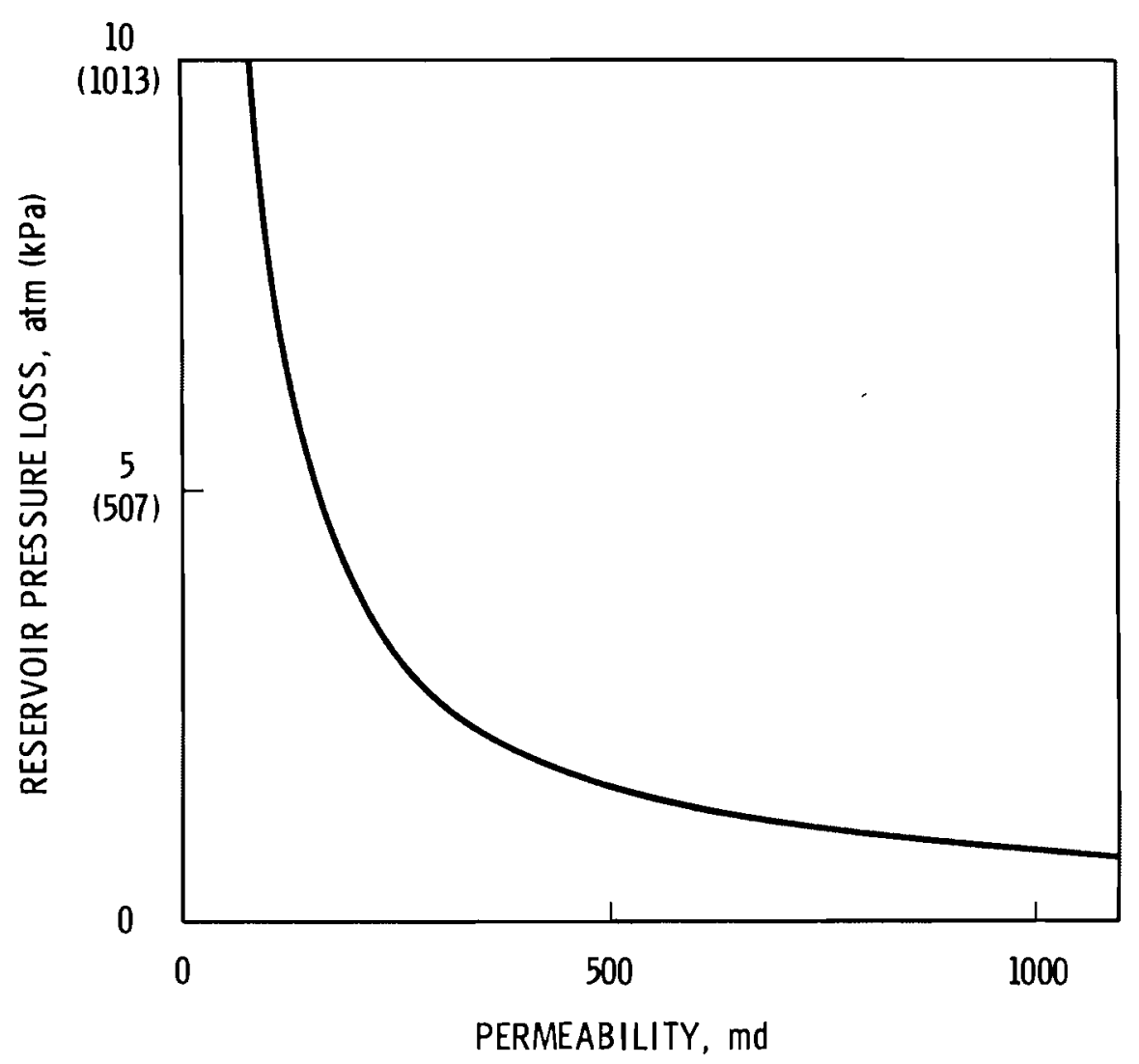

FIGURE 18. Reservoir Pressure Loss as a Function of Absolute Permeabilities for Homogeneous Reservoirs

It is a certainty that the reservoir design and operation will not be independent of permeability. Given that the pressure loss in the reference reservoir is typical, two other cases were developed. For a reservoir having a permeability of $1000 \mathrm{md}$ the reservoir diameter was set at $166 \mathrm{~m}$. For a reservoir having a permeability of $100 \mathrm{md}$ the reservoir diameter was set at $58 \mathrm{~m}$. Adjustment of the reservoir diameter while maintaining a constant percent of mass cycled resulted in a larger flow rate for the larger reservoir and a smaller flow rate for the smaller reservoir. Both cases resulted in a reservoir pressure loss about equal to that of the reference reservoir. The relative degree of water movement is shown by the saturation profiles of Figure 19. These results apply at the end of the 10-hour extraction and are taken from the $21.5-\mathrm{m}$ 


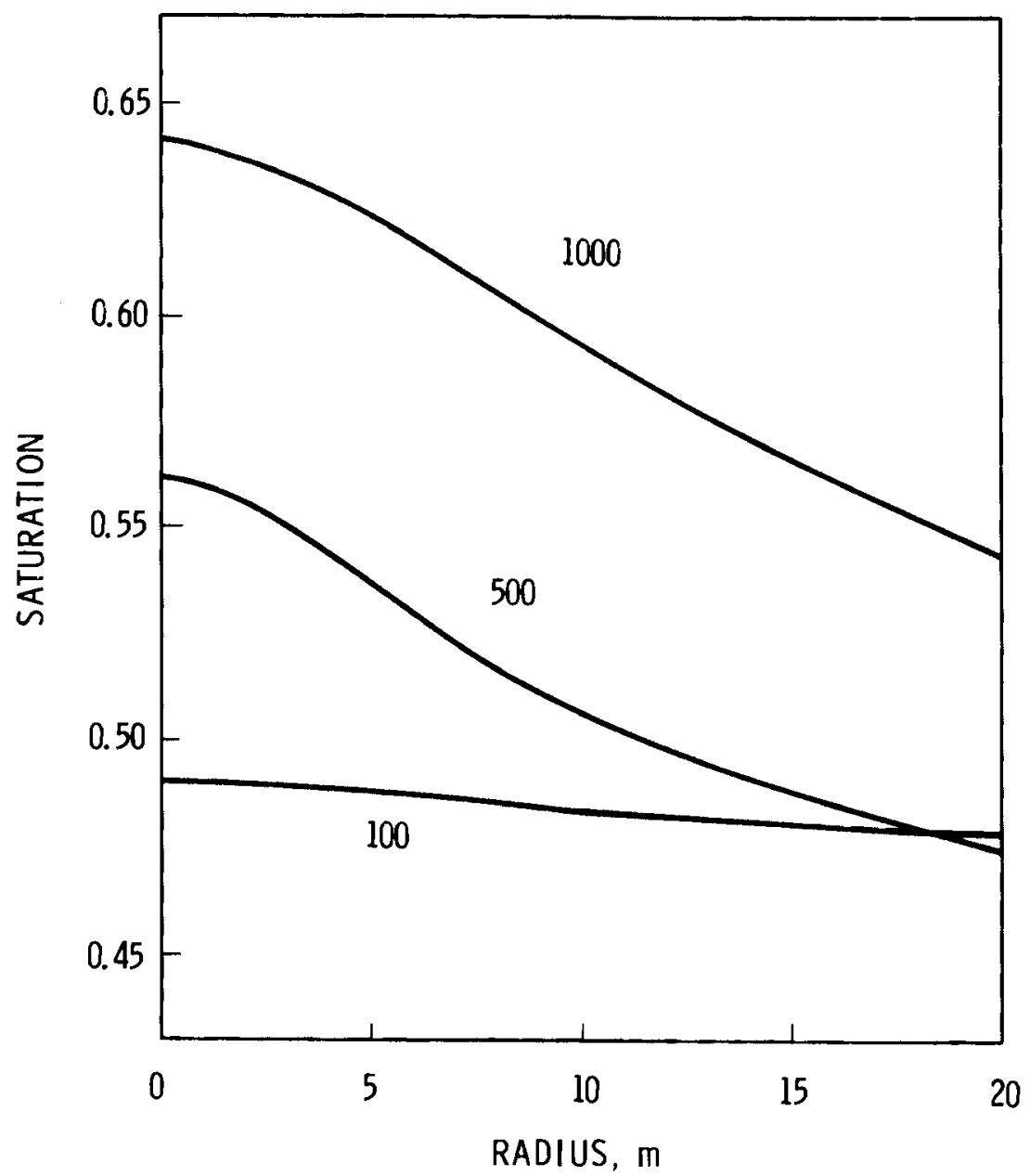

FIGURE 19. Radial Saturation Profiles After 10 Hours of Air Extraction for Reservoirs of Various Permeabilities (md) but Operating with Similar Pressure Losses

elevation defined by Figure 4. As would be expected, subject to similar pressure gradients in otherwise equivalent conditions, the water cone will develop faster in a reservoir having greater permeability.

\section{Permeability Ratio}

The permeability ratio is the ratio of the vertical permeability to the horizontal permeability. In most porous media aquifer sands the ratio is less than unity. Of course, any reduction of the vertical permeability will reduce the degree of water coning. The horizontal 
permeability used in this analysis was $500 \mathrm{md}$. Vertical permeabilities were varied from 50 to $2000 \mathrm{md}$. The permeability ratios above unity are not physically typical. The results for those cases may only be academically useful, serving to characterize the general behavior of water coning.

The saturation profiles for different permeability ratios are presented in Figure 20. These results apply at the conclusion of a 10-hour extraction cycle at an elevation of $21.5 \mathrm{~m}$ as defined by Figure 4 . The rate of water movement is very sensitive to the vertical permeability. Any reduction in vertical permeability will considerably diminish the problems associated with water coning.

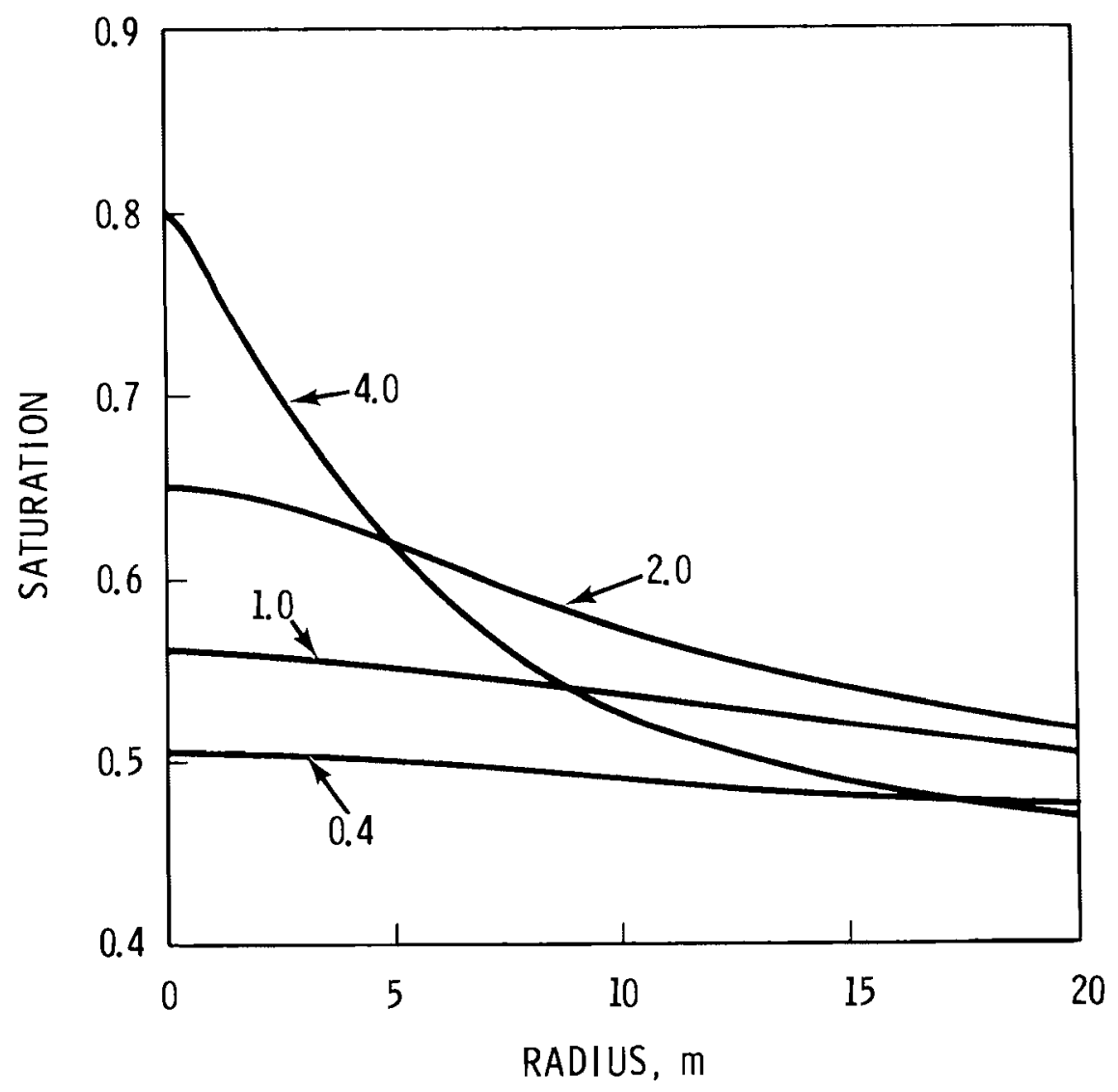

FIGURE 20. Radial Saturation Profiles After 10 Hours of Air Extraction for Various Ratios of Vertical to Horizontal Permeability. The horizontal permeability is $500 \mathrm{md}$. 


\section{Permeability Stratification}

If a distinct horizontal layer of low permeability exists in the reservoir it may inhibit vertical liquid transport regardless of the permeable nature of the remainder of the reservoir. Three cases were evaluated. Each used a $27-\mathrm{m}$ producing length with all other conditions at the reference values except for the stratified layer. The vertical center of a 3-m-thick layer with a permeability of $50 \mathrm{md}$ was defined to exist at elevations $21.5,24.5$ and $27.5 \mathrm{~m}$ as defined by Figure 4 . The bottom of the wellbore was at an elevation of $23 \mathrm{~m}$.

The relative degrees of water coning are shown by the saturation profiles in Figure 21. These results apply at the conclusion of a

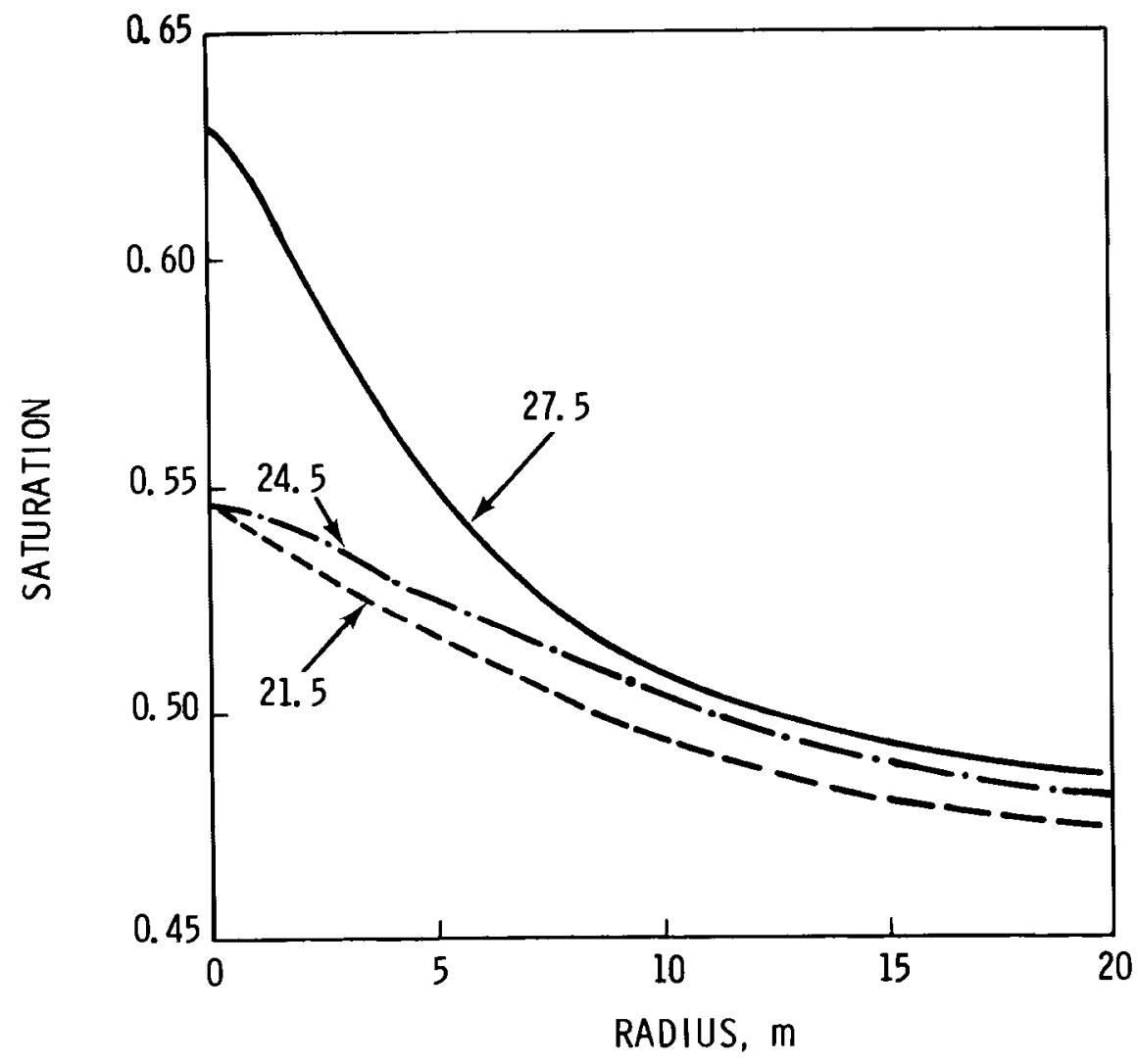

FIGURE 21. Radial Saturation Profiles After 10 Hours of Air Extraction for Three Cases of Permeability Stratification. The elevations, as defined by Figure 4 , are the vertical centers or 3-m-thick zones having a permeability of $50 \mathrm{md}$. 
simulated 10-hour extraction cycle. For the cases of the two lower elevations the bottom of the wellbore does not extend through the lowpermeability layer. The results suggest that as long as this is true the actual location of a low-permeability layer is unimportant with respect to the effect on water coning. When the wellbore penetrates the low permeability region, the occurance of water coning is essentially independent of the existence of the layer. However, in this case, the low-permeability layer may affect the reservoir pressure response, depending on the operation of the reservoir, and thereby affect water coning.

\section{SATURATION FUNCTIONS}

The relative permeability and the capillary pressure are both functions of the liquid saturation. Certain characteristics of these functions have been evaluated to determine their impact on reservoir performance, particularly with respect to water coning.

The capillary pressure and the relative permeability to the flow of water are considered to be coupled by one characteristic of the functions: the residual saturation. The saturation at which the relative permeability to water goes to zero is the same saturation for which the capillary pressure curve approaches an infinite slope. This condition is not met with the functions tested because the infinite slope could not be tolerated numerically. Also, the infinite slope is perhaps not physically realistic. The functions are written so that the infinite slope occurs at a saturation that is $5 \%$ below residual saturation.

Another characteristic of the capillary pressure function is the value of the capillary pressure at residual saturation. This determines the height of the transition zone.

A final characteristic is the value of the capillary pressure for a fully saturated condition. This may also be viewed as the saturation at which capillary pressure vanishes. In an initially saturated region a pressure buildup must occur before any water movement occurs. This 
pressure is referred to by Muskat (1949) as the "displacement pressure" and would apply rigorously to the desaturation process. Water coning involves resaturation in which water movement due to capillary forces is referred to as imbibition. For this case, the capillary pressure may vanish at a saturation below unity.

The reservoir performance was evaluated using a variety of capillary pressure functions representing the various conditions described above. The relative permeability function for water for each case was dependent only on the residual saturation. The relative permeability function for air was not changed in this analysis. Since the relationship between the relative permeabilities and the capillary pressure is not well defined, a more extensive coupling of the functions was not warranted. Furthermore, one of the purposes of this analysis was to show that water coning was not particularly sensitive to the exactness of the saturation functions.

The saturation functions used in this analysis are given in Table 6. Subsequent reference to a function is made by referring to the number to the left of the function. Also, note the capillary pressure function 4 was used in the analysis with the relative permeability function 4 , etc. The bottom of the transition zone is defined to occur at the 20-m elevation in Figure 4. The saturation distributions for the four numerical cells in the transition zone are given in Table 7 for the five capillary pressure functions. The reference functions were plotted in Figures 6,7 , and 8 . The remaining functions are plotted in Figures $22 \mathrm{a}$ through $22 \mathrm{e}$. The relative permeability function for air and the wellbore saturations functions, all defined in Table 1, were not changed.

The purpose of capillary pressure function 1 was to provide a vertically thinner transition zone. The capillary pressure at residual saturation is about $0.32 \mathrm{~atm}(32 \mathrm{kPa})$. With a smaller capillary pressure gradient to overcome at the wellbore, it was thought that breakthrough would occur earlier than breakthrough for the reference case. However, 
TABLE 6. Saturation Functions

$$
\begin{aligned}
& \text { Capillary Pressure Functions } \\
& \mathrm{PC} \text { in } \mathrm{atm} \\
& \text { REF ) } P^{C}=\frac{0.05525}{S-0.15}+0.065 \\
& \text { 1) } P^{C}=\frac{0.017}{S-0.15}-0.020 \\
& \text { 2) } P^{C}=\frac{0.048}{S-0.75}+0.044 \\
& \text { Transition Zone } \\
& \text { Height (m) } \\
& 10.74
\end{aligned}
$$

Relative Permeability Functions for Water

$$
\begin{aligned}
\text { REF \& 1-3) } k_{r}^{\ell} & =(S-0.20)^{3}\{4.93-3.72(S-0.20)\} \\
\text { 4) } k_{r}^{\ell} & =(S-0.40)^{3}\{8.06-5.72(S-0.40)\}
\end{aligned}
$$

TABLE 7. Transition Zone Saturation Distributions for the Capillary Pressure Functions

\begin{tabular}{clllllll}
$\begin{array}{c}\text { Elevation } \\
(\mathrm{m})\end{array}$ & $\begin{array}{l}\text { Capiliary Pressure } \\
\text { Function: }\end{array}$ & Ref & & 1 & 2 & 3 & \\
\cline { 1 - 1 } & Saturations: & 0.2 .027 & 0.2000 & 0.2001 & 0.2039 & 0.4007 \\
27.5 & & 0.2211 & 0.2000 & 0.2121 & 0.2235 & 0.4152 \\
24.5 & & 0.2643 & 0.2007 & 0.2506 & 0.2679 & 0.4537 \\
21.5 & & 0.4743 & 0.3176 & 0.4501 & 0.4805 & 0.6244
\end{tabular}




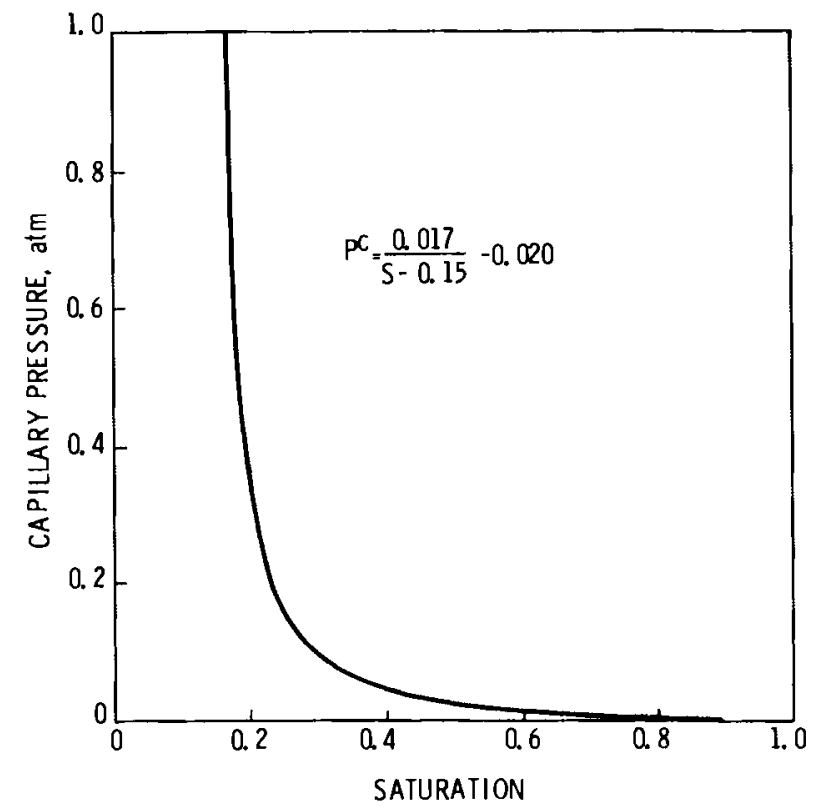

FIGURE 22a. Capillary Pressure Function 1

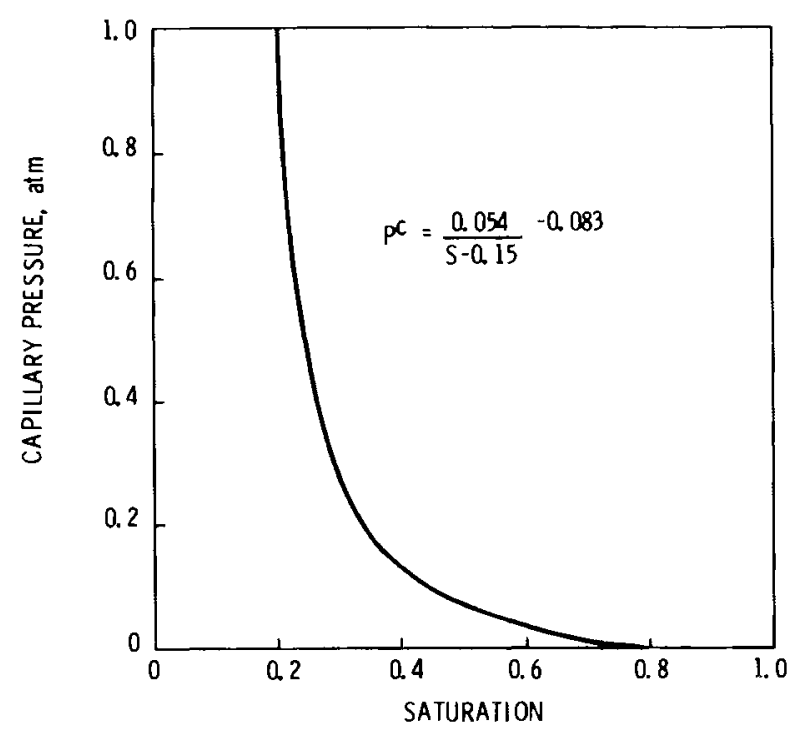

FIGURE 22c. Capillary Pressure Function 3

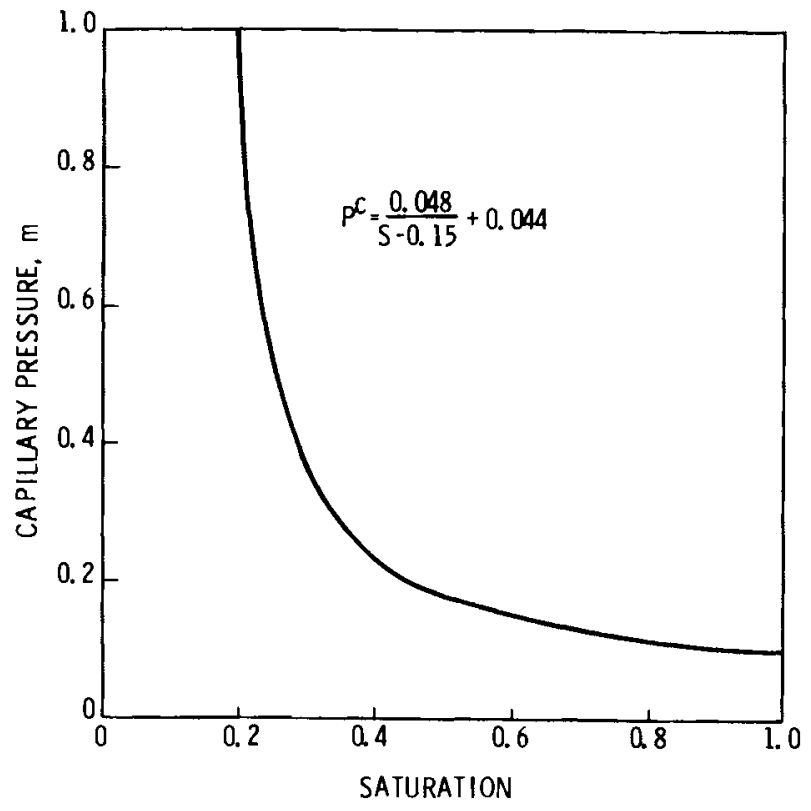

FIGURE 22b. Capillary Pressure Function 2

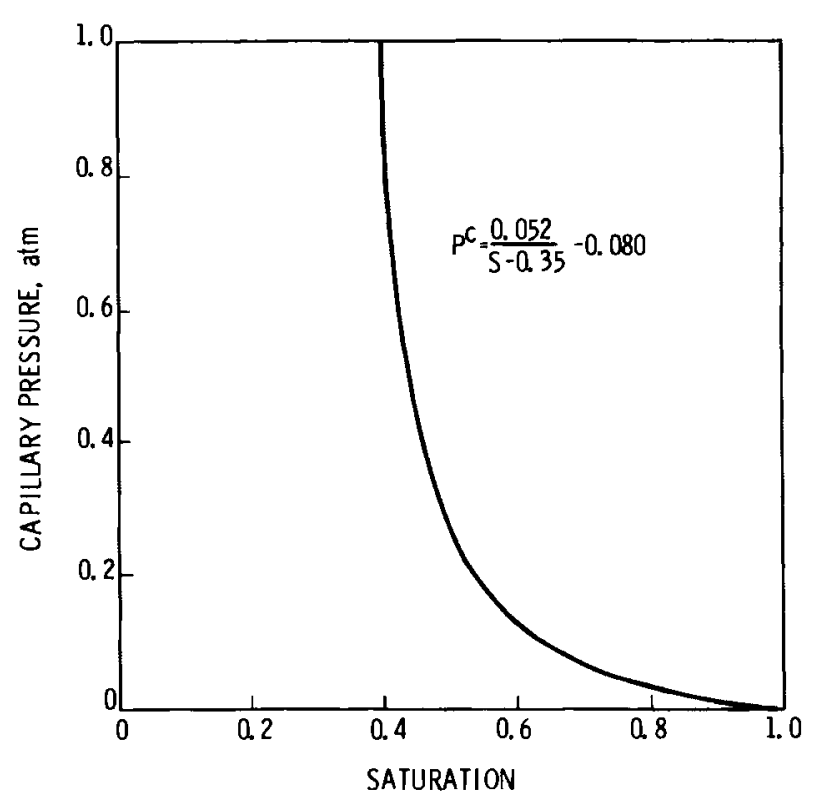

FIGURE 22d. Capillary Pressure Function 4 


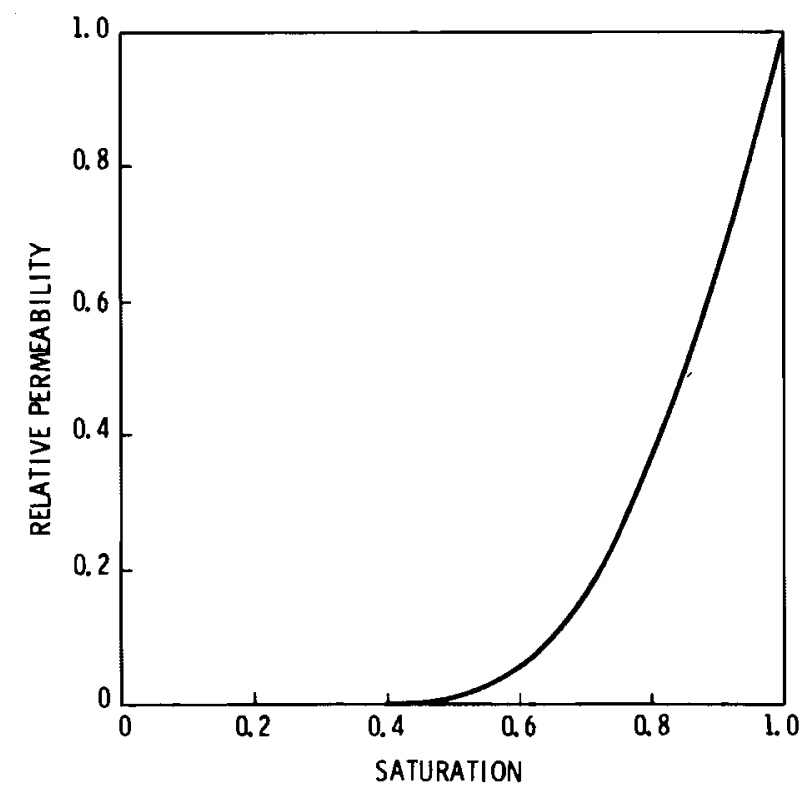

FIGURE 22e. Relative Permeability Function

other conditions of the analysis were not appropriately accounted for in this projection. The conditions imposed on the analysis were identical to the reference conditions except for the capillary pressure function. The extraction cycle simulation was carried out beyond the 10-hour interval to define the conditions at breakthrough. The time required for breakthrough was about the same for function 1 and the reference capillary pressure function. Since the 24-m-long wellbore extended down to the 26-m elevation, a saturation buildup was required with function 1 before the water adjacent to the wellbore would become mobile. This buildup was inhibited by the low relative permeability due to the generally lower saturation in the transition zone. For the reference function the water adjacent to the bottom of the wellbore is mobile at the outset of air extraction. Breakthrough occurs when the imposed pressure gradient overcomes the capillary pressure gradient, which is decreasing due to a saturation buildup. At the time of breakthrough the capillary pressure gradient is about the same for the reference case and with function 1. Therefore, this analysis showed that water coning and breakthrough were not uniquely dependent on the capillary pressure 
function alone. Other important factors are the fluid mobility and the extension of the wellbore into the transition zone.

Functions 2 and 3 defined in Tables 6 and 7 and shown in Figures 22b and $22 \mathrm{c}$ were intended to indicate the sensitivity of reservoir performance to the end point of the capillary pressure function. These functions and the reference function all have nearly the same capillary pressure at residual saturation. As a result, the gravitational-capillary equilibrium saturation distributions defining the transition zones are about the same for each case. Consequently, the mobilities are similar, and the fluid transport depends primarily on the pressure gradient. The contribution of the capillary pressure to the pressure gradients depends on the slope of the capillary pressure curve and the change in saturation over the interval in which the pressure gradient exists. Therefore, the shape of the capillary pressure curve may be more important than the end points. This analysis showed that the capillary pressure at large values of saturation was not particularly important to water coning. The saturation profiles for the three functions that were compared are essentially indistinguishable.

Capillary pressure function 4 was used to evaluate the effect of residual saturation on the reservoir performance. The function, shown in Figure 22d, is coupled to the relative permeability curve of Figure 22e. The significant difference between the reference function and function 4 is the slope of the capillary pressure and relative permeability curves. With function 4 the steeper slopes result in greater changes in capillary pressure and mobility for a given change in saturation. As a result, the saturation buildup occurs more rapidly with the use of function 4 than with the reference function. However, the differences related to water coning are still quite small compared to what might be expected from the differences in residual saturation. The most obvious impact of the different residual saturations is the effect on the pressure loss across the reservoir. The relative permeability function for air was 
used for all cases. With the greater residual saturation, the mobility of the air is reduced. The pressure drop associated with function 4 is about 20\% greater than for the reference case. 


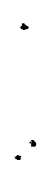


In this report the development, analysis, and results have been presented for the two-phase (air-water), two-dimensional (cylindrical) modeting of CAES porous media reservoirs.

The development of the numerical computer model for two-phase, twodimensional flow in porous media proved to be challenging. Unique numerical methods were required to deal with the combined effects of the nonlinear terms, the convergent nature of the flow, and the anisotropy at the wellbore.

The analysis of water coning was based upon a set of reference conditions about which single parameters or groups of parameters were varied to determine their effect on water coning.

The results obtained for the simulated operation of a CAES reservoir suggest that water coning should not be a severe problem. This is primarily due to the slow response of the water to the pressure gradients and the relatively short, cyclic duration in which those gradients exist. However, water coning will depend on site-specific conditions, particularly the fluid distributions following bubble development, and, therefore, should be included as part of site evaluation.

The parameters that were known to have an effect on the reservoir pressure response, and, therefore to water coning were evaluated with the following results:

- The wellbore producing length may extend to within a few meters of the air-water interface before significant intrusion of water into the wellbore will occur due to water coning by the conclusion of one air extraction cycle.

- The avoidance of water coning by reduction of the producing length will have a greater impact on the pressure response in vertically thin reservoirs. 
- The pressure drop across the reservoir is proportional to the air mass flow rate so that more severe water coning will be associated with higher flow rates.

- In reservoirs having homogeneous permeability the water coning is more severe for large values of permeability provided that, as a basis for comparison, the pressure drop across the reservoir is the same for all cases.

- Even a slight reduction in vertical permeability can significantly reduce the severity of water coning.

- A layer of low permeability will inhibit water coning only if the bottom of the wellbore does not extend through the layer.

- The severity of water coning was not particularly sensitive to the capillary pressure and relative permeability functions evaluated by this analysis.

Certain characteristics of water coning that were observed include:

- If water enters the bottom of the wellbore, the low flow resistance allows the water level in the wellbore to rise significantly faster than the air-water interface in the surrounding region. Then capillary forces can pull this water into the sand adjacent to the wellbore and ahead of the frontal advance of the air-water interface.

- The reservoir pressure response is affected most by accumulation of water in the sand immediately adjacent to the wellbore and to a lesser extent by the water content in the wellbore.

- Water coning may be described as having two modes. In one, water movement is a response to the sharp pressure gradients near the wellbore. In the second, the water movement is a response to the pressure differential across the entire reservoir. In this second mode the air-water interface apparently moves much more slowly. 
These results add to a growing knowledge of the fundamental behavior of the performance of a CAES porous media reservoir. In addition, the capability of the two-phase, two-dimensional model has been demonstrated. This modeling effort provides a basis for the next phase of reservoir analysis. The prospects for very long bubble development times will create problems in the scheduling of the construction of a CAES facility. It is important, therefore, that the required time be determined. It is also expected that a characterization of the behavior will lead to more efficient, time-saving methods of bubble development. 


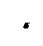

$\therefore$

. 


\section{KEFERENCES}

Amyx, J. W. D. M. Bass, Jr. and R. L. Whiting. 1960. Petroleum Reservoir Engineering $=$ Physical Properties. Mclaraw-Hill Book Company, New York.

Arthur, M. G. 1944. "Fingering and Coring of Water and Gas in Homogeneous 0i1 Sand." Trans. AIME. 155:184-201.

Blair, P. M. and C. F. Weinaug. 1969. "Solution of Two-Phase Flow Problems Using Implicit Difference Equations." Soc. Pet. Eng. J. pp. 417-424.

Brooks, R. and A. Corey. 1966. "Properties of Porous Media Affecting Fluid Flow." J. of the Irrigation and Drainage Division, ASCE, (IR2):61-88.

Buckley, S. E. and M. C. Leverett. 1942. "Mechanism of Fluid Displacement in Sands." Trans. AIME. 146:197-216.

Coats, K. H., R. L. Neilson, M. H. Terhune and A. G. Weber. 1967. "Simulation of Three-Dimensional, Two-Phase Flow in 0 il and Gas Reservoirs." Soc.

Pet. Eng. J. December, pp. 377-388.

Coats, K. H. and J. G. Richardson. 1967. "Calculation of Water Displacement by Gas in Development of Aquifer Storage." Soc. Pet. Eng. J. June, pp. 105-112.

Coats, K. H. and M. H. Terhune. 1966. "Comparison of Alternating Direction Explicit and Implicit Procedures in Two-Dimensional Flow Calculations." Soc. Pet. Eng. J., December, pp. 350-362.

Corey, A. 1954. "The Interrelation Between Gas and 0 il Relative Permeabilities." Producers Monthly. November, pp. 38-41.

Dquglas, J., Jr. 1955. "On the Numerical Integration of $\partial^{2} u / \partial x^{2}+$ $\partial^{2} u / \partial y^{2}=\partial u / \partial t$ by Implicit Methods." J. Soc. Indust. Appl. Math. $3: 42-65$.

Douglas, J., Jr., D. W. Peaceman and H. H. Rachford, Jr. 1959. "A Method for Calculating Multi-Dimensional Immiscible Displacement." Trans. AIME. 216:297-308.

Katz, D. L., D. Cornel1, R. Kobayashi, F. H. Poettman, J. A. Vary, J. R. Elenbaas and C. F. Weinaug. 1979. Handbook of Natural Gas Engineering.

McGraw-Hil1 Book Company, New York, pp. 463-464.

Katz, D. L. and E. R. Lady. May 1976. Compressed Air Storage. University of Michigan, Ann Arbor, MI.

Letkeman, J. P., and R. L. Ridings. 1970. "A Numerical Coning Mode1." Soc. Pet. Eng. J. December, pp. 418-424 
Leverett, M. C. 1941. "Capillary Behavior in Porous Solids." Trans. AIME. 142:152-169.

MacDonald, R. C. and K. H. Coats. 1970. "Methods for Numerical Simulation of Water and Gas Coning." Trans. AIME. 249:425-436.

Meyer, H. I. and D. F. Searcy. 1956. "Analog Study of Water Coning." J. of Pet. Tech. 8(4):61-64.

Muskat, M. 1949. Physical Principles of 0 il Production. McGraw-Hill Book Company, Inc., New York.

Muskat, M. and R. D. Wyckoff. 1935. "An Approximate Theory of Water Coning in 0 i1 Production." Trans. AIME. 114:144-163.

Nolen, J. S. and D. W. Berry. 1972. "Tests of the Stability and Time-Step Sensitivity of Semi-Implicit Reservoir Simulation Techniques." Soc. Pet. Eng. J. June, pp. 253-266.

Peaceman, D. W. 1977. Fundamentals of Numerical Reservoir Simulation. Elsevier Scientific Publishing Co.

Peaceman, D. W. and H. H. Rachford, Jr. 1955. "The Numerical Solution of Parabolic and Elliptic Differential Equations." J. Soc. Indust. Appl. Math. 3(1):28-41.

Price, H. S. and K. H. Coats. 1974. "Direct Methods in Reservoir Simulation." Trans. AIME 257:295-306.

Richtmyer, R. and K. Morton. 1967. Difference Methods for Initial Value Problems. 2nd edition, Interscience Publishers, 1967, $\overline{\mathrm{pp} .} \overline{198-201 .}$

Settari, A. and K. Aziz. 1974. "A Computer Model for Two-Phase Coning Simulation." Soc. Pet. Eng. J. June, pp. 221-236

Smith, G. C., L. E. Wiles and W. V. Loscutoff. 1979. Numerical Analysis of Temperature and Flow Effects in a Dry, One-Dimensional Aquifer Used for Compressed Air Energy Storage. PNL-2546, Pacific Northwest Laboratory, Richland, WA, 99352 .

Sonier, F., P. Besset and 0. Ombret. 1973. "A Numerical Model of MultiPhase Flow Around a We11." Soc. Pet. Eng. J. December, pp. 311-320.

Stone, H. L. 1968. "Iterative Solution of Implicit Approximations of Multidimensional Partial Differential Equations." SIAM J. Numer. Anal. $5: 530-558$.

Stottlemyre, J. A. and R. L. Erikson. 1980. An Experimental Study of the Response of the Galesville Sandstone to Simulated CAES Conditions. PNL-3399, Pacific Northwest Laboratory, Richland, WA, 99352. 
Weinstein, H. G., H. L. Stone and T. V. Kwan. 1969. "Simultaneous Solution of Multiphase Reservoir Flow Equations." Ind. and Eng. Chem. Fund. 8(2):281-287.

Welge, H. J. and A. G. Weber. 1974. "Use of Two-Dimensional Methods

for Calculating Wel1 Coning Behavior." Soc. Pet. Eng. J. December, pp. 345-355.

Wiles, L. E. March 1979. The Effects of Water on Compressed Air Energy Storage in Porous Rock Reservoirs. PNL-2869, Pacific Northwest Laboratory, Richland, WA, 99352 .

Wiles, L.E. October 1979. Numerical Analysis of Temperature and Flow Effects in a Dry, Two-Dimensiona 1, Porous Media Reservoir Used for Compressed Air Energy Storage. PNL-3047, Pacific Northwest Laboratory, Richland, WA, 99352. 


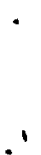

-

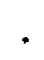


The finite difference equations are based on Equations 5, 6, and 7, but are developed directly from a mass balance rather than from the differential equations. The mass balance applicable to either phase is

$$
\left(m_{r_{j-1}}-m_{r_{j}}\right)_{k}+\left(m_{z_{k-1}}-m_{z_{k}}\right)_{j}+Q_{j, k}=\frac{\partial}{\partial t}(\phi \rho V S)_{j, k}
$$

The grid system which defines the nodes and surfaces applicable to this equation is shown in Figure A.1. With the assumption of axisymmetric flow, only one radian is accounted for such that the volume is

$$
v_{j, k}=r_{j} \Delta r_{j} \Delta z_{k}
$$

The mass flow rates, $m$, are defined as a product of a flow connector and a flow potential. The flow connector is a measure of the conductance; i.e., the inverse of resistance, to fluid flow in the porous media. The flow potential is a measure of the total pressure difference between two points in the fluid. It includes the imposed, gravitational, viscous, and capillary pressure terms. The mass flow rates are developed in Appendix B. From Equation B-12 and B-24

$$
m_{r_{j}}=A J_{j} \Phi J_{j}
$$

and

$$
m_{z_{k}}=A K_{k} \Phi K_{k} .
$$




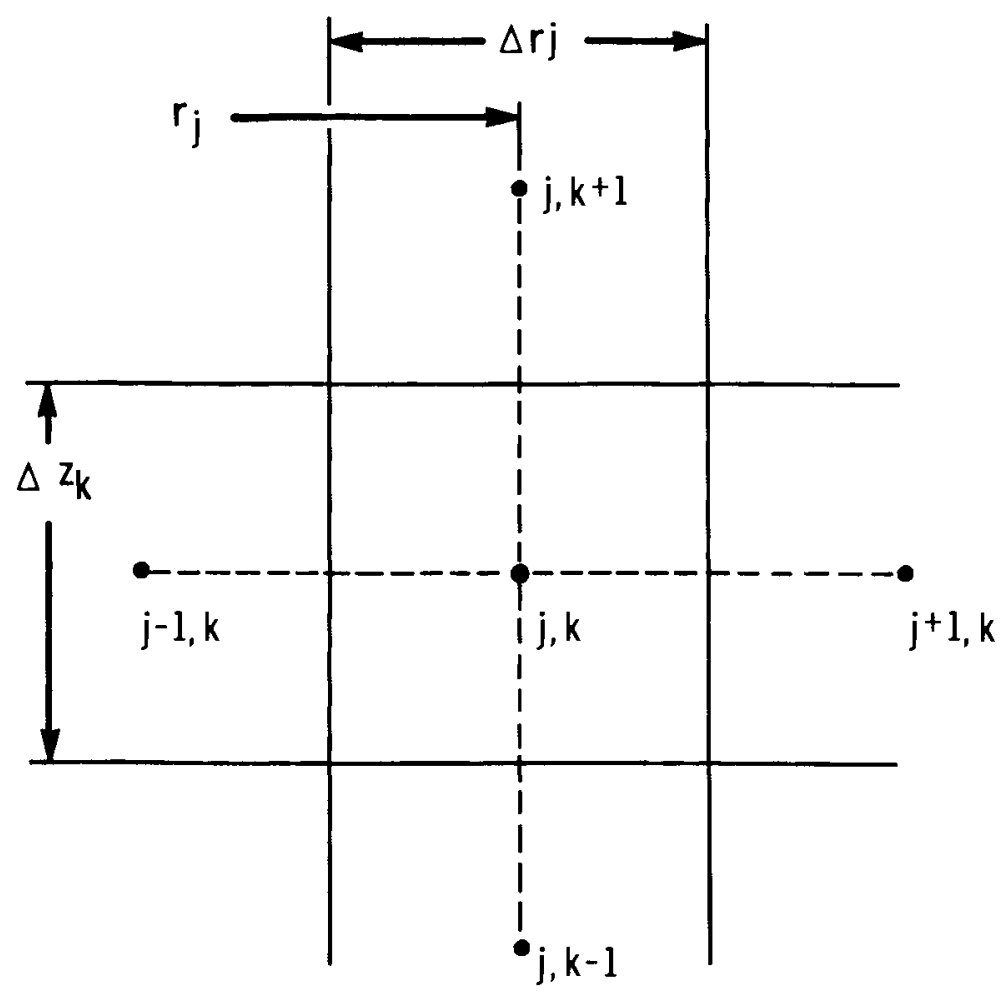

FIGURE A.1. Finite Difference Grid System

Equations $A-2, A-3$, and $A-4$ are substituted into Equation $A-1$ to give

$$
\begin{aligned}
& \left(A J_{j-1} \Phi J_{j-1}-A J_{j} \Phi J_{j}\right)_{k}+\left(A K_{k-1} \Phi K_{k-1}-A K_{k} \Phi K_{k}\right)_{j}+Q_{j, k} \\
& =\frac{\partial}{\partial t}\left(V_{p} \delta S\right)_{j, k}
\end{aligned}
$$

where

$$
\left(v_{p}\right)_{j, k}=\phi_{j, k}\left(r_{j} \Delta r_{j} \Delta z_{k}\right)
$$

is the pore volume of cell $\mathrm{j}, \mathrm{k}$. 
In general, the continuity equation is not satisfied. The error is defined as

$$
\begin{aligned}
D_{j, k} & =\left(A J_{j} \Phi J_{j}-A J_{j-1} \Phi J_{j-1}\right)_{k}+\left(A K_{k} \Phi K_{k}-A K_{k-1} \Phi K_{k-1}\right)_{j} \\
& -Q_{j, k}+\left(V_{p}\right)_{j, k} \frac{\partial}{\partial t}(\delta S)_{j, k} .
\end{aligned}
$$

It is the function of the numerical iterative procedure to reduce this error. To do this, the continuity error is assumed to be a function of gas pressure and saturation. Then the corrected or reduced continuity error is determined according to its sensitivity to these two parameters. Thus

$$
D_{j, k}^{C}=D_{j, k}+\left(\frac{\partial D}{\partial P^{g}}\right)_{j, k} \delta P_{j, k}^{g}+\left(\frac{\partial D}{\partial S}\right)_{j, k} \delta S_{j, k} \cdot
$$

It would be desirable to find gas pressure and saturation corrections, $\delta P G$ and $\delta S$, that would make the corrected error zero. This effort does not lead to the most rapid convergence, however. Experience dictates that it is more appropriate to compute the new continuity error as

$$
D_{j, k}^{C}=-\omega D_{j, k} .
$$

Subtracting Equation A-9 from A-8 gives

$$
\left(\frac{\partial D}{\partial P^{g}}\right)_{j, k} \delta P_{j, k}^{g}+\left(\frac{\partial D}{\partial S}\right)_{j, k} \delta S_{j, k}=-\Omega D_{j, k}
$$

where the coefficient $\Omega$ is referred to as the relaxation parameter which is taken from

$$
\Omega=1+\omega .
$$


For $0<\Omega<1$ the solution is under-relaxed. For $1<\Omega<2$ the solution is over-relaxed. For $\Omega \leq 0$ or $\Omega \geq 2$, the iterative procedure will not converge.

Equation A-10 is applied to A-7 to yield the corrections for gas pressure and saturation. These equations apply to either the gas or liquid except for the saturation in the time derivative term. This has to be (1-S) for the gas phase equation. To proceed, separate handling of each phase equation is necessary.

\section{Gas Phase}

For the gas phase, Equation A-7 becomes

$$
\begin{aligned}
D_{j, k}^{g} & =\left(A J_{j}^{g} \Phi J_{j}^{g}-A J_{j-1}^{g} \Phi J_{j-1}^{g}\right)_{k}+\left(A K_{k}^{g} \Phi K_{k}^{g}-A K_{k-1}^{g} \Phi K_{k-1}^{g}\right) \\
& -Q_{j, k}^{g}+\frac{\left(V_{p}\right)_{j, k}}{\Delta t}\left[\rho^{g}(1-S)-\left\{\rho^{g}(1-S)\right\}^{n}\right] j, k
\end{aligned}
$$

In this equation the only parameters evaluated at the previous time step, $\mathrm{n}$, are those designated in the storage term. All other parameters are evaluated implicitly or are updated according to the latest solution values.

In the application of Equation A-10 to Equation A-12, the flow connectors are considered to be functions of saturation only and the potentials are independent of saturation. Also, if the gas density in the gravitational term of the flow potential is treated explicitly by being updated after each iteration, then it is independent of the gas pressure correction. The result is 


$$
\begin{aligned}
& -\left\{A J_{j}^{g}\left(\delta P_{j+1}^{g}-\delta P_{j}^{g}\right)+A J_{j-1}^{g}\left(\delta P_{j-1}^{g}-\delta P_{j}^{g}\right)\right\}_{k} \\
& -\left\{A K_{k}^{g}\left(\delta P_{k+1}^{g}-\delta P_{k}^{g}\right)+A K_{k+1}^{g}\left(\delta P_{k-1}^{g}-\delta P_{k}^{g}\right)\right\}_{j} \\
& +\frac{\left(V_{p}\right)_{j, k}}{\Delta t}(1-S)_{j, k}\left(\frac{\partial \rho^{g}}{\partial p^{g}}\right)_{j, k} \delta P_{j, k}^{g} \\
& +\left[\Phi J_{j}^{g}\left\{\left(\frac{\partial A J_{j}^{g}}{\partial S_{j}}\right) \delta S_{j}+\left(\frac{\partial A J_{j}^{g}}{\partial S_{j+1}}\right) \delta S_{j+1}\right\}\right] k \\
& -\left[\Phi J_{j-1}^{g}\left\{\left(\frac{\partial A J_{j-1}^{g}}{\partial S_{j}}\right) \delta S_{j}+\left(\frac{\partial A J_{j-1}^{g}}{\partial S_{j+1}}\right) \delta S_{j-1}\right\}\right] k \\
& +\left[\Phi K_{k}^{g}\left\{\left(\frac{\partial A K_{k}^{g}}{\partial S_{k}}\right) \delta S_{k}+\left(\frac{\partial A K_{k}^{g}}{\partial S_{k+1}}\right) \delta S_{k+1}\right\}\right] j \\
& -\left[\Phi K_{k-1}^{g}\left\{\left(\frac{\partial A K_{k-1}^{g}}{\partial S_{k}}\right) \delta S_{k}+\left(\frac{\partial A K_{k-1}^{g}}{\partial S_{k-1}}\right) \delta S_{k-1}\right\}\right] j \\
& -\frac{\left(v_{p}\right)_{j, k}}{\Delta t} \rho_{j, k}^{g} \delta S_{j, k}=-\Omega D_{j, k}^{g} \text {. }
\end{aligned}
$$

The coefficients can be defined to simplify the equation. The gas phase equation becomes

$$
\begin{aligned}
& -\left(A J P_{j}^{g} \delta P_{j+1}^{g}+A J P_{j-1}^{g} \delta P_{j-1}^{g}\right)_{k}-\left(A K P_{k}^{g} \delta P_{k+1}^{g}+A K P_{k-1}^{g} \delta P_{k-1}^{g}\right)_{j} \\
& +B P \underbrace{g}_{j, k} \delta P_{j, k}^{g}-\left(A J S_{j}^{g} \delta S_{j+1}+C J S_{j-1}^{g} \delta S_{j-1}\right)_{k} \\
& -\left(A K S_{k}^{g} \delta S_{k+1}+C K S_{k-1}^{g} \delta S_{k-1}\right)_{j}+B S_{j, k}^{g} \delta S_{j, k}=-\Omega D_{j, k}^{g}
\end{aligned}
$$

$$
A-5
$$


where

$$
\begin{aligned}
B P P_{j, k}^{g}= & A J P_{j, k}^{g}+A J P_{j-1, k}^{g}+A K P_{j, k}^{g}+A K P_{j, k-1}^{g} \\
& +\frac{\left(V_{p}\right)_{j, k}}{\Delta t}(1-S)_{j, k}\left(\frac{\partial p}{\partial p}\right)_{j, k}^{g}
\end{aligned}
$$

and

$$
\begin{aligned}
B S_{j, k}^{g}= & C J S_{j, k}^{g}+A J S_{j-1, k}^{g}+C K S_{j, k}^{g}+A K S_{j, k-1}^{g} \\
& -\frac{\left(V_{p}\right)_{j, k}}{\Delta t} \rho g_{j, k}^{g} .
\end{aligned}
$$

In the analysis, upstream weighting of the relative permeability has been used. This is not built into the connectors multiplying the pressure corrections, AJP, AKP, BP, etc., but can be applied as demanded. On the other hand, the connectors multiplying the saturation corrections are defined according to the direction of flow. For example, for positive radial flow at cell interface $(j, k), \operatorname{cJS}_{j, k}^{g}$ is evaluated using the effective permeability function and saturation of cell $(j, k)$, while $A_{J S}^{g} j, k$ is zero. If the flow is negative at the cell interface then the effective permeability function and saturation of the upstream cell, $(j+1, k)$, are used to evaluate $A_{J S} S_{j+1}^{g}$, while CJS $_{j, k}^{g}$ is zero.

\section{Liquid Phase}

For the 1 iquid phase, Equation A-7 becomes

$$
\begin{aligned}
D_{j, k}^{\ell}= & \left(A J_{j}^{l} \Phi J_{j}^{l}-A J_{j-1}^{l} \Phi J_{j-1}^{l}\right)_{k}+\left(A K_{k}^{l} \Phi K_{k}^{l}-A K_{k-1}^{l} \Phi K_{k-1}^{l}\right)_{j} \\
& -Q_{j, k}^{l}+\frac{\left(V_{p}\right)_{j, k}}{\Delta t}\left\{\rho^{l} S-\left(F^{l} S\right)^{n}\right\}_{j, k^{*}}
\end{aligned}
$$


In this equation the only parameters evaluated at the previous time step, $n$, are those designated in the storage term. All other parameters are evaluated implicitly or are updated according to the latest solution values.

Equations $A-12$ and $A-17$ are the mass balance equations for the twophase system. To this point there are three unknowns; the pressures and the saturation. One of the unknowns must be eliminated using Equation 7 from the main text:

$$
p^{C}=p^{g}-p^{l}=f(S) .
$$

Explicit Saturations

The simplest method of solving the coupled mass balance equations is to use an approach called "explicit saturations". In this method the phase pressures are determined implicitly from Equations A-12 and A-17. Then Equation 7 is used to determine the saturation. In this way the solution for the phase pressures is obtained using saturations obtained from the previous iteration. In a system where the saturations can change rapidly, as is true of water coning, small time steps and/or excessive numbers of iterations are required to achieve convergence. In some cases, convergence can not be achieved. For these conditions the time steps that are required do not physically represent the system but are dictated by the numerical aspects of the solution. This was our experience when LSOR with additive corrections was applied to the explicit saturation formulation while also modeling the open wellbore. As a result, the equations were written to determine the gas pressure and saturation implicitly.

Implicit Saturations

In this method Equation 7 is used to eliminate the liquid pressure in Equation A-17. The resulting equation coupled with Equation A-12 forms a system of two equations and two unknowns, those being gas pressure and saturation. 
Equation 7 is rearranged to give

$$
p^{l}=p^{g}-f(S) .
$$

Equation A-18 is applied to the flow potentials defined by Equations $B-11$ and $B-23$ to give

$$
\Phi J_{j, k}^{l}=\left[P P_{j}^{g}-f\left(S_{j}\right)-\left\{P P_{j+1}^{g}-f\left(S_{j+1}\right)\right\}\right] k
$$

and

$$
\begin{aligned}
\Phi K_{j, k}^{\ell}= & {\left[P_{k}^{g}-f\left(S_{k}\right)-\left\{P_{k+1}^{g}-f\left(S_{k+1}\right)\right\}\right.} \\
& \left.+\frac{g_{z}}{2}\left\{\left(f^{\ell} \Delta Z\right)_{k}+\left(\rho^{\ell} \Delta Z\right)_{k+1}\right\}\right] j
\end{aligned}
$$

In a manner similar to that applied to the gas phase equation, Equation A-10 is applied to the combination of Equations A-17 through A20. The result is

$$
\begin{aligned}
& -\left\{A u_{j}^{l}\left(\delta P_{j+1}^{g}-\delta P_{j}^{g}\right)+A u_{j-1}^{l}\left(\delta P_{j-1}^{g}-\delta P_{j}^{g}\right)\right\}_{k} \\
& -\left\{A K_{k}\left(\delta P_{k+1}^{g}-\delta P_{k}^{g}\right)+A K_{k-1}^{l}\left(\delta P_{k-1}^{g}-\delta P_{k}^{g}\right)\right\}_{j} \\
& -\left\{A J_{j}^{l}\left(-f_{j+1}^{l}\right) \delta S_{j+1}+A u_{j-1}^{l}\left(-f_{j-1}^{\prime}\right) \delta S_{j-1}\right\}_{k} \\
& -\left\{A K_{k}^{l}\left(-f_{k+1}^{\prime}\right) \delta S_{k+1}+A K_{k-1}^{l}\left(-f_{k-1}^{\prime}\right) \delta S_{k-1}\right\}_{j} \\
& +\left\{\left(A J_{j}^{l}+A J_{j-1}^{l}\right)_{k}+\left(A K_{k}^{l}+A K_{k-1}^{l}\right)_{j}\right\}\left(-f_{j, k}^{\prime}\right) \delta S_{j, k} \\
& +\left[Q J_{j}^{l}\left\{\left(\frac{\partial A J_{j}^{l}}{\partial S_{j}}\right) \delta S_{j}+\left(\frac{\partial u_{j}^{l}}{\partial S_{j+1}}\right) \delta S_{j+1}\right\}\right] k \\
& -\left[\Phi J_{j-1}^{l}\left\{\left(\frac{\partial A J_{j-1}^{l}}{\partial S_{j}}\right) \delta S_{j}+\left(\frac{\partial A u_{j-1}^{l}}{\partial S_{j-1}}\right) \delta S_{j-1}\right\}\right] k
\end{aligned}
$$




$$
\begin{aligned}
& +\left[\Phi K_{k}^{\ell}\left\{\left(\frac{\partial A K_{k}^{\ell}}{\partial S_{k}}\right) \delta S_{k}+\left(\frac{\partial A K_{k}^{\ell}}{\partial S_{k+1}}\right) \delta S_{k+1}\right\}\right] j \\
& -\left[\Phi K_{k-1}^{\ell}\left\{\left(\frac{\partial A K_{k-1}^{\ell}}{\partial S_{k}}\right) \delta S_{k}+\left(\frac{\partial A K_{k-1}^{\ell}}{\partial S_{k-1}}\right) \delta S_{k-1}\right\}\right] j \\
& +\frac{\left(V_{p}\right)_{j, k}}{\Delta t} \rho_{j, k}^{\ell} \delta S_{j, k}=-\Omega D_{j, k}^{\ell}
\end{aligned}
$$

The coefficients can be defined to simplify the equation. The liquid phase equation becomes

$$
\begin{aligned}
& -\left(A J P_{j}^{\ell} \delta P_{j+1}^{g}+A J P_{j-1}^{\ell} \delta P_{j-1}^{g}\right)_{k}-\left(A K P_{k}^{\ell} \delta P_{k+1}^{g}+A K P_{k-1}^{l} \delta P_{k-1}^{g}\right)_{j} \\
& +B P_{j, k}^{\ell} \delta P_{j, k}^{g}-\left(A J S_{j}^{\ell} \delta S_{j+1}+C J S_{j-1}^{\ell} \delta S_{j-1}\right)_{k} \\
& -\left(A K S_{k}^{\ell} \delta S_{k+1}+C K S_{k-1}^{\ell} \delta S_{k-1}\right)+B S_{j, k}^{\ell} \delta S_{j, k}=-\Omega D_{j, k}^{\ell}
\end{aligned}
$$

where

$$
B P_{j, k}^{l}=A J P_{j, k}^{l}+A J P_{j-1, k}^{l}+A K P_{k}^{l}+A K P_{k-1}^{l}
$$

and

$$
\begin{aligned}
B S_{j, k}^{l}= & \operatorname{CJS}_{j, k}^{\ell}+A J S_{j-1, k}^{l}+C K S_{j, k}^{l}+A K S_{j, k-1}^{l} \\
& +\frac{\left(V_{p}\right)_{j, k}}{\Delta t} \rho_{j, k}^{\ell}
\end{aligned}
$$

The upstream weighting of the relative permeability described after Equation A-16 for the gas phase is applicable here to the liquid phase equation. The liquid phase is considered to be incompressible in this development. 



\section{APPENDIX B}

\section{FLOW CONNECTORS}

\section{Radial Direction}

The radial mass flow rate through a cylindrical surface of radius $r$ and height $\Delta z$ is

$$
\begin{aligned}
m_{r} & =\rho A v_{r} \\
& =\rho 2 \pi r \Delta z v_{r}
\end{aligned}
$$

If only one radian of the cylindrical surface is accounted for, due to axisymmetric flow, then

$$
m_{r}=\rho r \Delta z v_{r}
$$

The introduction of the Darcy flow equation gives

$$
m_{r}=-\rho r \Delta z \frac{k}{\mu} \frac{\partial P}{\partial r}
$$

where $k$ represents the effective permeability in the radial direction and the equation applies to either air or water. The gravitational force does not act in the radial direction, which is considered to be horizontal.

The relationship between pressure and radius is obtained by integrating between any two radial positions.

$$
\int_{r_{1}}^{r_{2}} m_{r} \frac{d r}{r}=-\int_{P_{1}}^{P_{2}} \rho \Delta z \frac{k}{\mu} d P
$$


The mass flow rate can be considered constant if the density is essentially constant. In this case

$$
m_{r} \int_{r_{1}}^{r_{2}} \frac{d r}{r}=-\rho \Delta z \frac{k}{\mu} \int_{P_{1}}^{P_{2}} d P
$$

where $k, \mu$, and $\Delta z$ are also constant. Integration and solution for the mass flow rate yields

$$
m_{r}=\Delta z \frac{\rho k}{\mu} \frac{P_{1}-P_{2}}{\ln \left(r_{2} / r_{1}\right)}
$$

Now consider the finite difference cells of Figure B.1. The node points, which are cell centered, are at points $j$ and $j+1$. The boundary between the cells is at a radius $r_{b}$.

The mass flow rate into the boundary equals the mass flow rate away from the boundary so that

$$
m_{r_{j, k}}=\Delta z\left(\frac{\rho k}{\mu}\right)\left\{\frac{P_{j}-P_{b}}{\ln \left(r_{b} / r_{j}\right)}\right\}_{k}
$$

and

$$
m_{r_{j, k}}=\Delta z\left(\frac{\rho k}{\mu}\right){ }_{j+1, k}\left\{\frac{P_{b}-P_{j+1}}{\ln \left(r_{j+1} / r_{b}\right)}\right\}_{k}
$$

Since the boundary pressure is unknown, it is eliminated by combination of Equations B-8 and B-9. The result is

$$
m r_{j, k}=\left\{\frac{\Delta z}{\left(\frac{\mu}{\rho k}\right)_{j} \ln \left(r_{b} / r_{j}\right)+\left(\frac{\mu}{\rho k}\right)_{j+1} \ln \left(r_{j+1} / r_{b}\right)}\left(P_{j}-P_{j+1}\right)\right\}_{k}
$$




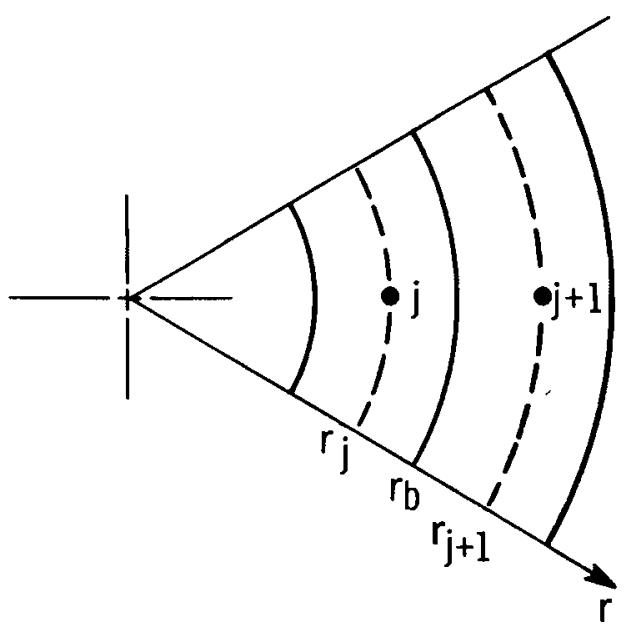

FIGURE B. 1. Geometry for Radial Flow Connector, $\mathrm{AJ}_{j, k}$

The radial flow potential is defined as

$$
\Phi J_{j, k}=\left(P_{j}-P_{j+1}\right)_{k}
$$

The coefficient of the flow potential is the radial flow connector, defined such that

$$
m r_{j, k}=A J_{j, k}{ }^{\Phi} J_{j, k}
$$

Vertical Direction

The vertical mass flow rate through an annular surface of nominal radius $r$ and annular width $\Delta r$ is

$$
\begin{aligned}
m_{z} & =\rho A v_{z} \\
& =\rho 2 \pi r \Delta r v_{z}
\end{aligned}
$$

If only one radian of the annular surface is accounted for, due to axisymetric flow, then

$$
m_{z}=\rho r \Delta r v_{z}
$$


The introduction of the Darcy flow equation gives

$$
m_{z}=-\rho r \Delta r \frac{k}{\mu}\left(\frac{\partial P}{\partial z}-\rho g_{z}\right)
$$

where $k$ represents the effective permeability in the vertical direction and the equation applies to either air or water. The gravitational term acts in the negative $z$ direction so that $g_{z}$ is negative.

The relationship between pressure and $z$ is obtained by integrating between any two vertical positions

$$
\int_{z_{1}}^{z_{2}} m_{z} d z=-\int_{P_{1}}^{P_{2}} \rho r \Delta r \frac{k}{\mu} d P+\int_{z_{1}}^{z_{2}} \rho r \Delta r \frac{k}{\mu} \rho g_{z} d z
$$

If the mass flow rate, density, permeability and viscosity are considered constant over the integration interval then

$$
m_{z} \int_{z_{1}}^{z_{2}} d z=-\rho r \Delta r \frac{k}{\mu}\left(\int_{P_{1}}^{P_{2}} d P-\rho g z_{z_{1}} \int_{2}^{z_{2}} d z\right)(B-18)
$$

Integration and solution for the mass flow rate yields

$$
m_{z}=\frac{r \Delta r}{\left(z_{2}-z_{i}\right)} \frac{\rho k}{\mu}\left\{\left(p_{1}-p_{2}\right)+\rho g_{z}\left(z_{2}-z_{1}\right)\right\}
$$

Now consider the finite difference cells of Figure B.2. The node points, which are cell centered, are at points $k$ and $k+1$. The boundary between the cells is identified by $z_{b}$.

The mass flow rate into the boundary equals the mass flow rate away from the boundary so that

$$
m_{z_{j, k}}=\frac{r_{j} \Delta r_{j}}{\left(z_{b}-z_{k}\right)} \quad\left(\frac{p k}{\mu}\right){ }_{j, k}\left\{\left(p_{k}-p_{b}\right)+\rho_{k} g_{z}\left(z_{b}-z_{k}\right)\right\}_{j}
$$




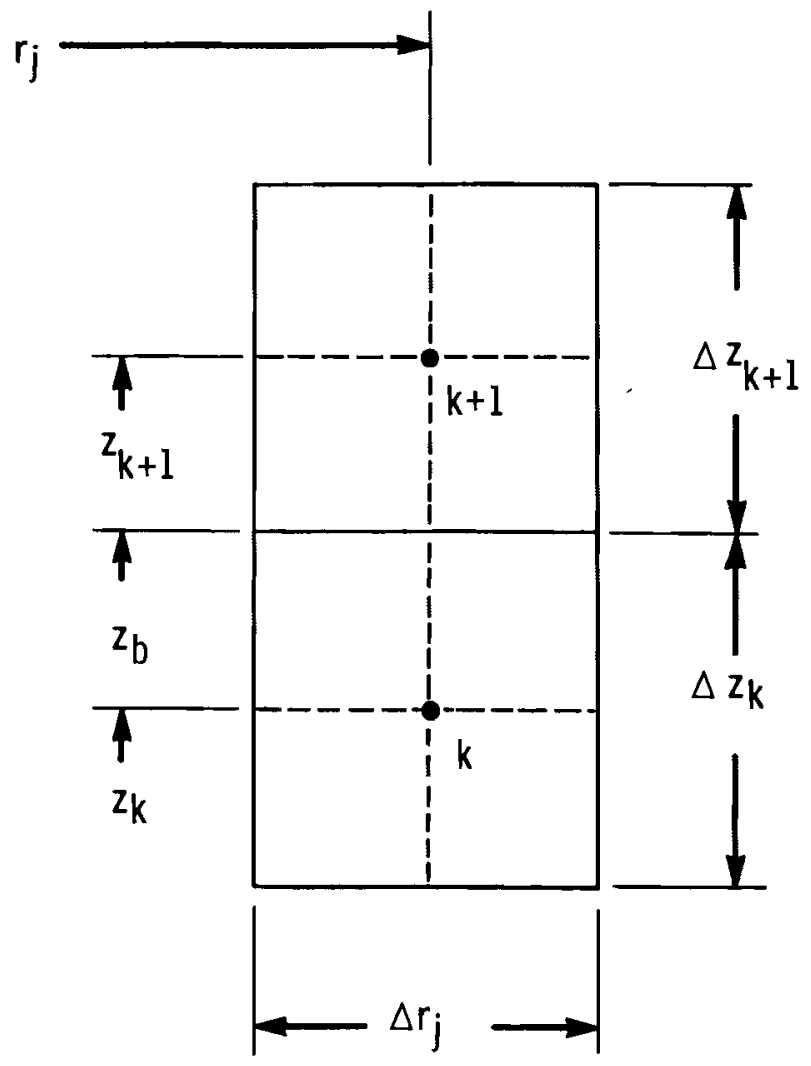

FIGURE B.2. Geometry for Vertical Flow Connector, $A K_{j, k}$

arid

$$
m_{z j, k}=\frac{r_{j} \Delta r_{j}}{\left(z_{k+1}-z_{b}\right)}\left(\frac{\rho k}{\mu}\right){ }_{j, k+1}\left\{\left(p_{b}-P_{k+1}\right)+\rho_{k+1} g_{z}\left(z_{k+1}-z_{b}\right)\right\}_{j}
$$

Since the boundary pressure is unknown, it is eliminated by combination of Equations $\mathrm{B}-20$ and $\mathrm{B}-21$. The result is

$$
m_{z_{j}, k}=\frac{2 r_{j} \Delta r_{j}}{\left(\frac{\mu \Delta Z}{\rho k}\right)_{j, k}+\left(\frac{\mu \Delta z}{\rho}\right)_{j, k+1}}\left[P_{k}-P_{k+1}+\frac{g_{z}}{2}\left\{(\rho \Delta z)_{k}+(\rho \Delta z)_{k+1}\right)\right]_{j}
$$

The vertical flow potential is defined as

$$
\Phi K_{j, k}=\left[P_{k}-P_{k+1}+\frac{g}{2}\left\{(\rho \Delta z)_{k}+(\rho \Delta z)_{k+1}\right\}\right]_{j}
$$


The coefficient of the flow potential is the vertical flow connector, defined such that

$$
m_{z_{j, k}}=A K_{j, k} \Phi K_{j, k}
$$




\section{APPENDIX C}

\section{SIMULTANEOUS SOLUTION ALGORITHM}

The simultaneous solution algorithm solves Equations A-14 and A22 which are the mass balance equations for the gas and liquid, respectively. The solution algorithm is developed here for a line solution along a row (fixed $k$ ). Subscript changes are the only requirement to establish the solution for columns (fixed $j$ ).

For solution along a row, the mass balance equations become

Gas Phase

$$
\begin{aligned}
& \left(-A J P_{j}^{g} \delta P_{j+1}^{g}+B P_{j}^{g} \delta P_{j}^{g}-A J P_{j-1}^{g} \delta P_{j-1}^{g}\right. \\
& \left.-A J S_{j}^{g} \delta S_{j+1}+B S_{j}^{g} \delta S_{j}-C J S_{j-1}^{g} \delta S_{j-1}\right)_{k}=-\Omega D_{j, k}^{g}
\end{aligned}
$$

\section{Liquid Phase}

$$
\begin{aligned}
& \left(-A J P_{j}^{l} \delta P_{j+1}^{g}+B P_{j}^{l} \delta P_{j}^{g}-A J P_{j-1}^{\ell} \delta P_{j-1}^{g}\right. \\
& \left.-A J S_{j}^{l} \delta S_{j+1} B S_{j}^{l} \delta S_{j}-C J S_{j-1}^{l} \delta S_{j-1}\right)_{k}=-\delta D_{j, k}^{l}
\end{aligned}
$$

The following relationships are assumed for the dependent variables:

$$
\delta S_{j, k}=E P_{j}^{l} \delta P_{j+1, k}^{g}+E S_{j}^{l} \delta S_{j+1, k}+F_{j}^{l}
$$

and

$$
\delta P_{j, k}^{g}=E P_{j}^{g} \delta P_{j+1, k}^{g}+E S_{j}^{g} \delta S_{j+1, k}+F_{j}^{g}
$$


These relationships are equivalent to those used by Douglas, Peaceman and Rachford (1959). This apparently is an extension of a similar algorithm for single-phase flow as presented by Richtmyer and Morton (1967).

The goal is to obtain two equations, relating the dependent variables at node $j, k$ to those at $j+1, k$. Equations $C-3$ and $C-4$ are written for $\delta P{ }_{j-1, k}^{g}$ and $\delta S_{j-1, k}$ and substituted into Equations $C-1$ and $C-2$. After rearranging terms the mass balance equations are

\section{Gas Phase}

$$
\begin{aligned}
& \left(B P_{j}^{g}-A J P_{j-1}^{g} E P_{j-1}^{g}-C J S_{j-1}^{g} E P_{j-1}^{\ell}\right)_{k} \delta P_{j, k}^{g}-A J P_{j, k}^{g} \delta P_{j+1, k}^{g} \\
& +\left(B S_{j}^{g}-A J P_{j-1}^{g} E S_{j-1}^{g}-C J S_{j-1}^{g} E S_{j-1}^{l}\right)_{k} \delta S_{j, k}-A J S_{j, k}^{g} \delta S_{j+1, k} \\
& =\left(A J P_{j-1}^{g} F_{j-1}^{g}+C J S_{j-1}^{g} F_{j-1}^{\ell}\right)_{k}-\Omega D_{j, k}^{g}
\end{aligned}
$$

\section{Liquid Phase}

$$
\begin{aligned}
& \left(B P_{j}^{l}-A J P_{j-1}^{l} E P_{j-1}^{g}-C J S_{j-1}^{l} E P_{j-1}^{\ell}\right) \delta P_{j, k}^{g}-A J P_{j, k}^{l} \delta P_{j+1, k}^{g} \\
& +\left(B S_{j}^{l}-A J P_{j-1}^{l} E S_{j-1}^{g}-C J S_{j-1}^{l} E S_{j-1}^{l}\right)_{k} \delta S_{j, k}-A J S_{j, k}^{\ell} \delta S_{j+1, k} \\
& =\left(A J P_{j-1}^{l} F F_{j-1}^{g}+C J S_{j-1}^{l} F_{j-1}^{l}\right)_{k}-\Omega D_{j, k}^{l}
\end{aligned}
$$

In slightly abbreviated form these equations become

Gas Phase

$$
\overline{B P}_{j, k}^{g} \delta P_{j, k}^{g}+\overline{B S}_{j, k}^{g} \delta S_{j, k}=\overline{\bar{D}}_{j, k}^{g}
$$

Liquid Phase

$$
\overrightarrow{B P}_{j, k}^{\ell} \delta P_{j, k}^{g}+\overline{B S}_{j, k}^{l} \delta S_{j, k}=\bar{D}_{j, k}^{\ell}
$$


Equations C-7 and C-8 are solved simultaneously using Cramer's Rule. The determinant of the coefficients is

$$
\operatorname{det}=\overline{\mathrm{BP}}_{j, k}^{\mathrm{g}} \overline{\mathrm{BS}}_{j, k}^{\ell}-\overline{\mathrm{BP}}_{j, k}^{\ell} \overline{\mathrm{BS}}_{j, k}^{\mathrm{g}}
$$

The solution is

$$
\delta P_{j, k}^{g}=\frac{1}{\operatorname{det}}\left(\overline{B S}_{j, k}^{l} \overline{\bar{D}}_{j, k}^{g}-\overline{B S}_{j, k}^{g} \overline{\bar{D}}_{j, k}^{l}\right)
$$

and

$$
\delta S_{j, k}=\frac{1}{\operatorname{det}}\left(\overline{\mathrm{BP}}_{j, k}^{g} \overline{\bar{D}}_{j, k}^{\ell}-\overline{\mathrm{BP}}_{j, k}^{\ell} \overline{\bar{D}}_{j, k}^{g}\right)
$$

By equating the terms in Equations $\mathrm{C}-10$ and $\mathrm{C}-11$ to those in Equations $\mathrm{C}-3$ and $\mathrm{C}-4$ the following terms are defined

$$
\begin{aligned}
& E P_{j}^{g}=\frac{1}{\operatorname{det}}\left(\overline{B S}_{j}^{l} A J P_{j}^{g}-\overline{B S_{j}^{g}} A J P_{j}^{l}\right)_{k} \\
& E S_{j}^{g}=\frac{1}{\operatorname{det}}\left(\overline{B S}_{j}^{l} A J S_{j}^{g}-\overline{B S_{j}^{g}} A J S_{j}^{l}\right)_{k} \\
& F_{j}^{g}=\frac{1}{\operatorname{det}}\left\{\overline{B S}_{j}^{l}\left(-\Omega D_{j}^{g}\right)-\overline{B S}_{j}^{g}\left(-\Omega D_{j}^{l}\right)\right\} k \\
& E P_{j}^{l}=\frac{1}{\operatorname{det}}\left(\overline{B P}_{j}^{g} A J P_{j}^{l}-\overline{B P}_{j}^{l} A J P_{j}^{g}\right)_{k} \\
& E S_{j}^{l}=\frac{1}{\operatorname{det}}\left(\overline{B P}_{j}^{g} A J S_{j}^{l}-\overline{B P}_{j}^{l} A J S_{j}^{g}\right)_{k} \\
& F_{j}^{l}=\frac{1}{\operatorname{det}}\left\{\overline{B P}_{j}^{g}\left(-\Omega D_{j}^{l}\right)-\overline{B P}_{j}^{l}\left(-\Omega D_{j}^{g}\right)\right\} k
\end{aligned}
$$

These terms are computed by sweeping over all the computational cells in the direction of increasing $j$. Given that the first computational cell is at $j=2$, then values of these terms are required for $j=1$. As long 
as the boundaries are impermeable (zero flow), the values of the terms are arbitrary. After this forward sweep, the pressure and saturation corrections are determined using Equations $\mathrm{C}-3$ and $\mathrm{C}-4$ by sweeping along the same row in the reverse direction. Given that the last computational cell is at $\mathrm{J}-1$, then values of the pressure and saturation corrections are required at $\mathrm{J}$. For $\mathrm{j}=\mathrm{J}$ the corrections are set to zero because the boundaries are impermeable.

\section{REFERENCES}

Douglas, J., Jr., D. W. Peaceman and H. H. Rachford, Jr. 1959. "A Method for Calculating Multi-Dimensional Immiscible Displacement." Trans. AIME. 216:297-308.

Richtmyer, R. and K. Morton. 1967. Difference Methods for Initial Value Problems. 2nd edition, Interscience Publishers, 1967, pp. 198-201. 


\section{ADDITIVE CORRECTIONS}

The additive correction method has been the subject of several papers (Poisson 1968, Watts 1971, Settari, Aziz 1973). The importance of the method in petroleum reservoir analys is is discussed by Peaceman (1977). The method is outlined here so that it can be understood in the context of the complete development of the numerical model.

For two-dimensional problems where certain physical behavior occurs primarily in one direction it may be advantageous to apply additive corrections only to that direction. In the present analysis, the radial air mass flow and vertical water coning suggest that corrections be computed for both directions.

The method can be applied to the two dimensions either simultaneously or in an uncoupled fashion. The simultaneous method is computationally more efficient although proportionally more complicated. We found that either approach was satisfactory, providing essentially identical results.

The uncoupled version is developed first. The one-dimensional correction will be applied to the j-direction. The analogous equations apply to the k-direction.

The method is applied to the twodimensional grid system of Figure D.1. The uniformity of the grid is inconsequential. The dashed boundary grid represents non-computational cells. Corrections that will reduce the continuity error are sought for the gas pressure, $\alpha_{j}^{g}$, and the saturation, $\alpha_{j}^{S}$. The values of $\alpha_{j}^{g}$ and $\alpha_{j}^{s}$ that are defined for a given value of $j$ apply to all $k$ for that value of $j$. In the development of the simultaneous method, the corrections sought for the $k$-direction are $\beta_{k}^{g}$ and $\beta_{k}^{S}$. For the uncoupled correction in the j-direction, Equations A-14 and A-22 become 


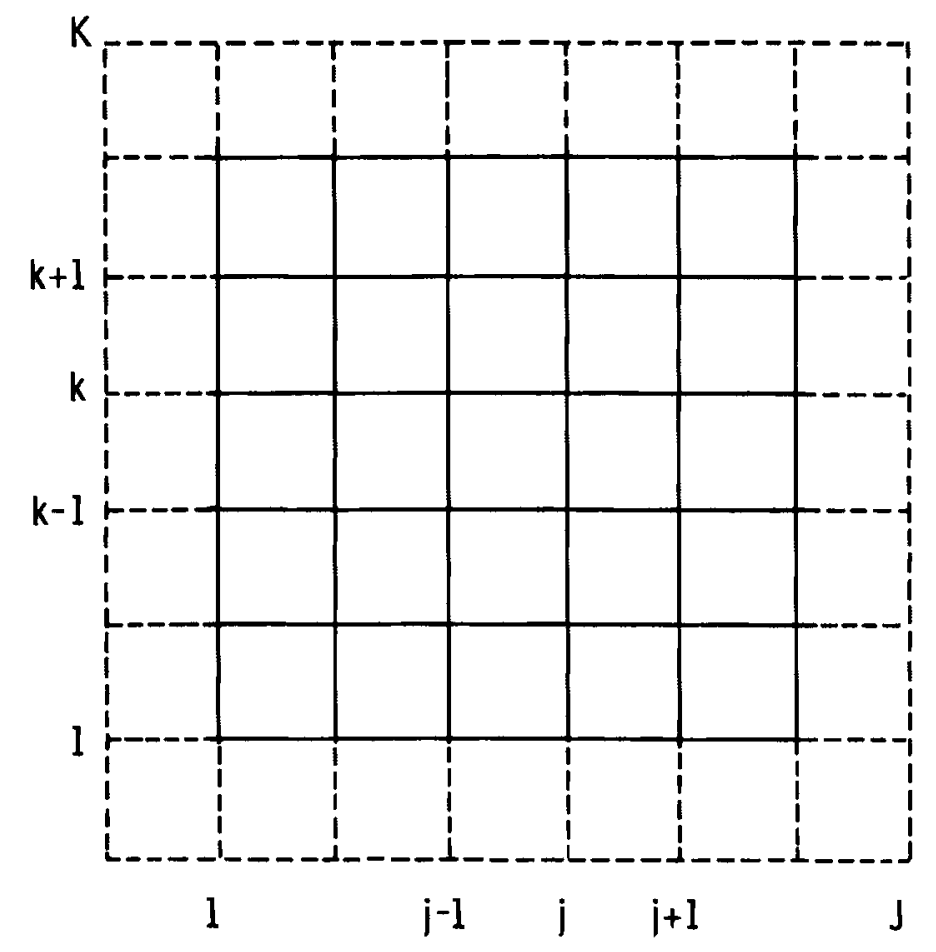

FIGURE D.1. Two-Dimensional Grid System

Gas Phase

$$
\begin{aligned}
& -A J P P_{j, k}^{g} \alpha_{j+1}^{g}-A J P_{j-1, k}^{g} \alpha_{j-1}^{g}-\left(A K P_{k}^{g}+A K P_{k-1}^{g}-B P{ }_{k}^{g}\right)_{j} \alpha_{j}^{g} \\
& -A J S_{j, k}^{g} \alpha_{j+1}^{S}-C J S_{j-1, k}^{g} \alpha_{j-1}^{S}-\left(A K S_{k}^{g}+C K S_{k-1}^{g}-B S_{k}^{g}\right)_{j} \alpha_{j}^{s} \\
& =-S D_{j, k}^{g}
\end{aligned}
$$

\section{Liquid Phase}

$$
\begin{aligned}
& -A J P_{j, k}^{\ell} \alpha_{j+1}^{g}-A J P_{j-1, k}^{l} \alpha_{j-1}^{g}-\left(A K P_{k}^{l}+A K P_{k-1}^{l}-B P_{k}^{l}\right)_{k} \alpha_{j}^{g} \\
& -A J S_{j, k}^{l} \alpha_{j+1}^{S}-C J S_{j-1, k}^{l} \alpha_{j-1}^{S}-\left(A K S_{k}^{l}+C K S_{k-1}^{l}-B S_{k}^{\ell}\right)_{j} \alpha_{j}^{S} \\
& =-\Omega D_{j, k}^{l}
\end{aligned}
$$


To implement the method we sum over $k$ for each $j$ for the computational cells only. The summation does not include $j=1$ or $j=j$. As a result, the grid system effectively reduces to that of Figure D.2. The definitions of Equations A-15, A-16, A-23, and A-24 are applied. If the boundaries are closed, the mass balance equations reduce to

Gas Phase

$$
\begin{aligned}
& -\left(\sum_{k}^{\Sigma} A J P \underset{j, k}{g}\right) \alpha_{j+1}^{g}-\left(\sum_{k}^{\Sigma} A J P P_{j-1, k}^{g}\right) \alpha_{j-1}^{g} \\
& +\left\{\sum_{k}\left(A J P_{j, k}^{g}+A J P_{j-1, k}^{g}+C P_{j, k}^{g}\right)\right\} \alpha_{j}^{g}-\left({ }_{k}^{\Sigma} A J S_{j, k}^{g}\right) \alpha_{j+1}^{s} \\
& -\left(\sum_{k}^{\Sigma} \operatorname{CJS} S_{j-1, k}^{g}\right) \alpha_{j-1}^{s}+\left\{\sum_{k}\left(\operatorname{CJS} S_{j, k}^{g}+\operatorname{AJS}_{j-1, k}^{g}+C S_{j, k}^{g}\right)\right\} \alpha_{j}^{s} \\
& =-\Omega\left(\sum_{k}^{\Sigma} D_{j, k}^{g}\right)
\end{aligned}
$$

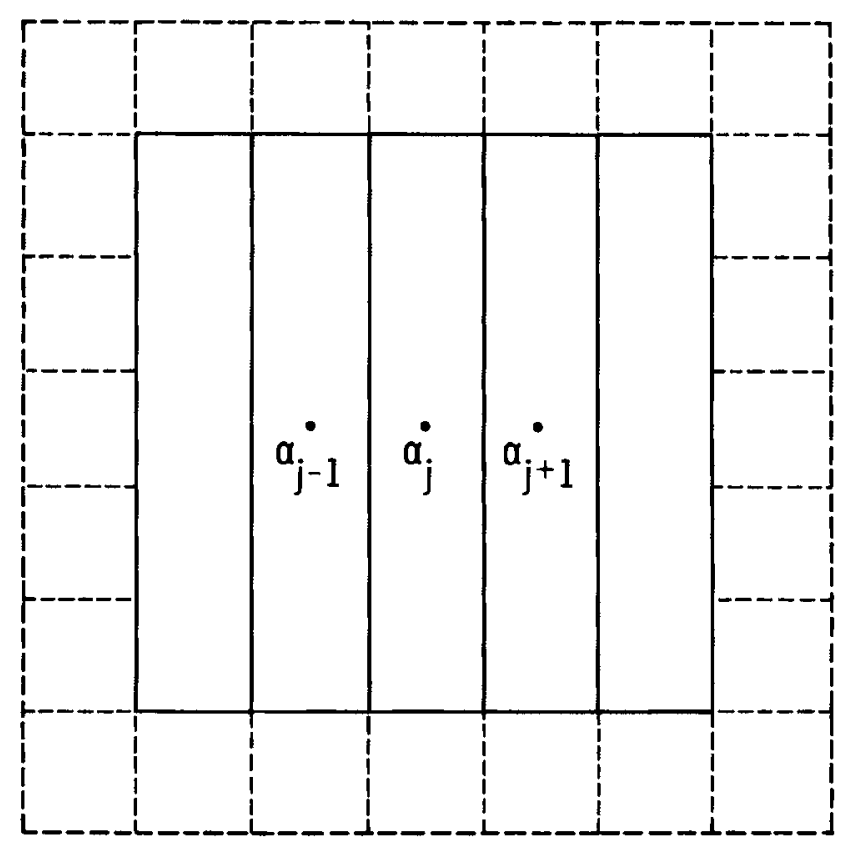

FIGURE D.2. Effective Grid System for One-Dimensional Correction in the j-Direction 


\section{Liquid Phase}

$$
\begin{aligned}
& -\left(\sum_{k}^{\sum} A J P P_{j, k}^{\ell}\right) \alpha_{j+1}^{g}-\left(\sum_{k}^{\Sigma} A J P P_{j-1, k}^{\ell}\right) \alpha_{j-1}^{g} \\
& +\left\{\begin{array}{l}
\sum \\
k
\end{array}\left(A J P_{j, k}^{\ell}+A J P_{j-1, k}^{\ell}+C P_{j, k}^{\ell}\right)\right\} \alpha_{j}^{g}-\left(\sum_{k}^{\Sigma} A J S_{j, k}^{\ell}\right) \alpha_{j+1}^{S} \\
& -\left(\sum_{k}^{\Sigma} \operatorname{cJS}_{j-1, k}^{\ell}\right) \alpha_{j-1}^{s}+\left\{\sum_{k}\left(\operatorname{CJS}_{j, k}^{\ell}+\operatorname{AJS}_{j-1, k}^{\ell}+\operatorname{CS}_{j, k}^{\ell}\right)\right\} \alpha_{j}^{s} \\
& =-\Omega\left(\begin{array}{l}
\Sigma \\
k
\end{array} D_{j, k}^{\ell}\right)
\end{aligned}
$$

where

$$
\begin{aligned}
& C P_{j, k}^{g}=\frac{\left(V_{p}\right)_{j, k}}{\Delta t}(1-S)_{j, k}\left(\frac{\partial \rho g}{\partial P^{g}}\right)_{j, k} \\
& C S_{j, k}^{g}=-\frac{\left(V_{p}\right)_{j, k}}{\Delta t} \rho{ }_{j, k}^{g} \\
& C P_{j, k}^{\ell}=0 \\
& C S_{j, k}^{\ell}=\frac{\left(V_{p}\right)_{j, k}}{\Delta t} \rho_{j, k}^{\ell}
\end{aligned}
$$

Equations $D-3$ and $D-4$ can be seen to be of the form of Equations A14 and $A-22$. The solution for $\alpha_{j}^{g}$ and $\alpha_{j}^{S}$ is obtained by applying the simultaneous solution algorithm of Appendix $C$.

For the simultaneous two-dimensional method, corrections that will reduce the continuity error are sought for the gas pressure and saturation. These corrections are of the form

and

$$
\left.\begin{array}{l}
\delta P_{j, k}^{g}=\alpha_{j}^{g}+\beta_{k}^{g} \\
\delta S_{j, k}=\alpha_{j}^{g}+\beta_{k}^{S}
\end{array}\right\}
$$


The values of $\alpha_{j}^{g}$ and $\alpha_{j}^{s}$ apply as before. Similarly, the values of $\beta_{k}^{g}$ and $\beta_{k}^{S}$ that are computed for a given $k$ apply to all the cells in the $j-$ direction for that value of $k$.

When Equations D-6 are substituted into Equations A-14 and A-22 and terms are collected the result is

Gas Phase

$$
\begin{aligned}
& -A J P_{j, k}^{g} \alpha_{j+1}^{g}-A J P_{j-1, k}^{g} \alpha_{j-1}^{g}-\left(A K P_{k}^{g}+A K P_{k-1}^{g}-B P_{k}^{g}\right)_{j} \alpha_{j}^{g} \\
& -A K P_{j, k}^{g} \beta_{k+1}^{g}-A K P_{j, k-1}^{g} B_{k-1}^{g}-\left(A J P_{j}^{g}+A J P_{j-1}^{g}-B P_{j}^{g}\right)_{k} \beta_{k}^{g} \\
& -A J S_{j, k}^{g} \alpha_{j+1}^{s}-C J S_{j-1, k}^{g} \alpha_{j-1}^{s}-\left(A K S_{k}^{g}+C K S_{k-1}^{g}-B S_{k}^{g}\right)_{j} \alpha_{j}^{s} \\
& -A K S_{j, k}^{g} \beta_{k+1}^{S}-C K S_{j, k-1}^{g} \beta_{k-1}^{s}-\left(A J S_{j}^{g}+C J S_{j-1}^{g}-B S_{j}^{g}\right)_{k} B_{k}^{s} \\
& =-\Omega D_{j, k}^{g}
\end{aligned}
$$

Liquid Phase

$$
\begin{aligned}
& -A J P_{j, k}^{\ell} \alpha_{j+1}^{g}-A J P_{j-1, k}^{\ell} \alpha_{j-1}^{g}-\left(A K P_{k}^{l}+A K P_{k-1}^{l}-B P_{k}^{l}\right) \alpha_{j}^{g} \\
& -A K P_{j, k}^{l} \beta_{k+1}^{g}-A K P_{j, k-1}^{l} \beta_{k-1}^{g}-\left(A J P_{j}^{l}+A J P_{j-1}^{l}-B P_{j}^{l}\right)_{k} \beta_{k}^{g} \\
& -A J S_{j, k}^{\ell} \alpha_{j+1}^{S}-\operatorname{CJS}_{j-1, k}^{\ell} \alpha_{j-1}^{S}-\left(A K S_{k}^{\ell}+C K S_{k-1}^{l}-B S_{k}^{\ell}\right)_{j} \alpha_{j}^{S} \\
& -A K S_{j, k}^{\ell} \beta_{k+1}^{S}-C K S_{j, k-1}^{\ell} \beta_{k-1}^{S}-\left(A J S_{j}^{\ell}+C J S_{j-1}^{\ell}-B S_{j}^{\ell}\right)_{k} \beta_{k}^{S} \\
& =-\Omega D_{j, k}^{\ell}
\end{aligned}
$$

To implement the two-dimensional correction method, a solution is obtained in one direction using guessed values of the corrections for the other direction. The process is repeated iteratively until the corrections converge. Satisfactory convergence is achieved usually in 
less than four iterations. The iterative procedure is quite fast because none of the coefficients need to be evaluated within the cycle.

To describe the solution for one-dimension the j-direction will be used. This requires a summation over all the computational cells in the k-direction in Equations $D-7$ and D-8. The coefficients of $\alpha_{j}^{g}$ and $\alpha_{j}^{g}$ are the same as in Equations $D-3$ and D-4. Consider the summation for the $\beta^{g}$ terms in Equation $D-7$.

$-\sum_{k}\left(A K P_{j, k}^{g} B_{k+1}^{g}\right)-\sum_{k}^{\Sigma}\left(A K P_{j, k-1}^{g} \beta_{k-1}^{g}\right)+\sum_{k}^{\Sigma}\left\{\left(A K P_{j, k}^{g}+A K P_{j, k-1}^{g}+C P_{j, k}^{g}\right) B_{k}^{g}\right\}$ where $C P_{j, k}^{g}$ is defined by Equation $D-5$.

The summation begins for $k=2$. If $K=6$, the summation concludes at $k=5$. The terms are

$$
\begin{aligned}
& -A K P_{j, 2}^{g} \beta_{3}^{g}-A K P_{j, 1}^{g} \beta_{1}^{g}+A K P_{j, 2}^{g} B_{2}^{g}+A K P_{j, 1}^{g} \beta_{2}^{g}+C P_{j, 2}^{g} \beta_{2}^{g} \\
& -A K P_{j, 3}^{g} \beta_{4}^{g}-A K P_{j, 2}^{g} \beta_{2}^{g}+A K P_{j, 3}^{g} B_{3}^{g}+A K P_{j, 2}^{g} \beta_{3}^{g}+C P P_{j, 3}^{g} \beta_{3}^{g} \\
& -A K P_{j, 4}^{g} \beta_{5}^{g}-A K P_{j, 3}^{g} \beta_{3}^{g}+A K P_{j, 4}^{g} \beta_{4}^{g}+A K P_{j, 3}^{g} \beta_{4}^{g}+C P P_{j, 4}^{g} \beta_{4}^{g} \\
& -A K P_{j, 5}^{g} \beta_{6}^{g}-A K P_{j, 4}^{g} \beta_{4}^{g}+A K P_{j, 5}^{g} \beta_{5}^{g}+A K P_{j, 4}^{g} \beta_{5}^{g}+C P{ }_{j, 5}^{g} \beta_{5}^{g}
\end{aligned}
$$

The terms that do not cancel are

$$
-A K P_{j .1}^{g}\left(\beta_{1}^{g}-\beta_{2}^{a}\right)-A K P_{j, 5}^{g}\left(\beta_{6}^{g}-\beta_{5}^{g}\right)+\sum_{k}\left(C P_{j, k}^{g} \beta_{k}^{g}\right)
$$

For closed boundaries the connectors $\operatorname{AKP}_{j, 1}^{g}$ and $\mathrm{AKP}_{j, 5}^{g}$ are zero so that only the summation on the storage term remains. This process is repeated for $\beta^{g}$ in the liquid continuity equation and for $\beta^{S}$ in both equations. The resultant set of equations is 
Gas Phase

$$
\begin{aligned}
& -\left(\begin{array}{l}
\sum \\
k
\end{array} A J P{ }_{j, k}^{g}\right) \alpha_{j+1}^{g}-\left(\sum_{k}^{\Sigma} A J P \underset{j-1, k}{g}\right) \alpha_{j-1}^{g} \\
& +\left\{\sum_{k}\left(A J P{ }_{j, k}^{g}+A J P_{j-1, k}^{g}+C P_{j, k}^{g}\right)\right\} \alpha_{j}^{g}-\left(\sum_{k}^{\Sigma} A J S_{j, k}^{g}\right) \alpha_{j+1}^{S}
\end{aligned}
$$

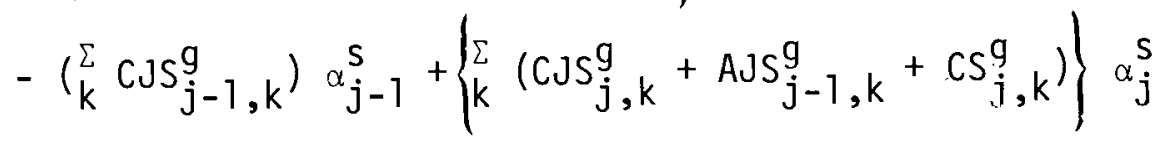

$$
\begin{aligned}
& =-\Omega\left({ }_{k}^{\Sigma} D_{j, k}^{g}\right) \\
& -\sum_{k}\left\{\left(C J S_{j}^{g}+A J S_{j-1}^{g}-C J S_{j-1}^{g}-A J S_{j}^{g}+C S_{j}^{g}-C P{ }_{j}^{g}\right)_{k} \beta_{k}^{g}\right\}
\end{aligned}
$$

\section{Liquid Phase}

$$
\begin{aligned}
& -\left(\sum_{k}^{\sum} A J P_{j, k}^{\ell}\right) \alpha_{j+1}^{g}-\left(\sum_{k}^{\sum} A J P_{j-1, k}^{\ell}\right) \alpha_{j-1}^{g} \\
& +\left\{\begin{array}{l}
\sum \\
k
\end{array}\left(A J P_{j, k}^{\ell}+A J P_{j-1, k}^{\ell}+C P_{j, k}^{\ell}\right)\right\} \alpha_{j}^{g}-\left(\sum_{k}^{\Sigma} A J S_{j, k}^{\ell}\right) \alpha_{j+1}^{S} \\
& -\left(\sum_{k}^{\Sigma} \operatorname{cus}_{j-1, k}^{\ell}\right) \alpha_{j-1}^{s}+\left\{\sum_{k}\left(\operatorname{CJS}_{j, k}^{\ell}+\operatorname{AJS}_{j-1, k}^{\ell}+\operatorname{cs}_{j, k}^{\ell}\right)\right\} \alpha_{j}^{S} \\
& =-\Omega\left({ }_{k}^{\Sigma} D_{j, k}^{l}\right) \\
& -\sum_{k}\left\{\left(C J S_{j}^{\ell}+A J S_{j-1}^{\ell}-\operatorname{CuS}_{j-1}^{\ell}-\operatorname{AJS}_{j}^{\ell}+C S_{j}^{\ell}+C P_{j}^{\ell}\right)_{k} B_{k}^{S}\right\}
\end{aligned}
$$

Again, note that the left sides of these two equations are identical to the left sides of Equations D-3 and D-4. Only the right sides have been changed to accommodate the simultaneous two-dimensional correction method.

Equations $D-12$ and $D-13$ are solved simultaneously for $\alpha_{j}^{g}$ and $\alpha_{j}^{S}$ using previously determined values for the $\beta_{k}$. Then an equivalent set of equations is solved for $\beta_{k}^{g}$ and $\beta_{k}^{S}$ using the previous values of $\alpha_{j}$. 


\section{REFERENCES}

Peaceman, D. W. 1977. Fundamentals of Numerical Reservoir Simulation. Elsevier Scientific Publishing Co.

Poussin, F., 1968. "An Accelerated Relaxation Algorithm for Iterative Solution of Elliptic Equations." SIAM J. Numer. Anal. 5:340-351.

Settari, A. and K. Aziz, 1973. "A Generalization of the Additive Correction Methods for the Iterative Solution of Matrix Equations." SIAM J. Numer. Ana 1. 10:506-521.

Watts, J. W. 1971. "An Iterative Matrix Solution Method Suitable for Anisotropic Problems." Soc. Pet. Eng. J. March, pp. 47-51. 


\section{APPENDIX E}

\section{EQUIVALENT WELLBORE PERMEABILITY}

The frictional pressure drop in the wellbore is

$$
\Delta P_{f}=\rho f \frac{L}{D} \frac{\nu^{2}}{2}
$$

The Darcy equation for the velocity is

$$
v=-\frac{k}{\mu} \frac{\Delta P_{d}}{\Delta x}
$$

which is rearranged to give

$$
\Delta P_{d}=-\frac{v \mu \Delta x}{k}
$$

Equations E-1 and E-3 are equated to yield

$$
\text { of } \frac{L}{D} \frac{v^{2}}{2}=-\frac{v \mu \Delta x}{k}
$$

which is rearranged to give

$$
k=\frac{2 \mu D}{f_{\rho v}}
$$

Using the definition of Reynolds number for pipe flow, we find that

$$
k=\frac{2 D^{2}}{f R e}
$$

For the reference conditions of the analysis

$$
R e=\frac{\rho D V}{\mu}\left(=\frac{D m}{\mu A}=\frac{2 D m}{\mu r^{2}}\right)
$$

The equivalence is based on the use of one radian as the flow area to determine $\mathrm{m}$. Thus, 


$$
\begin{aligned}
\operatorname{Re} & =\frac{2 \cdot 20 \cdot(\mathrm{cm}) 500 \cdot\left(\frac{\mathrm{gm}}{\mathrm{sec}}\right)}{1.81 \cdot 10^{-4}\left(\frac{\mathrm{gm}}{\mathrm{cm} \cdot \mathrm{sec}}\right) 10^{2}\left(\mathrm{~cm}^{2}\right)} \\
& =1.105 \cdot 10^{6} \\
f & =f(\operatorname{Re}) \\
& \cong 0.012 \\
\therefore \quad & \frac{2.20^{2}(\mathrm{~cm})^{2}}{0.0121 .105 \cdot 10^{6}} \frac{\mathrm{md}}{9.85 \cdot 10^{-12}\left(\mathrm{~cm}^{2}\right)} \\
& =6.13 \cdot 10^{9} \mathrm{md}
\end{aligned}
$$

The equivalent wellbore permeability is about seven orders of magnitude greater than the reference value of permeability, which is $500 \mathrm{md}$. 


\section{APPENDIX F}

\section{TRANSITION ZONE FLUID DISTRIBUTION}

In this section the method for computing the transition zone fluid distribution under aravitational-capillary equilibrium is presented.

For equilibrium with $z$ downward

$$
\begin{aligned}
& \frac{\partial P^{g}}{\partial z}=\rho^{g} g \\
& \frac{\partial P^{\ell}}{\partial z}=\rho^{\ell} g
\end{aligned}
$$

The capillary pressure relation is

$$
p^{l}=p^{g}-p^{c}
$$

Combining Equations $\mathrm{F}-2$ and $\mathrm{F}-3$ qives

$$
\frac{\partial P^{g}}{\partial z}-\frac{\partial P^{C}}{\partial z}=\rho^{l} g
$$

which can be rearranged, employing Equation F-1, to give

$$
f^{\prime} \frac{\partial S}{\partial z}=\frac{g}{R T} p^{g}-\rho^{l} g
$$

where

$$
f^{\prime}=\frac{\partial P^{C}}{\partial S}
$$


Now Equation $\mathrm{F}-1$ is integrated as

$$
\int \frac{\partial p^{g}}{\partial z}=\frac{g}{R T} \int d z
$$

to give

$$
\ln p^{g}=\frac{g}{R T} z+C_{1}
$$

If the gas pressure at the top of the reservoir is $P_{0}{ }^{g}$ then

$$
p^{g}=p_{0}^{g} e^{\left(\frac{g}{R T} z\right)}
$$

The capillary pressure function is of the form

$$
P^{c}=\frac{a}{s+b}+c
$$

so that

$$
\begin{aligned}
& \qquad \frac{\partial P^{c}}{\partial S} \equiv f^{\prime}=-\frac{a}{(S+b)^{2}} \\
& \text { Combining Equations } F-5, F-9 \text {, and } F-11 \text { qives } \\
& -\frac{a}{(S+b)^{2}} \frac{\partial S}{\partial z}=\frac{g}{R T} P_{0}^{g} e^{\left(\frac{g z}{R T}\right)}-\rho^{\ell} g
\end{aligned}
$$


If the saturation at the top of the transition zone is $S_{0}$, then Equation $F-12$ can be integrated to find the saturation $S$ for any value of $z$. The result is

$$
S=\frac{1}{\frac{1}{S_{0}+b}+{\frac{P_{0} g}{\left(e^{\left(\frac{g z}{R T}\right)}-1\right\}-\rho^{\ell} g z}}_{a}^{-b}}
$$

Because (gz/RT) is generally a very small number, then

$$
e^{\left(\frac{g z}{R T}\right)} \cong 1+\frac{g z}{R T}
$$

with this inclusion Equation F-13 becomes

$$
S=\frac{1}{\frac{1}{S_{0}+b}+\left(\frac{P_{0}^{g}}{a} \frac{g}{R T}-\frac{\rho^{l} g}{a}\right) z}-b
$$

The height of the transition zone is evaluated by setting $S=1.0$ and evaluating $z$. Equation F-15 is of the form

$$
S=\frac{1}{A+B z}-b
$$

The average fluid saturation between any two levels in the transition zone is then

$$
\bar{s}_{z_{1}-z_{2}}=\frac{\int_{z_{1}}^{z_{2}} s d z}{z_{1}-z_{2}}
$$

From this equation the fluid distribution through the transition zone can be evaluated. 


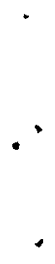




\section{DISTRIBUTION}

No of

Copies

OFFSITE

Acres American, Inc.

Attn: D. Willett

Liberty Bank Building

Main at Court

Buffalo, NY 14202

Acres American, Inc.

Attn: M. J. Hobson

The Clark Building

Suite 329

Columbia, MD 21044

Bechtel National Inc.

Attn: W. Stevens (50/20/B37)

Res \& Eng.

PO Box 3965

San Francisco, CA 94119

Black and Veatch

Attn: D. R. Bervig

1500 Meadow Lake Parkway

PO Box 8405

Kansas City, MO 64114

Central Illinois Public Service Co.

Attn: A. H. Warnke

Vice President Power Supply

607 East Adams Street

Springfield, IL 62701

Commonwealth Edison Co.

Attn: T. J. Maiman

Sta. Mech. Engr. Dept. Mgr.

36 FN West

PO Box 767

Chicago, IL 60690

Commonwea 1 th Edison Co.

Attn: D. E. DeViney

1319 South First Avenue

Maywood, IL 60153
No of

Copies

213 DOE Technical Information Center

5 US Department of Energy

Attn: S. Strauch

Office of Energy Systems Res. (CS-66)

Forrestal Building (Room 1G-080)

1000 Independence Ave., S.W.

Washington, DC 20585

US Department of Energy

Attn: J. H. Swisher

Office of Energy Systems Res. (CS-66)

Forrestal Building (Room 1G-080)

1000 Independence Ave., S.W.

Washington, DC 20585

US Department of Energy

Attn: J. Gahimer

Office of Energy Systems Res. (CS-66)

Forrestal Building (Room 1G-080)

1000 Independence Ave., S.W.

Washington, DC 20585

US Department of Energy

Attn: A. A. Churm

Chicago Patent Group

Chicago Operations office

9800 South Cass Avenue

Argonne, IL 60439

US Department of Energy

Attn: CP Demos

Chicago Operations Office

9800 S. Cass Avenue

Argonne, IL 60439

5 US Department of Energy

Attn: B. Gallagher

Office of Energy Systems Res. (CS-66)

Forrestal Building (Room 1G-080)

1000 Independence Ave., S.W.

Washington, DC 20585 
No of

Copies

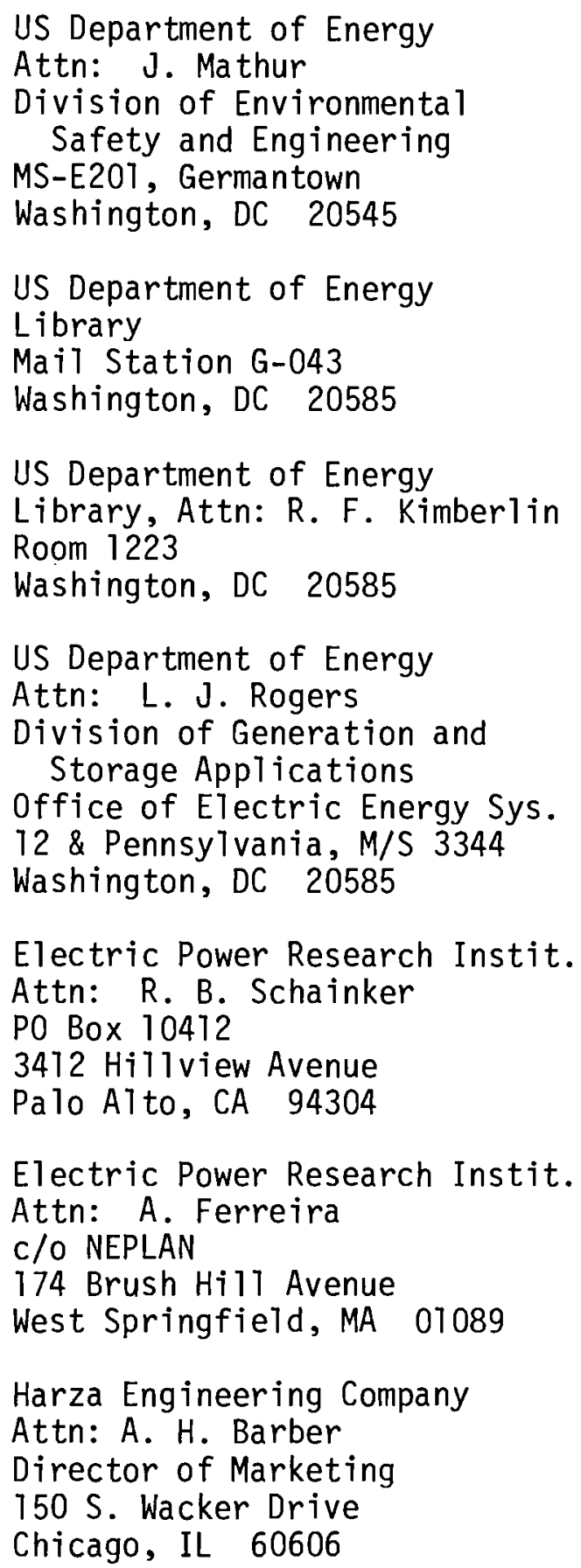

No of

Copies

Illinois Power Company

Attn: Mr. G. E. Huck

Manager of Planning

500 South 27th St.

Decatur, IL 62525

Lawrence Berkeley Laboratory

Attn: Library

University of California

B1dg 50, Room 134

Berkeley, CA 94720

2 Lawrence Livermore Laboratory

Attn: Tech. Info. Dept., L-3

University of California

PO Box 808

Livermore, CA 94550

Lawrence Livermore Laboratory

Attn: T. Barlow

P0 Box 808

Livermore, CA 94550

Los Alamos Scientific Laboratory

Attn: Jim BTacic

G-6-LASL-Stop 978

P0 Box 1663

Los ATamos, NM 87545

Louisiana State University

Attn: R. L. Thoms

Institute for Environmental Studies

Room 42, Atkinson $\mathrm{Hall}$

Baton Rouge, LA 70803

Marchwood Engineering Labs

Attn: I. Glendenning

Head of Long-Term Studies

Southampton, England

Massachusetts Institute of Tech.

Attn: J. L. Nash-Webber

Energy Lab

Cambridge, MA 02139 
No of

Copies

Middle South Services

Attn: L. A. Wilson

Advanced Energy Program Section

Box 6100

New Orleans, LA 70161

National Science Foundation

Division of Advanced Energy Research and Technology

Room 1140

1800 G Street, NW

Washington, DC 20550

Northern Research \& Eng. Corp. Attn: Jerry 0. Melconian 39 01ympia Avenue

Woburn, MA 01801

PB-KBB Inc.

Attn: J. Istvan

P0 Box 19672

Houston, TX 77024

Potomac Electric Power Co

Attn: P. E. Schaub

1900 Pennsylvania Avenue

Washington, DC 20006

Public Service of Indiana

Attn: T. W. McCafferty

$1000 \mathrm{E}$ Main Street

Plainfield, IN 46168

$\mathrm{Re} / \mathrm{Spec}$ Inc.

Attn: A. F. Fossum

P0 Box 725

Rapid City, SD 57701

Sandia Laboratories

Attn: Tech. Library Div. 3141

Albuquerque, NM 87185

Sandia Laboratories

Attn: H. M. Dodd

Organization 5743

A1buquerque, NM 87115
No of

Copies

Sandia Laboratories

Attn: R. 0. Woods

Organization 4715

Albuquerque, NM 87115

Sandia Laboratories

Attn: William G. Wilson

P0 Box 969

Organization 8453

Livermore, CA 94550

Sargent and Lundy Engineers

Attn: Mr. W. C. Walke

Project Manager

55 East Monroe Street

Chicago, IL 60603

Soyland Power Cooperative, Inc.

Attn: Royal B. Newman

P0 Box A1606

Decatur, IL 62525

Tennessee Valley Authority

Energy Research Section

1360 Commerce Union Bank B1dg

Chattanooga, TN 37401

Tennessee Valley Authority

Attn: Gerald Phillips

1150 Chestnut, Tower 2

Chattanooga, TN 37401

TRW Energy Systems Group

Attn: E. Berman

Technical Library

7600 Colshire Drive

McLean, VA 22101

Union Electric Co.

Attn: E. M. Mabuce

Manager - Applied Research

Corporate Planning Dept.

P0 Box 149

St. Louis, MO 63166 
No of

Copies

United Technologies Research Center

Attn: R. D. Lessard

Silver Lane

East Hartford, CT 06108

University of California

Attn: T. L. Brekke

Department of Civil Engineering

1847 Yosemite Road

Berkeley, CA 94707

University of Massachusetts

Attn: 0. C. Farquhar

Dept. of Geology \& Geography

Morri11 Science Center

Amherst, MA 01003

University of Michigan

Attn: Donald L. Katz

Dept. of Chemical Engineering

2042 E. Engr. B1dg.

Ann Arbor, MI 48109

University of Wisconsin

Attn: H. J. Pincus

Dept. of Geological Sciences

Sabin Hall and Greene Museum

PO Box 413

Milwaukee, WI 53201

Westinghouse Electric Corp.

Attn: W. F. Kobett

CAES Project Manager

Combustion Turbine Sys. Div.

Long Range Develop-Lab 100

PO Box 251

Concordville, PA 19331

Westinghouse Electric Corp.

Attn: D. Ayers

Manager, Fluid Systems Laboratory

1291 Cumberland Avenue

West Lafayette, IL 47906
No of

Copies

ONSITE

DOE Richland Operations Office

D. K. Jones

H. E. Ransom

Pacific Northwest Laboratory

R. D. Allen

T. J. Doherty

J. R. Eliason

R. L. Erikson

L. D. Kannberg (15)

J. E. Minor

R. Raymond

R. W. Rei11y

J. A. Stott lemyre

A. M. Sutey

L. E. Wiles (15)

F. R. Zaloudek

Technical Information (5)

Publishing Coordination (2) 